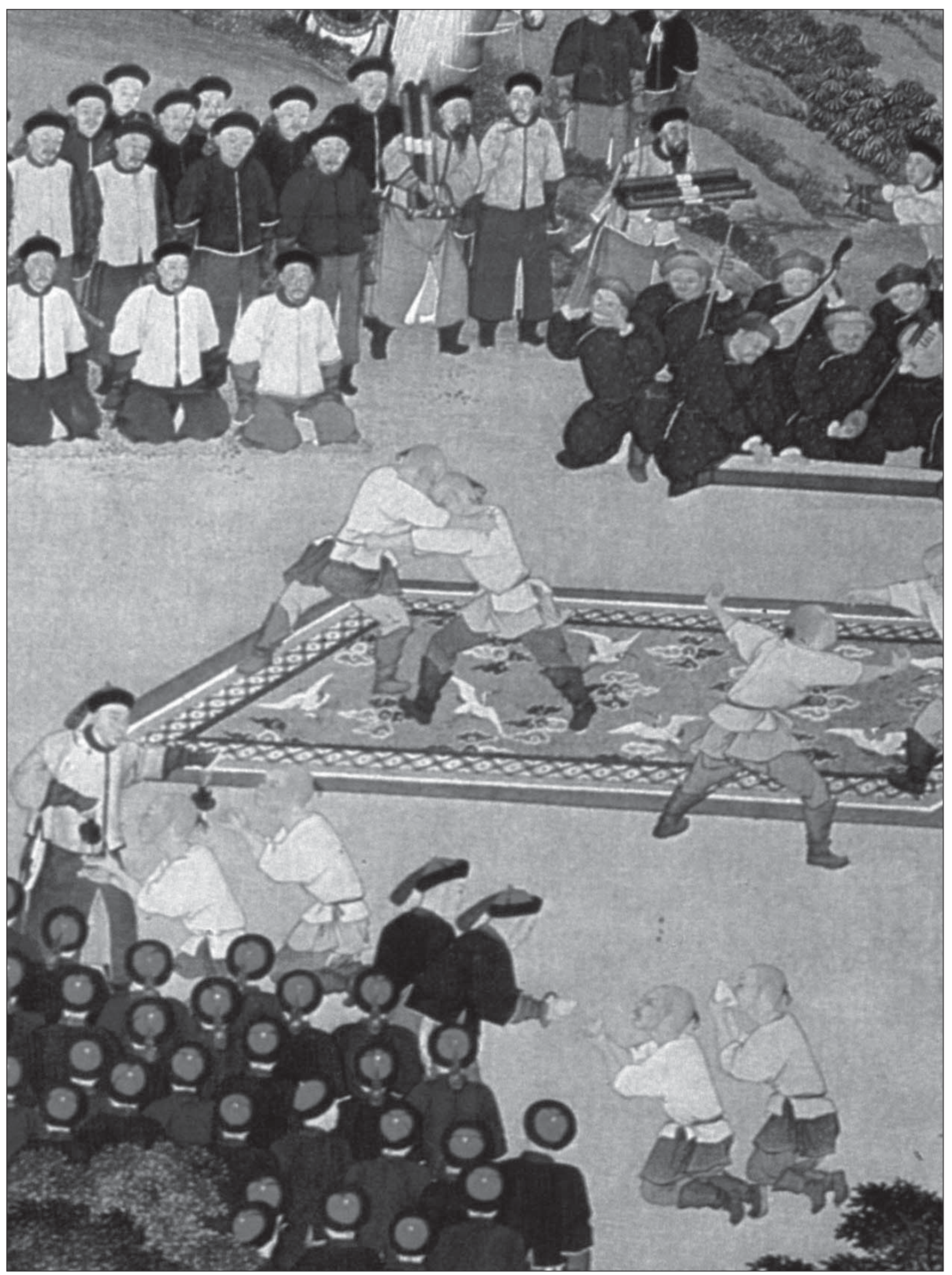




\title{
Shuai Jiao: \\ Introducción al Arte Chino \\ de las Proyecciones
}

\author{
Zhang Yun
}

\section{Introducción}

En las artes marciales tradicionales chinas hay cuatro categorías de habilidades básicas de combate:

$\mathrm{Ti}$ - técnicas de golpeo con las piernas

Da - técnicas de golpeo con las manos

Shuai - técnicas de proyección, y

$\mathrm{Na}$ - técnicas de control y luxación

Estas habilidades se manifiestan en casi cualquier estilo marcial. El grado de desarrollo de cada una de ellas depende del grado de interés de cada estilo en dicha habilidad. Por ejemplo, en el Tantui (técnicas de piernas o "pierna muelle"), las patadas están muy desarrolladas. En el Quinna (agarres y controles), las habilidades de agarrar, luxar, y controlar reciben una mayor atención. Para el caso del Shuai Jiao, este destaca por sus habilidades de proyección. El Shuai Jiao no es solamente una parte genérica del entrenamiento de las artes marciales, sino que actualmente tiene un gran número de personas dedicadas exclusivamente a su práctica.

Shuai Jiao se traduce normalmente como "lucha china". Es un sistema especial de combate que enseña cómo hacer tropezar a un oponente para proyectarle. El Shuai Jiao también se considera un deporte, y por esta razón se han creado un conjunto de reglas. Bajo estas reglas no están permitidos los golpeos, las patadas y las luxaciones. En una competición de Shuai Jiao, con una excepción, si cualquier parte del cuerpo excepto los pies toca el suelo, pierdes. En el Shuai Jiao nunca se puede lanzar una patada que pueda herir directamente al oponente. La patada de Shuai Jiao es un barrido, donde sólo se puede golpear por debajo del tobillo del oponente.

En chino shuai significa "proyectar hacia abajo", y jiao significa "tropezar" o "caer debido a una zancadilla". En el Shuai Jiao, la investigación se centra únicamente en las habilidades necesarias para proyectar a un oponente al suelo. Las técnicas de lucha en el suelo no se estudian debido a que, de acuerdo con las reglas, si te encuentras en esa posición ya has perdido. Esta es la razón por la que las habilidades de proyección del Shuai Jiao se diferencian ampliamente de las del Judo o de la lucha libre occidental. Hablando de forma rigurosa, no es exacto traducir Shuai Jiao como "lucha", ya que no se usa ninguna técnica de lucha. Sería más preciso traducirlo simplemente como "proyección".

El Shuai Jiao no sólo se usa como demostración o competición, sino que también es un sistema de combate. Sólo hay un sistema de entrenamiento para estos tres usos. Si se utiliza para la pelea, únicamente hay que ignorar las reglas. Las mismas habilidades se aplican de forma diferente dependiendo de la situación. En el pasado, el Shuai Jiao se utilizaba para el entrenamiento de las artes marciales, la competición deportiva y la representación.

\section{Detalle \\ Cuadro \\ "Banquetes en una Fortaleza \\ Fronteriza" \\ por Giuseppe Castiglione, ahora en el Museo del Palacio Imperial, Beijing.}

Todas las fotografías son cortesía de Zhang Yun. 


\section{Historia y desarrollo del shuai jiao}

El Shuai Jiao tiene una historia muy larga. Se dice que esta se remonta en el tiempo hasta hace unos 5000 años, cuando Huangdi, el jefe de una tribu, lucho con Chiyou, otro jefe. Los soldados del ejercito de Chiyou practicaban el "Jiao Di", el antiguo nombre para el Shuai Jiao. También hacían competiciones y representaciones.

La Tabla 1 muestra los diferentes nombres que ha tenido el Shuai Jiao a lo largo de la historia. Hoy en día no sabemos exactamente las habilidades y reglas que se seguían en el pasado. Pero por las descripciones escritas, sabemos que estas habilidades fueron desarrolladas hasta un nivel muy alto. Las Figuras 1 y 2 muestran algunos testimonios de Shuai Jiao de la antigüedad.

Figura 1

Placa de bronce tallada con dibujos de lucha en

pronunciado relieve, Periodo de Guerra entre los Estados (475 AC-221 AC), desenterrado en el pueblo Kesheng, Xian,

Provincia de Shaanxi.

Tabla 1

Diferentes nombres del Shuai Jiao

\section{Caracteres Romanización Chinos Pin Yin}

角抵 Jiao Di 相扑 Xiang Pu 手搏 Shou Bo 相搏 Xiang Bo 掼跤 Guan Jiao 布库戏 BuKuXi 橑跤 Liao Jiao 争跤 Zheng Jiao 摔角 Shuai Jiao (3) 摔跤 Shuai Jiao (1)

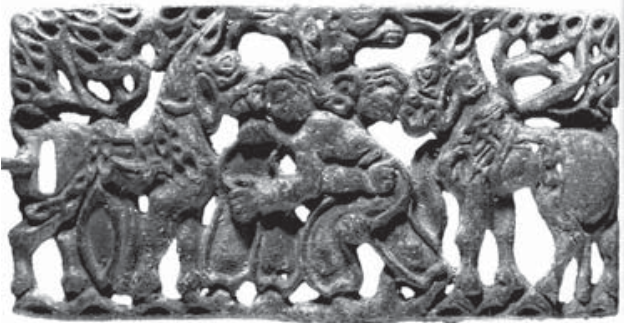

El desarrollo de las habilidades y reglas del Shuai Jiao son más evidentes cuando nos acercamos a su versión moderna, durante la Dinastía Quing (1644-1911). Cuando hablamos del Shuai Jiao en la Dinastía Quing, es imposible no mencionar al "Shan Pu Ying" -el campamento para la guardia de seguridad personal del emperador-y el equipo de Shuai Jiao.

El emperador Kangxi estableció el Shan Pu Ying en 1669, abriendo inicialmente la afiliación al mismo únicamente a los manchurianos. Más tarde se permitió que Han Chinese se uniese. Su origen es una historia interesante, un acontecimiento significativo en la historia de la Dinastía Quing.

Kangxi tenía sólo 8 años cuando heredó el trono en 1661. Durante la época de su padre, el emperador Shunzhi, los manchurianos completaron su conquista y control sobre toda China. Puesto que Kangxi era tan sólo un niño, el propio Shunzhi nombró cuatro oficiales de alto nivel como consejeros, dándoles el poder de gobernar hasta que Kangxi tuviese la edad para hacerlo él mismo.

Uno de estos oficiales era el general Aobai. Físicamente un hombre muy alto y fuerte, fue condecorado como "Guerrero $\mathrm{N}^{\circ} 1$ de Manchuria" debido a su bravura y habilidades exhibidas durante las incontables batallas de su carrera. Aobai comenzó a apropiarse del poder para sí mismo, y con el tiempo llegó a ser la persona más poderosa del país. Todo el mundo le temía y obedecía. Tal era su arrogancia que ni siquiera se preocupaba por mostrar respeto al joven emperador. Entraba directamente en la oficina del emperador y usaba su pluma real y su papel especial para escribir cualquier orden que le placiese, y usaba el nombre del emperador. Cuando Kangxi tenía alrededor de 12 años, Aobai quiso matar varios oficiales de alto rango del gobierno ya que estos no siempre le obedecían. Al principio el emperador se negó, pero el general Aobai fue capaz de intimidar al joven emperador con amenazas. Aunque temía a Aobai, Kangxi decidió matarle. Esto era una tarea extremadamente difícil, ya que Aobai controlaba todo, incluyendo la guardia del emperador. No había nadie alrededor de él en ese momento en quien pudiera confiar.

Kangxi, sin embargo, fue uno de los emperadores más listos en la historia china. Con el tiempo, consiguió grandes cosas, y reinó durante 60 años. Aobai iba a ser su primer reto. El Shuai Jiao era muy popular en aquella época, especialmente en la cultura guerrera de Manchuria. Kangxi seleccionó quince chicos jóvenes de su familia para practicar Shuai Jiao con él todos los días. Practicaban abiertamente en los jardines de la Ciudad Prohibida, sin tratar nunca de ocultar su práctica. Así nadie sospechó de sus verdaderas intenciones. La gente pensaba que solamente eran niños comportándose como niños. Al mismo tiempo, Kangxi no demostró nada sino plena confianza en Aobai, permitiéndole controlar todo sin mediar protesta. 
En la mente de Aobai, Kangxi no era diferente a ningún niño de su edad, preocupado únicamente de jugar y pasárselo bien. Pasaron tres años en esta situación, hasta que el emperador tuvo quince años. En todo este tiempo Aobai llegó a ser más y más poderoso. Nadie se dio cuenta de que el emperador y sus compañeros de Shuai Jiao se habían hecho mucho más fuertes y habían adquirido unas habilidades especialmente buenas.

El 16 de mayo de 1669, Aobai fue como siempre a la oficina del emperador. Cuando entró en la misma la puerta se cerró tras él. El emperador y sus compañeros de Shuai Jiao estaban en la habitación. El emperador le preguntó a Aobai, "¿Sabes que eres culpable de traición?" “¡No se nada de eso!” replicó Aobai desafiante. "AAtadle!” ordenó el emperador a sus

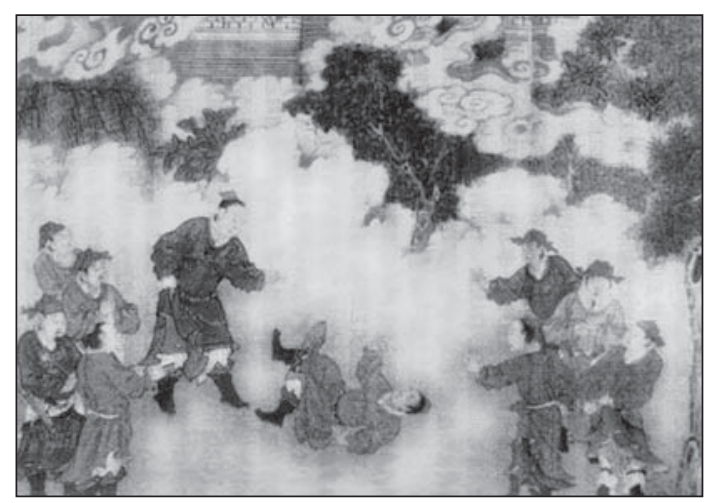
acompañantes. Cuando Aobai escuchó esta orden, soltó una gran carcajada ya que pensó que se trataba de una broma.

Se dice que la lucha fue increíblemente violenta: al principio Aobai golpeó gravemente a varios de los chicos. Entonces uno de los chicos le hizo tropezar. Inmediatamente el resto saltó sobre él. Finalmente fue sujetado contra el suelo y atado. Todo el mundo en el gobierno se sorprendió por la repentina captura de Aobai. Si antes todos temían a Aobai, ahora temían al joven emperador. Inmediatamente todos le prometieron su apoyo. Aobai fue encarcelado y el emperador restauró su poder.

Después de esto, el Emperador Kangxi estableció un nuevo campamento de guardias personales llamado Xiang Pu Ying tomando como base a sus acompañantes de Shuai Jiao. Se cambió su nombre al de Shan Pu Ying. "Shan Pu" significa "buena proyección o lucha" y "Ying" significa "campamento". En este campamento todo el mundo tenía que practicar Shuai Jiao.

El jefe del Shan Pu Ying tenía que ser un príncipe, o el hermano o hijo del emperador. El campamento tenía dos divisiones que se situaban en la parte oriental y occidental de Beijing, llamados normalmente los Campamentos Oriental y Occidental. Por lo general, cada campamento estaba formado por unos doscientos soldados. Una parte de la altamente selectiva prueba de admisión era un examen de Shuai Jiao. Tras su admisión, cada uno recibía un rango de acuerdo a su destreza. Existían cuatro niveles, siendo el primero el más alto. El salario de cada uno se relacionaba con su rango. La paga era mayor que en la mayoría de trabajos que un ciudadano medio podía conseguir. Las Figuras 3 y 4 muestran los luchadores del Shan Pu Ying en sus campamentos.

Aunque los Shan Pu Ying eran parte de lo cuerpos de seguridad del emperador, no tenían muchas obligaciones. Así que básicamente eran practicantes profesionales de Shuai Jiao que se entrenaban durante todo el día. Por esta razón, la guardia del Shan Pu Ying se considera a veces como el equipo nacional de Shuai Jiao. Aparte de sus entrenamientos, su trabajo más importante era participar en las exhibiciones y competiciones que se celebraban para el emperador varias veces al año.

En el calendario chino, había tres grandes exhibiciones y competiciones alrededor del Año Nuevo Chino: 23 de diciembre, 29 de diciembre y 29 de enero. El 23 de diciembre, los luchadores de Shan Pu Ying representaban Shuai Jiao para el emperador en el Palacio Yangxin Dian, donde estaba la oficina principal del emperador. Aunque no importaba mucho quien ganase o perdiese en este acontecimiento, todos querían presumir de sus habilidades delante del emperador.
Figura 2

Xiang Pu en la Dinatía Song del Norte (960-1126).

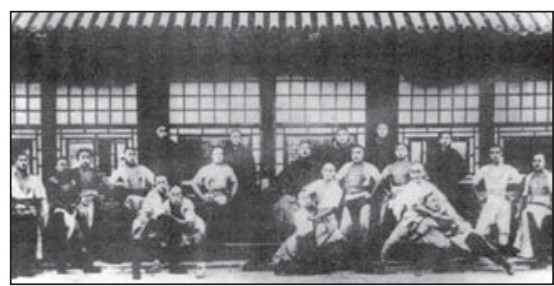

Figura 3

Luchadores del Shan Pu Ying.

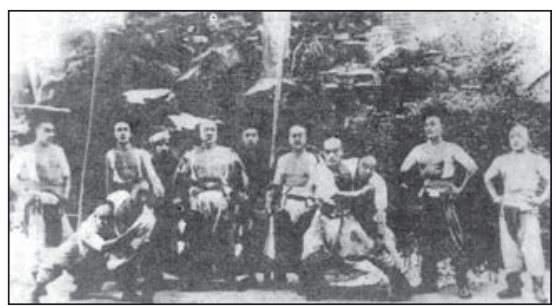

Figura 4

Luchadores del Shan Pu Ying. 
El 29 de diciembre, justo antes del Año Nuevo Chino, el emperador se reunía con los oficiales de otros reinos y grupos extranjeros en un palacio (Yangxin Dian) para recibir los regalos de Año Nuevo. De acuerdo con la tradición, algunos grupos, como los mongoles, podían traer sus luchadores para representar el Shuai Jiao y competir delante del emperador. Así, también el emperador llamaba a sus luchadores para que se exhibiesen y compitiesen contra los visitantes. Este era un momento duro para los luchadores del Shan Pu Ying, ya que eran el equipo del emperador y estaban obligados a ganar la competición. Si perdían, entonces el emperador quedaba mal y seguramente hubiese severos castigos. De modo que el entrenamiento de todo el año se dirigía a ganar este acontecimiento. Durante la competición, no se especulaba. Los documentos señalan que en varias ocasiones, en el fragor de la competición, los maestros del Shan Pu Ying mataron a luchadores visitantes con fuertes técnicas de proyección.

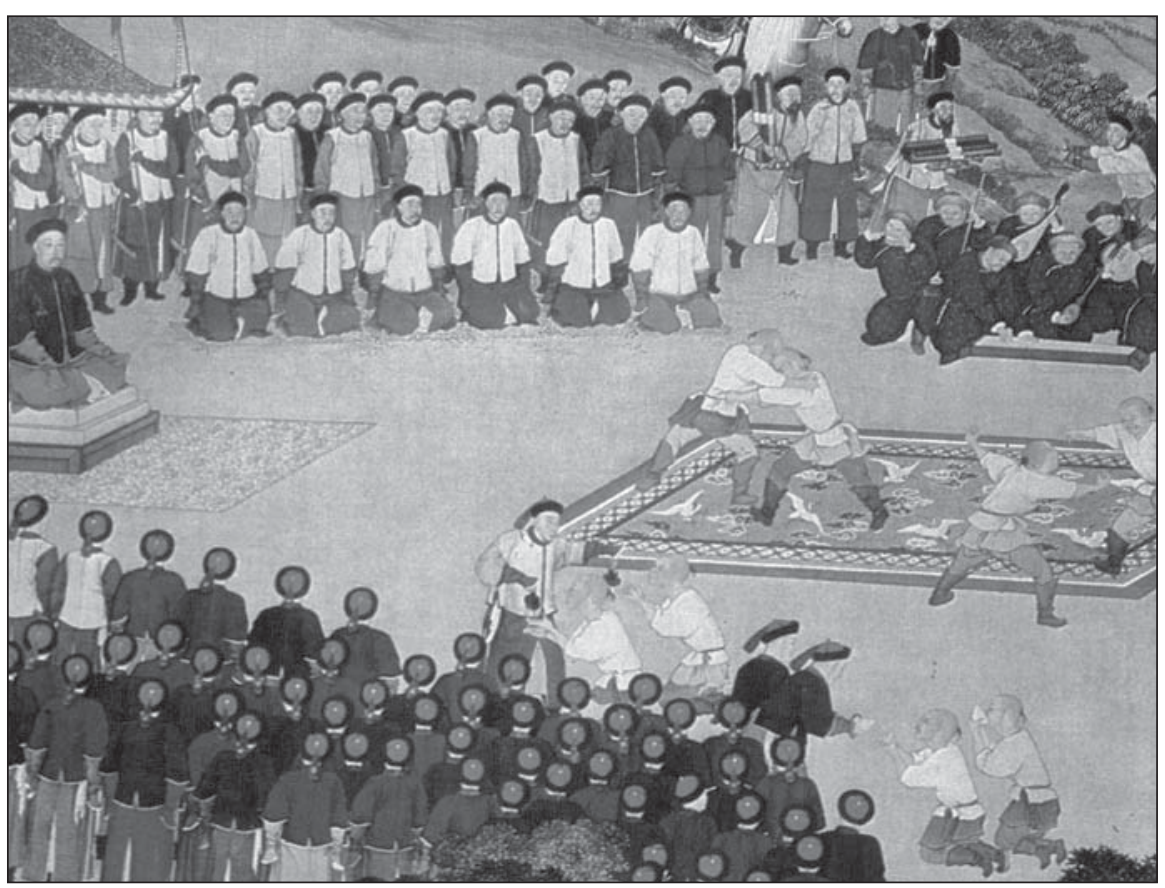

Figura 5 Cuadro "Banquetes en una Fortaleza Fronteriza" por Giuseppe Castiglione, ahora en el Museo del Palacio Imperial, Beijing.
El 29 de enero, después del Año Nuevo Chino, el emperador celebraba una gran fiesta en el palacio de Ziguang Ge para aquellos oficiales que habían hecho un buen trabajo durante el año anterior. Durante esta fiesta, había una gran competición entre los campamentos Oriental y Occidental. Los luchadores recibían ascensos dependiendo de los resultados en esta competición. Los enfrentamientos se echaban a suertes, y la competición era de eliminación simple a muerte súbita: cae una vez y estás eliminado. Así este acontecimiento también presionaba mucho a los luchadores del Shan Pu Ying para que practicasen duro e investigasen sus técnicas con gran detalle y en profundidad.

Además de estos tres acontecimientos, a veces los luchadores del Shan $\mathrm{Pu}$ Ying representaban el Shuai Jiao para el emperador por mero divertimento. Por ejemplo, cada otoño el emperador solía ir al norte para realizar grandes cacerías. Durante estas salidas, se realizaban equitación, tiro con arco, manejo de la espada, y Shuai Jiao ante el emperador. La Figura 5 es la parte de una pintura "Banquete en una Fortaleza Fronteriza" que muestra a los luchadores del Shan Pu Ying luchando ante el emperador Quianlong (1736-1796). En la imagen, el hombre sentado en el lado izquierdo es el Emperador Quianlong. A la derecha, dos parejas de luchadores están peleando y las otras dos parejas acaban de terminar y están recibiendo sus premios. En la parte superior derecha hay personas tocando música para acompañar la competición. El cuadro, que actualmente se encuentra en el Museo del Palacio Imperial de Beijing, fue pintado por Giuseppe Castiglione (1688-1766), un misionero y artista italiano que vivió 51 años en China. Sirvió a tres emperadores chinos y realizó muchos cuadros famosos sobre las vidas y acontecimientos reales de los emperadores.

También cada año, los campamentos Oriental y Occidental competían dos veces más para comprobar su entrenamiento y promover ascensos. Hacerse miembro del Shan Pu Ying no garantizaba que se pudiera mantener el trabajo para siempre. Si el rendimiento no era suficientemente bueno, se podía ser despedido en cualquier momento. Sin embargo, si el rendimiento era bueno y se recibía un grado alto, cuando te hacías viejo podías ser trasladado a otro trabajo en el gobierno hasta la jubilación. 
A partir de estos acontecimientos se formalizaron las reglas de competición. Puesto que la competición era tan intensa, realmente fomentaba el desarrollo de las habilidades y del sistema de entrenamiento, haciendo ambos más refinados y detallados. Otro factor importante que fomentó el desarrollo de la habilidad fue la falta de divisiones por pesos. El luchador más pequeño debía tener muy buenas habilidades simplemente para seguir formando parte del equipo. Además, en la mayoría de las competiciones el ganador se decidía por una única proyección. La combinación de todos estos factores condujo a un nivel de desarrollo de las habilidades del Shuai Jiao muy alto. Tal fue el ambiente durante alrededor de 250 años. Durante aquellos años, más de 400 de los mejores luchadores del país vivían juntos cada día, practicando e investigando bajo presiones e incentivos increíbles.

Debido al carácter único del gobierno manchuriano de la época, fue durante este periodo cuando las habilidades del Shuai Jiao chinas se fusionaron con las habilidades de Shuai Jiao de Mongolia y Manchuria, formando gradualmente un nuevo sistema. Hoy en día, la corriente moderna principal de las habilidades y del sistema de entrenamiento del Shuai Jiao son herencia directa de este sistema.

\section{Popularización y difusión del shuai jiao}

Durante la dinastía Quing muchos soñaron con llegar a ser luchadores en el Shan Pu Ying. La práctica de Shuai Jiao era muy popular, especialmente en el norte. En estos tiempos existían muchos Jiao Chang, escuelas privadas de Shuai Jiao. Estos lugares ofrecían entrenamiento básico para la gente corriente, pero también entrenamiento intensivo para aquella gente que deseaba pertenecer al Shan $\mathrm{Pu}$ Ying. Estas escuelas sólo podían ofrecer entrenamiento de bajo nivel. Normalmente desarrollaban una base para los jóvenes, pero lo más importante es que hacían que el Shuai Jiao fuera mucho más popular. En algunas ciudades del norte de China, como Beijing, Tianjin, y Baoding, el Shuai Jiao llegó a ser el estilo de arte marcial más popular.

Después de la Revolución Republicana de 1911, la dinastía Quing fue derrocada y el Shan Pu Ying disuelto. Puesto que la mayoría de los luchadores de Shan Pu Ying no tenían otra habilidad de la que vivir, muchos fundaron sus propias escuelas privadas o se unieron a otras organizaciones. Ahora las habilidades de más alto nivel llegaron al pueblo. Desde la década de 1910 a la de 1930, la escuela más famosa en Beijing fue la de Hong Miao (Templo Rojo) Jiao Chang. Estaba dirigida por Wan Yongshun, un antiguo luchador del Shan Pu Ying, quien era ayudado por otros antiguos luchadores también del Shan Pu Ying. Durante aquel periodo, los luchadores más famosos, como Shen Yousan, Bao Shanlin, Zhang Wenshan, y Xu Zunquing, todos venían de esta escuela de entrenamiento. Así la disolución del Shan Pu Ying tuvo dos consecuencias en el Shuai Jiao: una fue la de que el mejor entorno para su desarrollo se había perdido, y la otra fue que mucha gente tuvo la posibilidad de aprender las habilidades de más alto nivel.

El Shuai Jiao llegó a ser popular no sólo como práctica sino también como entretenimiento. Más y más gente llegó a ver el Shuai Jiao. Ya que la mayoría de los luchadores del Shan Pu Ying no tenían otra habilidad aparte del Shuai Jiao, cuando perdieron sus trabajos sus vidas fueron muy difíciles. De esta manera, muchos exhibían el Shuai Jiao en la calle para ganar dinero. Al principio, algunos pensaban que este arte sólo podía realizarse para el emperador, y aquellos que lo realizaban en la calle perdieron el respeto de sus compañeros. Hubo una intensa resistencia a esto. Pero con el paso del tiempo la mayoría de la gente terminó aceptando este nuevo rumbo. Aunque no muchos viejos maestros hicieron esto, muchos de sus alumnos sí lo hicieron. Se había convertido en una nueva oportunidad de trabajo para la generación más joven de practicantes de Shuai Jiao. El negocio del Shuai Jiao co- 


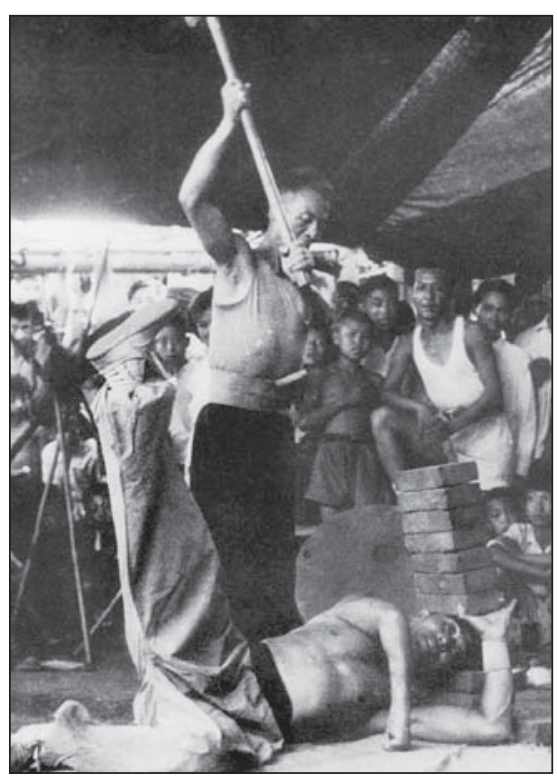

Figura 6

Exhibición de qigong fuerte o duro, rompiendo ladrillos sobre la cabeza con un martillo grande.

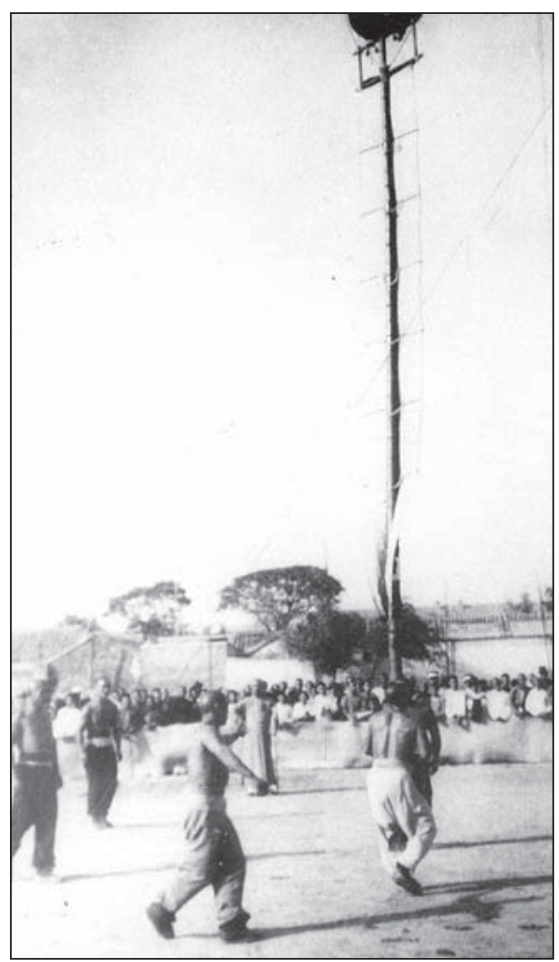

Figura 7

Bao Saner haciendo una demostración del poste largo. menzó en Beijing y pronto se extendió a muchos lugares por todo el país, llevando las habilidades de mayor nivel a muchos lugares.

Realizar Shuai Jiao en las calles no era un trabajo fácil. Los profesores de Shuai Jiao tenían muchos retos. De acuerdo con las reglas tradicionales, si uno perdía en un reto, no podía continuar trabajando en esa zona. Tenía que moverse un lugar nuevo, pero incluso esto era difícil. Estos profesores tenían que practicar duro cada día para mantener sus niveles de habilidad altos. Aunque estos profesores ejecutaban muchas habilidades "falsas" únicamente por su belleza o para exhibiciones humorísticas, todavía tenían un verdadero gongfu [habilidad o destreza superior desarrollada gracias a un entrenamiento continuo e intenso. N. del T.]. En segundo lugar, tenían que hacer que la gente disfrutase con sus representaciones. Así que no podían ejecutar tan sólo técnicas reales de Shuai Jiao. Necesitaban mezclar técnicas reales, charlas y demostraciones circenses. Normalmente tenían que contar muchas historias graciosas a modo de comediantes, demostrar habilidades especiales como el qigong fuerte o duro, y después realizar Shuai Jiao. La Figura 6 muestra una demostración de qigong fuerte o duro.

Una de las exhibiciones más famosas en el Shuai Jiao de Beijing era Zhong Fan -el poste largo. Bao Shanlin, conocido como Bao Saner, era el mejor en esto. La representación consistía en un poste de 25 pies de largo [7,6 m.] decorado con banderitas, flores y banderas. El ejecutante llevaba el poste verticalmente sobre diferentes partes de su cuerpo: brazo, hombro, cabeza, etc. Entonces lanzaba al aire el poste y usaba su mano, brazo, hombro, espalda, frente, o incluso la parte superior de la cabeza para cogerlo. El poste se mantenía vertical todo el tiempo. La Figura 7 muestra la representación de Zhong Fan hecha por Bao Saner. Esta se convirtió en una representación de moda.

Por lo general un grupo constaba de varios buenos amigos y sus estudiantes. Podían viajar o permanecer en el mismo lugar para actuar. Además del espectáculo, también vendían medicinas especiales apropiadas para el desarrollo del Shuai Jiao. Ya que el Shuai Jiao siempre causa lesiones, los luchadores normalmente tienen algunas medicinas muy buenas para autotratarse. Alcanzaron fama por estas medicinas y mucha gente las compraba. Por añadidura de las representaciones, los maestros enseñaban a sus estudiantes. Así el lugar de la representación llegaba a ser el lugar de entrenamiento. Desde la década de 1920 a la de 1960, la mayoría de los grandes luchadores de Shuai Jiao trabajaban en estos grupos o venían de estos grupos. En Beijing, el lugar más famoso para los espectáculos de Shuai Jiao está próximo a un puente llamado Tianqiao (el Puente del Cielo).

Desde 1928, el Shuai Jiao fue incluido en los juegos nacionales chinos y llegó a ser un acontecimiento deportivo moderno. Fue la primera vez en la que los luchadores fueron divididos por pesos. Algunas de las reglas fueron modificadas, por ejemplo, cada pareja de luchadores competía tres veces y quien ganaba dos de los tres enfrentamientos era el ganador. Estas competiciones daban a los luchadores de diferentes áreas del país la oportunidad de intercambiar técnicas y experiencias, y fueron algo positivo para el desarrollo del Shuai Jiao. Desafortunadamente, debido a las guerras civiles y la Segunda Guerra Mundial, en los años 30 y 40 estas competiciones siempre se interrumpieron o tenían una concurrencia muy baja. Debido a las dificultades de viajar a través de un país devastado por la guerra, muchos buenos luchadores simplemente no tenían la oportunidad de participar.

Comenzando la década de 1950, China entro en un periodo más estable. Muchas ciudades y provincias organizaron sus propios equipos de Shuai Jiao. El gobierno ofrecía un apoyo total. Los luchadores de Shuai Jiao se habían convertido en atletas profesionales. El sistema de entrenamiento tradicional y el sistema de entrenamiento deportivo moderno se sintetizaron. Se modificaron las reglas para estar más de acuerdo con las competiciones deportivas modernas. En los años 70, una nueva generación de luchadores llevó el entrenamiento de Shuai Jiao a otro punto de inflexión en su desarrollo. En los años 90, sin embargo, el gobierno adoptó una nueva política deportiva que favorecía las pruebas olímpicas. El gobierno retiró su apoyo a las pruebas no-olímpicas, y los equipos de Shuai Jiao fueron disueltos una vez más. Esta vez, la decisión cambió el ambiente e hizo que esta práctica perdiese popularidad. 


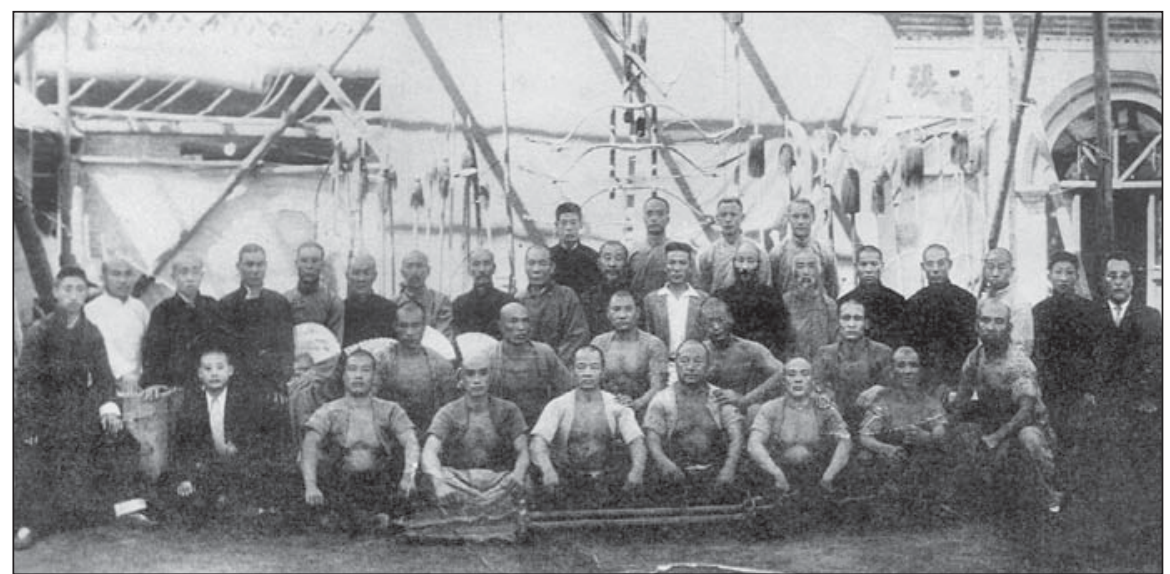

Hoy en día algunos viejos maestros siguen enseñando. Han fundado pequeños clubes, pero sin el entorno profesional, se enfrentan a muchas dificultades, especialmente económicas y de selección de atletas. Durante los últimos 300 años, el Shuai Jiao había conocido dos épocas doradas, durante el periodo del Shan $\mathrm{Pu}$ Ying y entre las décadas de 1950 y 1980. Tras su rápido declive hace aproximadamente veinte años, ha recuperado algo de popularidad.

\section{Análisis de los principios básicos}

El Shuai Jiao se compone de técnicas de proyección. Una técnica de proyección completa se llama ban o banzi. Cada técnica de proyección se compone de dos partes: desestabilización y poner la zancadilla.

Normalmente no hay manera de proyectar directamente a una persona bien entrenada cuando mantiene una postura estable. Por ello lo primero es desestabilizarle. Cuando se mueve al oponente, se mueve su centro de gravedad. Tienes que hacer que su cuerpo no esté cómodo para estorbar los movimientos de sus pies. Sólo cuando se mueve el centro de gravedad del oponente se tiene la oportunidad de desestabilizarle. Sólo cuando su cuerpo esta incómodo tiene la necesidad de modificar su posición. Y cuando comete un error en su respuesta, da al practicante la posibilidad de aprovechar su error para desestabilizarlo. Sólo cuando su juego de piernas está desestabilizado es cuando tiene dificultad para realizar los ajustes necesarios. Cuando el oponente esta inestable, sus movimientos son lentos, creando la oportunidad para mantenerle en una situación de inestabilidad. Desde aquí puedes llevarle a estar desequilibrado. Existen muchas técnicas de desestabilización, muchas de las cuales usan técnicas de brazos y el juego de piernas.

Muchas zancadillas se realizan con las piernas. Pero la clave siempre está en cómo usar las manos de manera coordinada con los pies. Aunque la desestabilización y la zancadilla son dos partes de la técnica, no existe una clara separación. En la mayoría de las ocasiones se solapan o se realizan de forma conjunta. La integración y coordinación del movimiento de todo el cuerpo es muy importante. Se suele decir que los movimientos de la parte superior del cuerpo, incluidos brazos y manos, cabeza, y tronco, tienen que integrarse con los movimientos de la parte inferior del cuerpo, incluyendo caderas, piernas y pies. Todo el entrenamiento básico y técnico del Shuai Jiao gira entorno a esta capacidad. Para aprender las técnicas de proyección, primero se deben entender las técnicas básicas de manos, el juego de piernas, el movimiento del cuerpo, y luego cómo realizar las zancadillas.

\section{Figura 8}

Famosos maestros de exhibiciones callejeras de Beijing en su lugar de exhibiciones en Tianqiao en 1942.

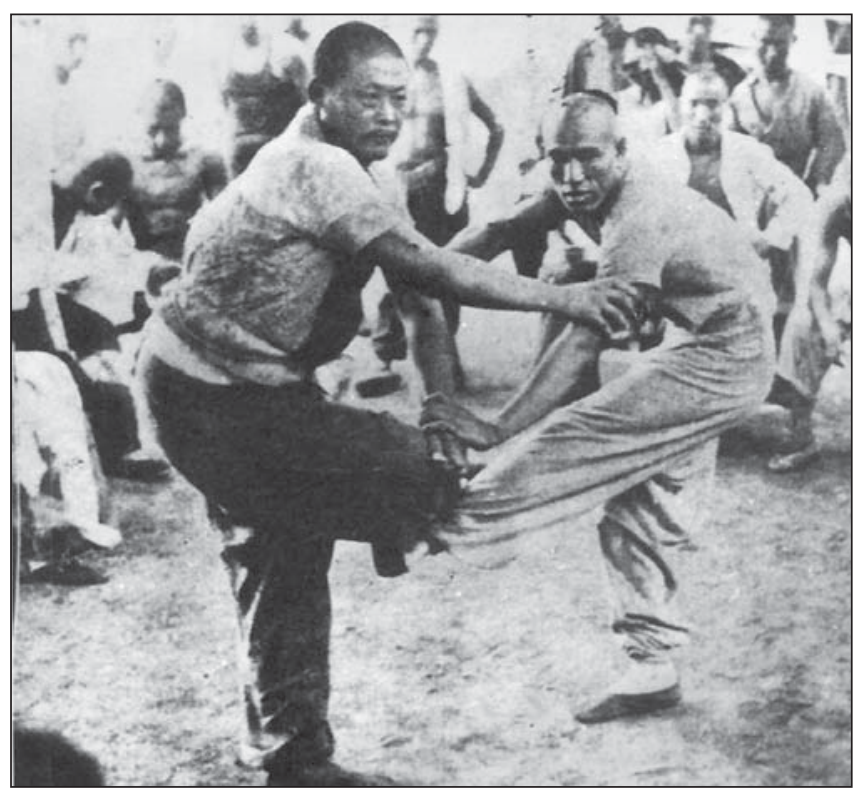

Figure 9

El maestro Zhang Wenshan (izquierda) practicando en la calle. En 1935 logró la segunda plaza de los pesos pesados en los campeonatos nacionales. 


\section{Figura 10}

Posiciones de agarre con una mano

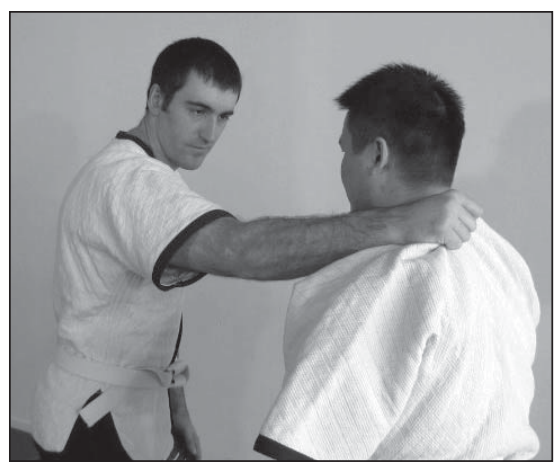

a. Agarre al cuello del traje

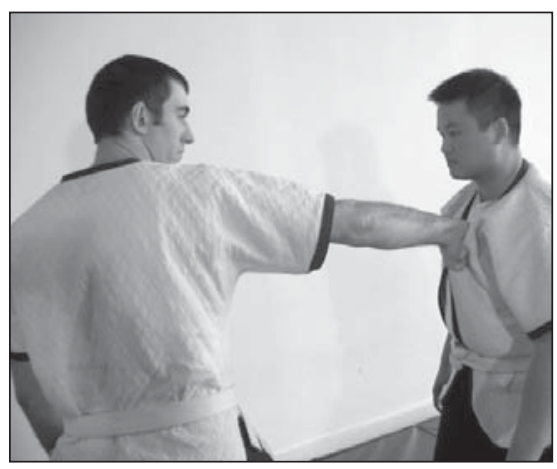

d. Agarre inverso a la solapa del mismo lado

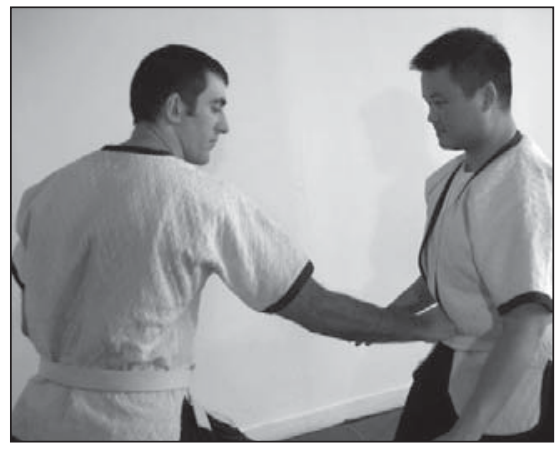

g. Agarre al centro del cinturón

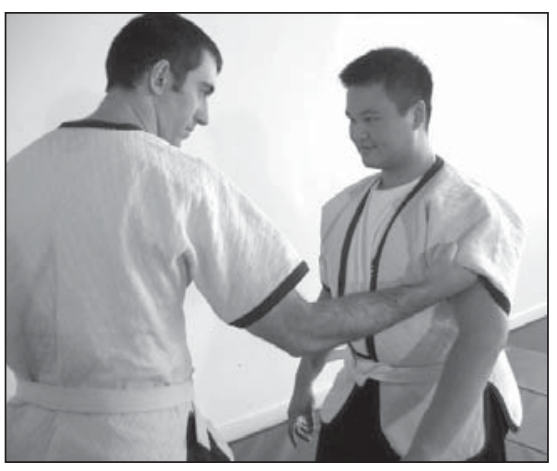

b. Agarre a la manga

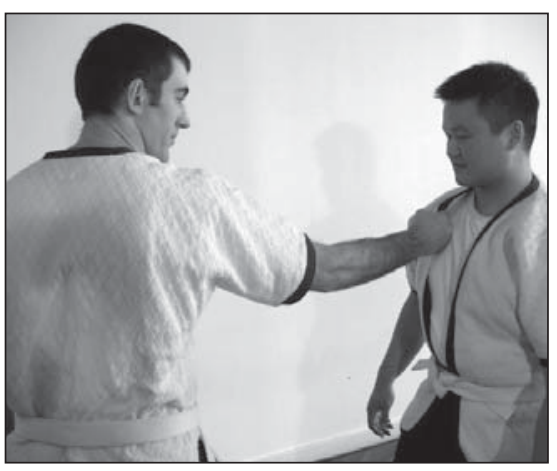

e. Agarre de la solapa contraria

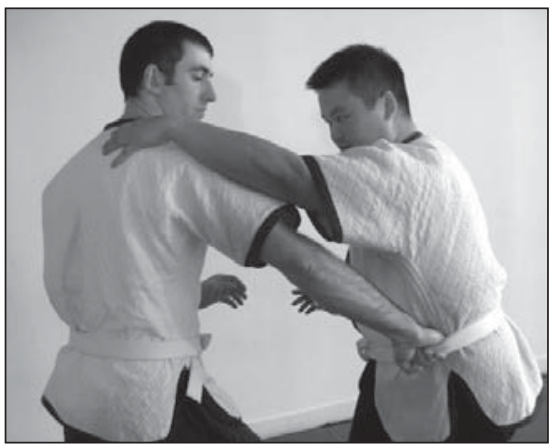

h. Agarre lateral al cinturón

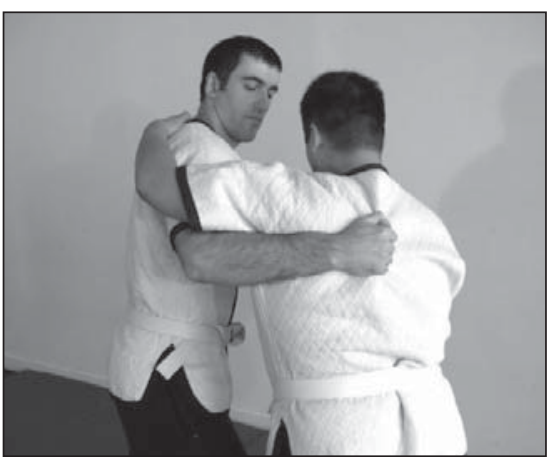

j. Agarre a la espalda del traje

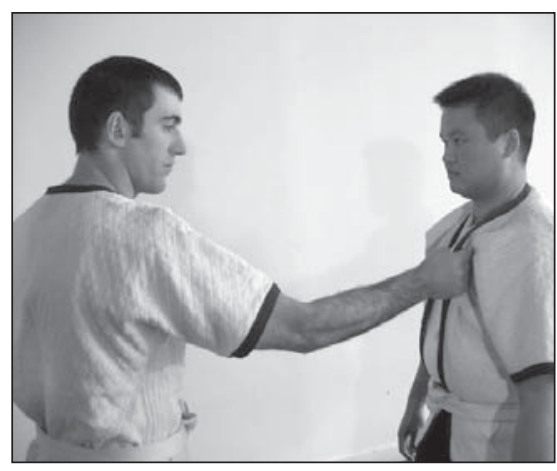

c. Agarre a la solapa del mismo lado

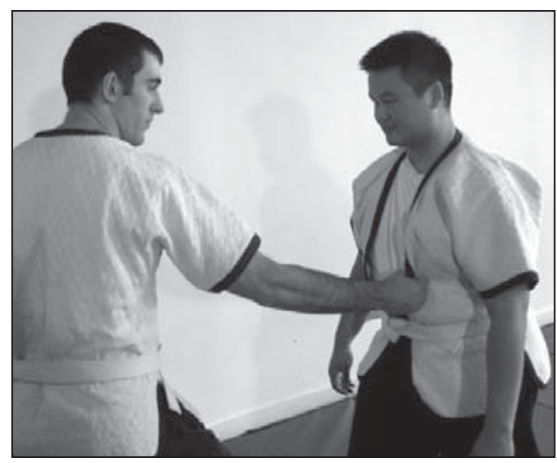

f. Agarre bajo a la solapa

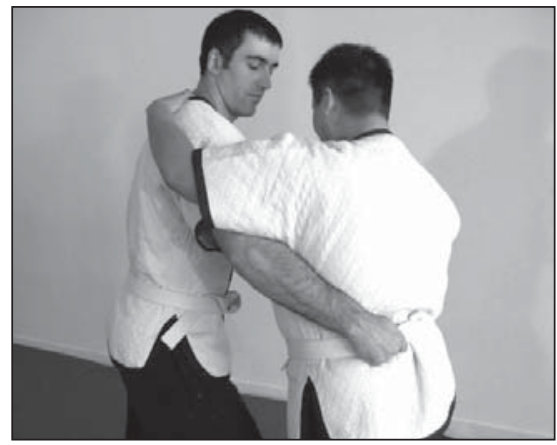

i. Agarre a la parte posterior del cinturón

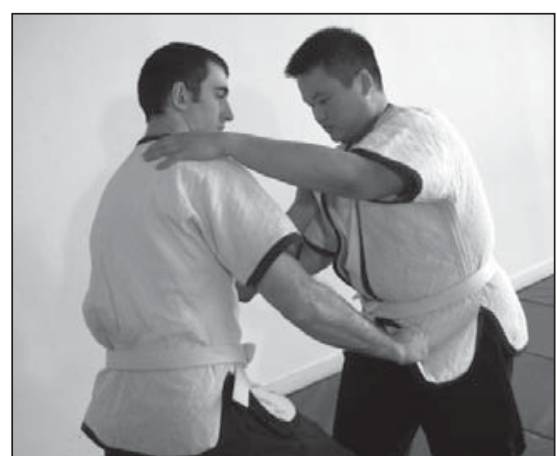

k. Agarre a la parte inferior del traje 
Figura 11

Posiciones de agarre a dos manos

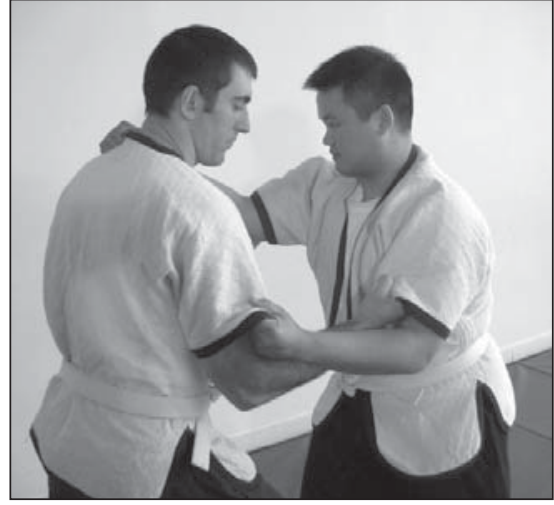

a. Manga y cuello

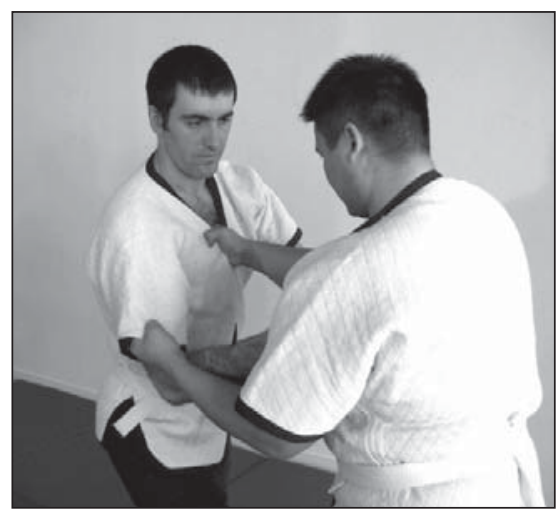

d. Manga y solapa contraria

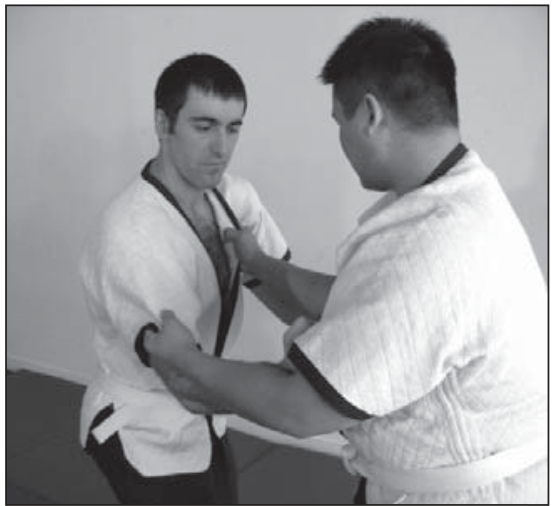

b. Manga y la solapa del mismo lado

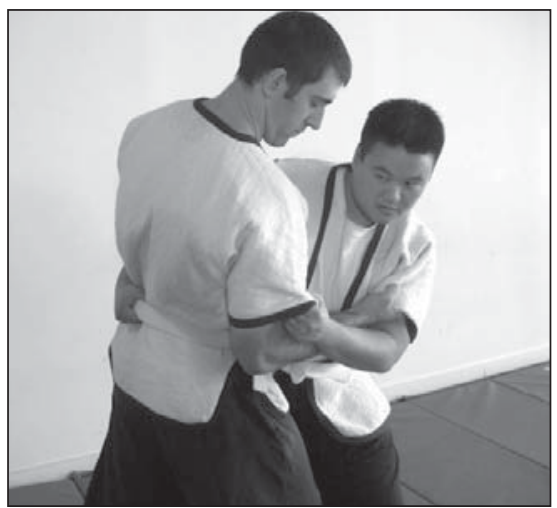

e. Manga y parte posterior del cinturón

\section{Técnicas de manos}

Las técnicas de manos del Shuai Jiao son muy detalladas y refinadas. Su conocimiento incluye cómo agarrar $(b a)$, cómo soltar el agarre, y cómo usar la fuerza.

En competición, se viste un traje especial (da lian). Este traje es muy grueso para poder ejercer mucha fuerza. Es importante dónde y cómo coger el traje de tu oponente. La serie de fotografías en la Figura 10 muestran varias formas comunes de agarre con una mano (ba wei).

La competición de Shuai Jiao comienza con los competidores sin tocarse. Así, la primera preocupación técnicamente hablando es el agarre (qiang ba, tomar) combatir) en el cual ambas partes tratan de lograr una mejor posición de agarre. Cada técnica es diferente y exige la aplicación de una fuerza distinta así como de una posición de agarre diferente.

Generalmente, si prefieres avanzar con el pie derecho o usar el pie derecho para realizar la zancadilla, usarás tu mano izquierda para agarrar la manga de tu oponente, y usarás tu mano derecha para coger su cuello, la solapa contraria, la solapa del mismo lado, o el centro del cinturón. Las fotografías en la Figura 11 muestran algunas posiciones comunes de agarre a dos manos. Agarrar la manga, la solapa del mismo lado, o la solapa contraria puede ser lo más fácil para tirar del oponente, forzándole a moverse. Agarrar el cuello y el centro del cinturón es adecuado para controlar su centro de gravedad.

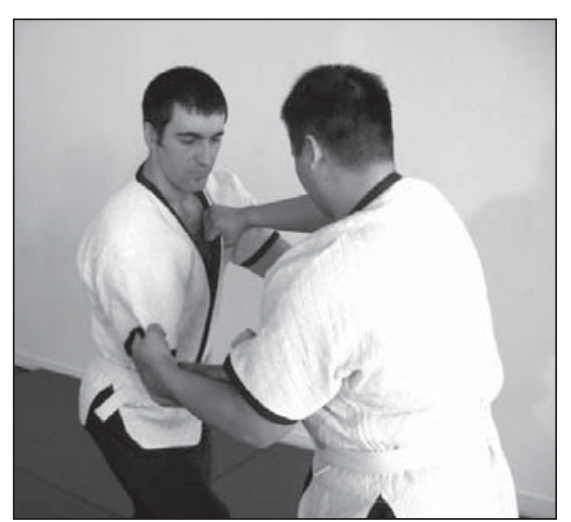

c. Manga y agarre inverso a la solapa del mismo lado

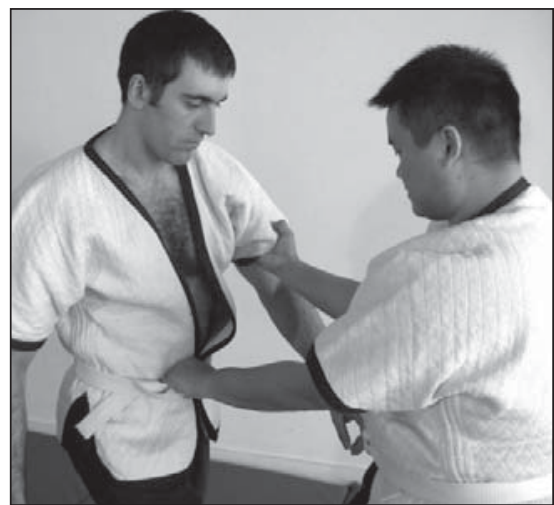

f. Centro del cinturón y manga

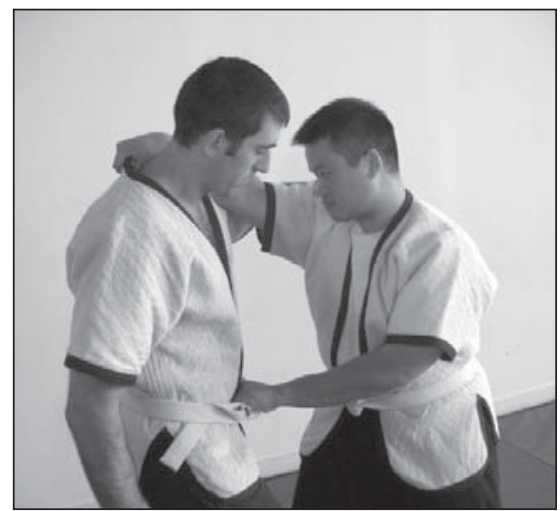

g. Cuello y centro del cinturón 
Figura 12

Tres cambios de agarre

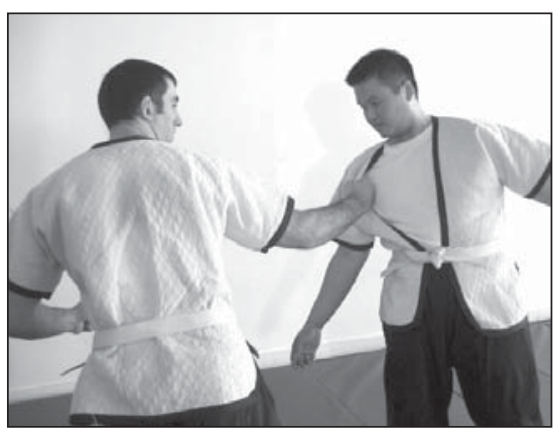

a La mano derecha agarra y tira hacia la izquierda

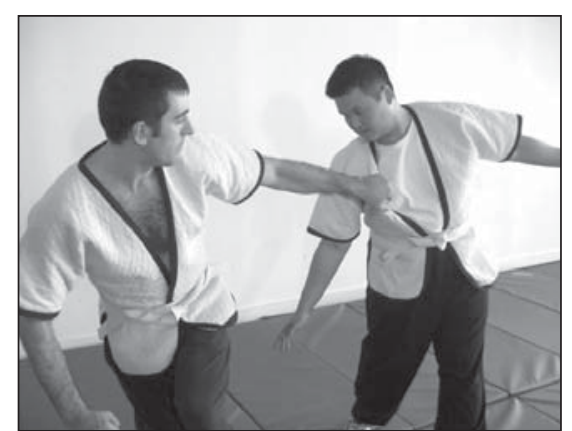

b. La mano izquierda agarra y tira hacia la derecha

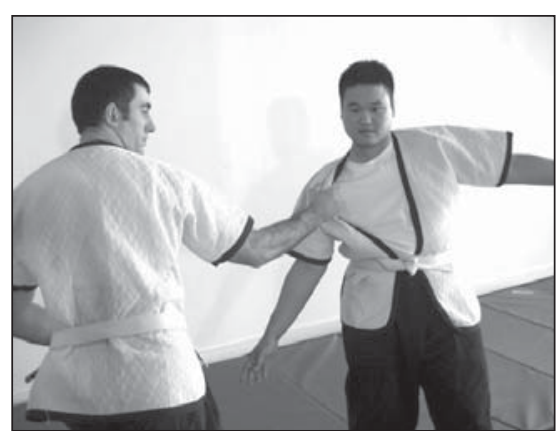

c. La mano derecha agarra y tira hacia la izquierda

\section{Figura 13}

Agarre a la muñeca

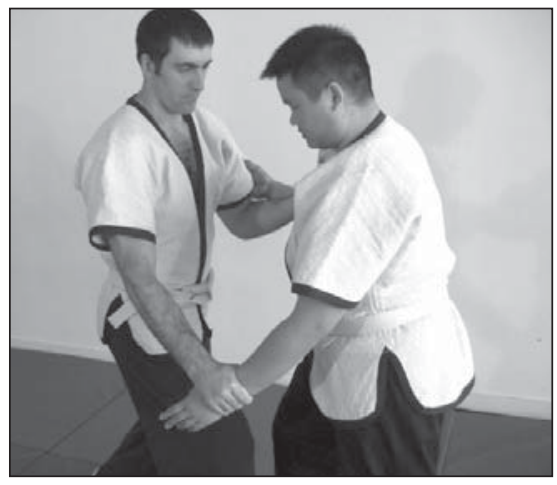

a. Agarre a la muñeca por arriba

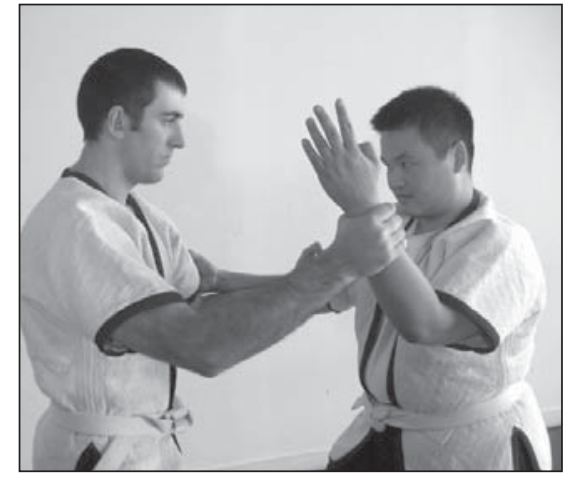

b. Agarre a la muñeca por debajo
Figura 15

Sujeción por la pierna

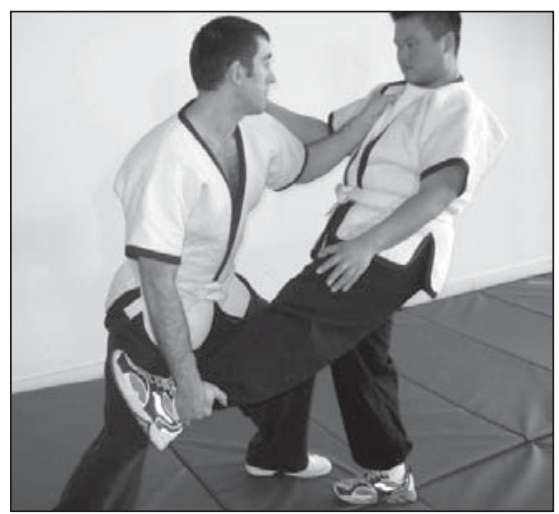

a. Sujeción de la pierna con una mano

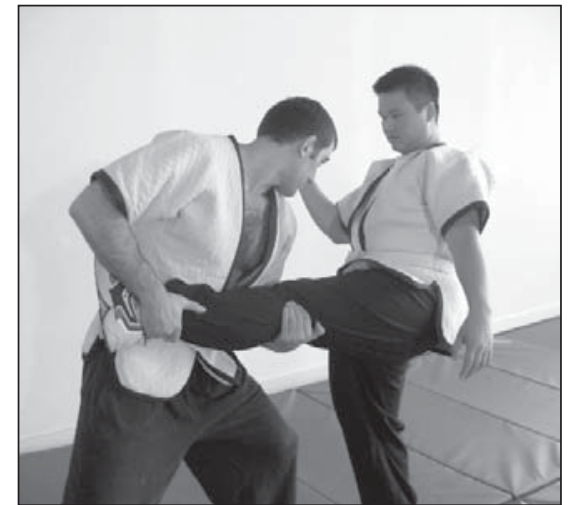

b. Sujeción de la pierna con dos manos

\section{Figura 14 \\ Sujeción por la cintura}

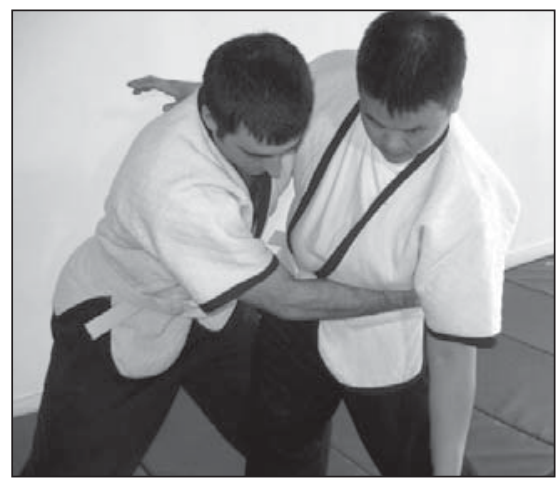

El agarre no es rígido ni inmutable, antes al contrario, tiene que ser flexible y variable. Cambiar la posición del agarre significa cambiar la dirección de la fuerza. Cambiar la posición es una forma sencilla de confundir al oponente para hacer que pierda el equilibrio. La técnica más común es "cambiar el agarre de la mano" (dao ba) como en la Figura 12. Aquí se agarra y tira del oponente, entonces de repente se cambia la dirección del tirón. Normalmente esta técnica de mano tiene que combinarse con el juego de piernas.

Además de agarrar al traje, las reglas del Shuai Jiao permiten coger la muñeca del oponente o sujetar su cintura o piernas. No se puede agarrar el pantalón. Las Figuras 13, 14 y 15 muestran varias técnicas comunes para agarrar la muñeca y sujetar la cintura y piernas del rival. 
Escapar del agarre de tu oponente se denomina "patear fuera la mano" (deng shou o deng ba). En mandarin, deng significa "patear". Aquí se utiliza la mano para empujar fuera la mano del oponente cuando trata de agarrar. La sensación de la mano en esta técnica debería ser similar a la de patear con el pie la mano o brazo del oponente. Ya que el traje es muy robusto, el oponente puede agarrarlo y sujetarlo con mucha fuerza. Las técnicas de deng shou no son fáciles de realizar. Observe la Figura 16 en la siguiente página donde se detallan cuatro técnicas de deng shou frecuentes para los practicantes de Shuai Jiao.

Lo siguiente son algunas ideas básicas que deben recordarse. Primero, estos tipos de técnicas deberían usarse antes de que el oponente tenga una sujeción fuerte. Lo cual significa que se debería "patear" su mano justo cuando esta toma contacto. En ese momento, su agarre es vulnerable. Segundo, el ángulo es muy importante. Hay bastantes técnicas que implican patear el agarre del oponente. Para aplicar estas técnicas, el ángulo correcto es fundamental, debiéndose estudiar con detalle. Normalmente el ángulo correcto puede hacer que tu oponente se sienta incómodo o colocarle en una posición dolorosa, de modo que tendrá que soltar su mano. Usando las reglas de Shuai Jiao, sin embargo, nunca puedes luxar las articulaciones de tu oponente para hacerle daño. Tercero, la fuerza que se aplica debería ser repentina, rápida e integrada. La sorpresa y la rapidez no dan al oponente la oportunidad para ajustar su fuerza y posición. Integración significa que todo el cuerpo debería moverse como un todo. Esto es importante porque la mayor parte del tiempo cuerpo y mano van en direcciones contrarias.

A continuación se especifican algunas maneras de usar la mano de agarre para producir diferentes fuerzas:

Tui - empujar: empuja al oponente.

$\mathbf{L} \boldsymbol{a}$ - tirar: tira del oponente hacia ti, de modo que se pueda estar más cerca de él para realizar la zancadilla.

Ti - levantar: levanta al oponente para hacerle perder su base de sustentación.

$\mathbf{Y a}$ - presionar: presionar al oponente hacia abajo para dificultarle sus movimientos.

Pai - golpear / palmear: una fuerza rápida que se usa para mover al oponente. Los objetivos son normalmente la mano, el hombro, la espalda, etc. En Shuai Jiao, generalmente no te enfrentas al adversario con la fuerza de tu pai. Pai se usa normalmente en la misma dirección que sigue la fuerza del oponente.

Ning - retorcer: retuerce parte del cuerpo del contrario, por ejemplo el brazo, para llevarle a una posición incómoda.

Fan - cambiar de dirección: cambiar la fuerza a lo largo de una curva para girar al oponente.

Dou - zarandear: una fuerza cambiante repentina y en sucesión, en dos o más direcciones, para zarandear al oponente, de modo que no pueda permanecer equilibrado.

Xuan - dar vueltas: dos manos aplican fuerzas en direcciones opuestas haciendo un círculo para hacer girar el cuerpo del contrario.

Rao - amasar (o frotar): fuerza suave usada para cambiar la dirección de las fuerzas, así el oponente encontrará dificultad para saber lo que harás después. 
Figura 16

Técnicas de patear la mano
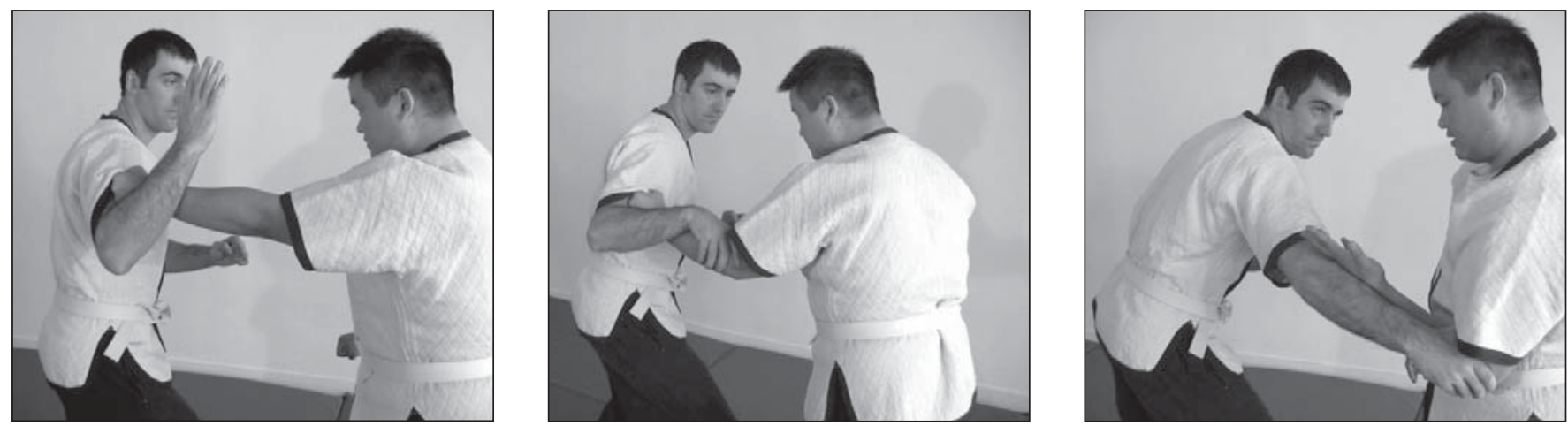

Pateo de la mano que agarra la manga
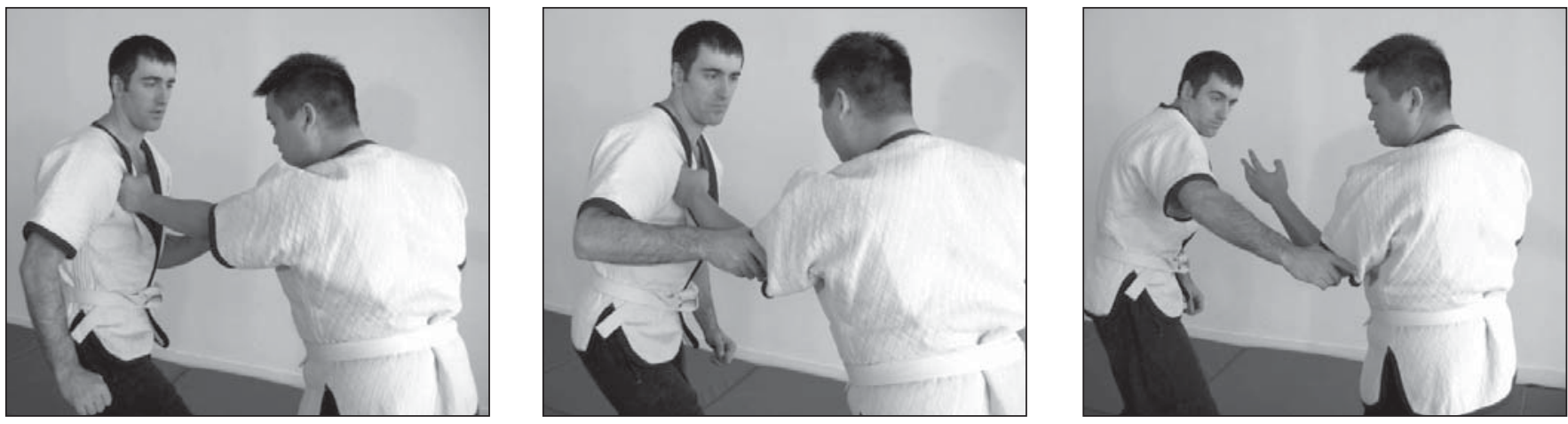

Pateo de la mano que agarra la solapa del mismo lado
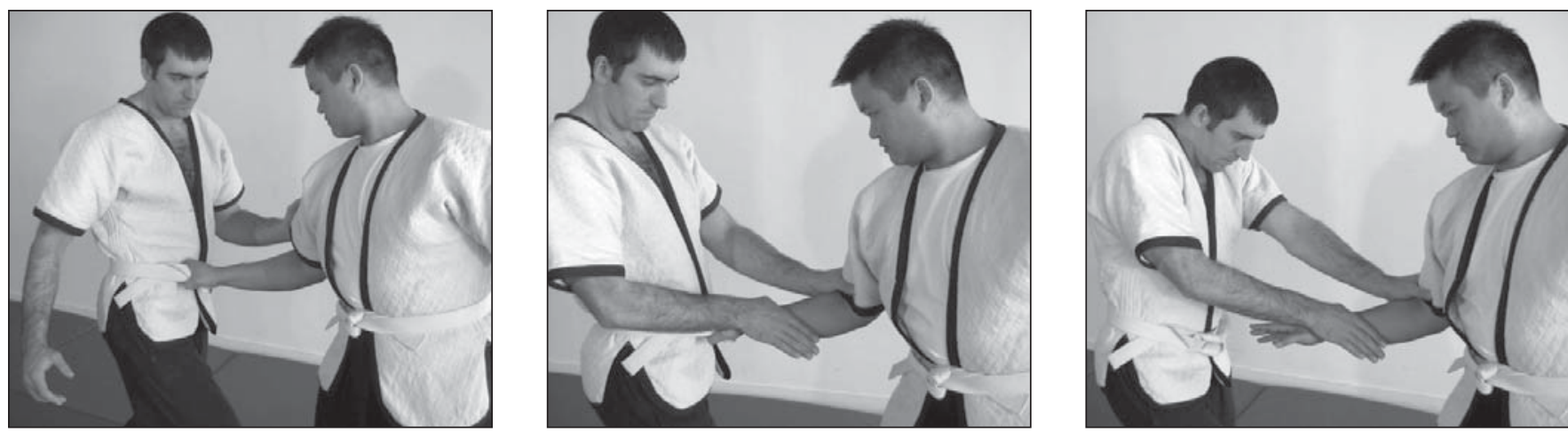

Pateo de la mano que agarra el centro del cinturón
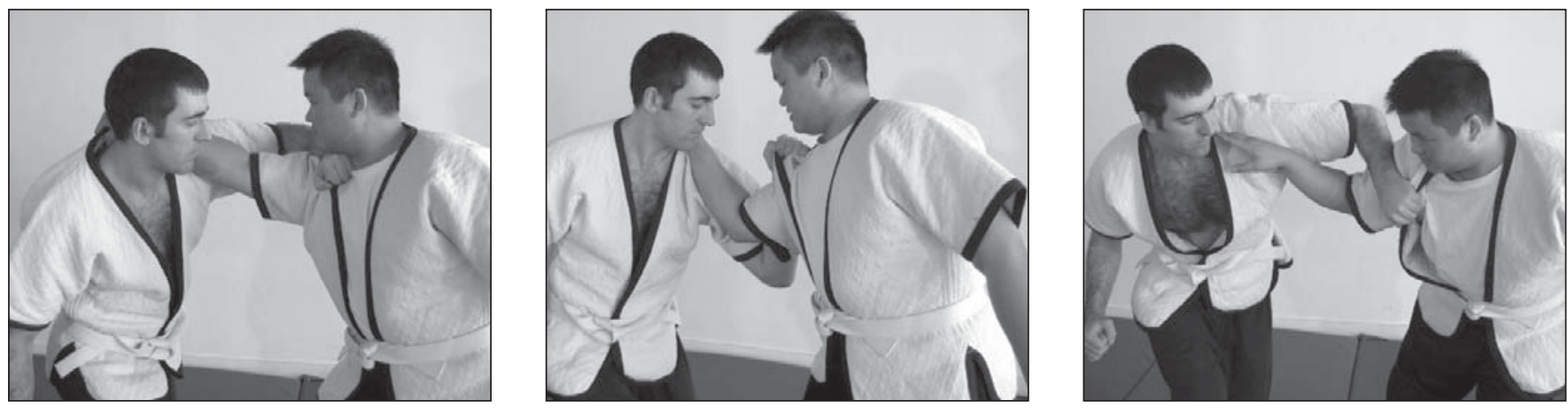

Pateo de la mano que agarra el cuello del traje 
Por supuesto en situación real se combinan algunas de estas fuerzas. El cambio continuo de fuerzas es muy importante para confundir al adversario. Por ejemplo, si quieres tirar de él hacia ti, primero puedes empujarle. Cuando sientas su empujón hacia atrás, entonces tira de él. A veces es más eficaz añadir un zarandeo cuando se empuja al contrario.

\section{Trabajo de piernas}

En la mayoría de las ocasiones el uso de las técnicas de mano no es suficiente para desestabilizar a una persona. También se deben usar los pies. Los movimientos de pies y manos deben ser coordinados. La mayor parte del entrenamiento del juego de piernas del Shuai Jiao se basa en cómo cambiar las direcciones, cómo usar la fuerza, cómo ajustar el centro de gravedad y cómo mover los pies. Las técnicas de movimientos de pies del Shuai Jiao deben ser rápidas (kwai), estables (wen), hábiles (ling), y variables (bian).

Los movimientos rápidos de pies dificultan que el oponente te siga. Los movimientos estables te permiten mantener el propio equilibrio, ya que es fácil perder el equilibrio cuando se mueven los pies. La habilidad significa que los pies se pueden mover rápidos, ligeros y de manera precisa. La variabilidad significa que siempre se puede cambiar de dirección y usar distintos tipos de movimientos de pies, como en la Figura 17. Un buen juego de piernas permite conseguir el control y da problemas al adversario. A veces incluso se puede tirar al oponente sin una zancadilla usando simplemente el juego de piernas.

Durante una competición de Shuai Jiao, la mayor parte del tiempo se tiene que usar la postura de T o L (ding $b a b u)$, una postura relativamente estable que facilita el cambio en el juego de piernas. El paso hacia delante (shang bu) se usa para avanzar hacia delante comenzando con la pierna retrasada. El paso circular hacia atrás (che lun bu) se usa para retroceder con la pierna adelantada y girar el cuerpo lateralmente. Este paso se usa con frecuencia para ir hacia atrás rápidamente. El paso cruzado (jiao cha bu) se usa para cruzar un

\section{Figura 17}

\section{Posturas y pasos}
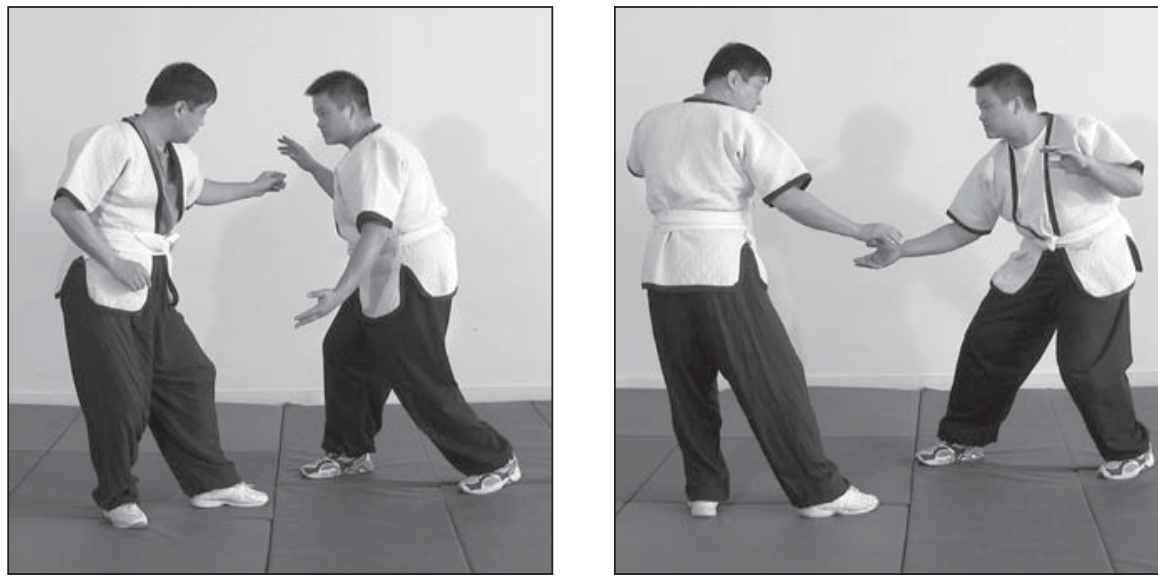

Postura de T o L
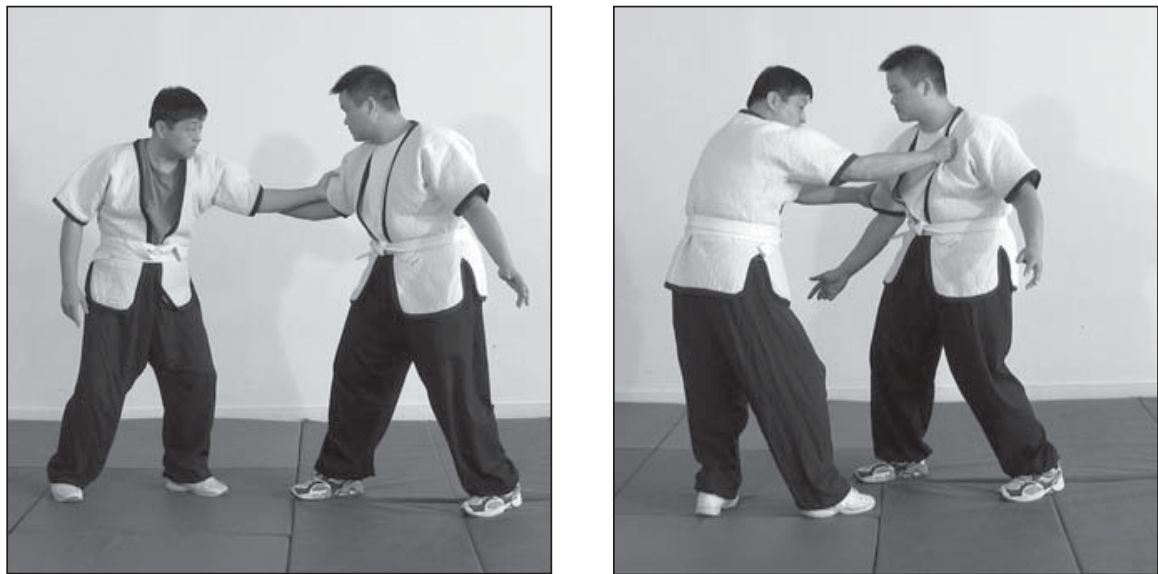

Paso hacia delante
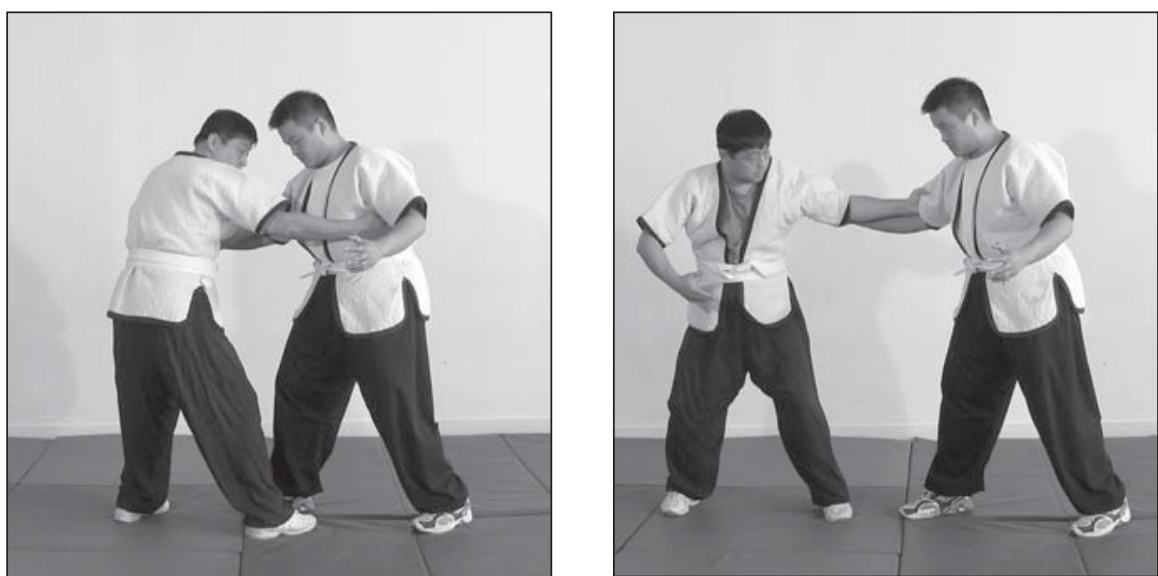

Paso circular hacia atrás 


\section{Figura 17}

Posturas y pasos (continuación)

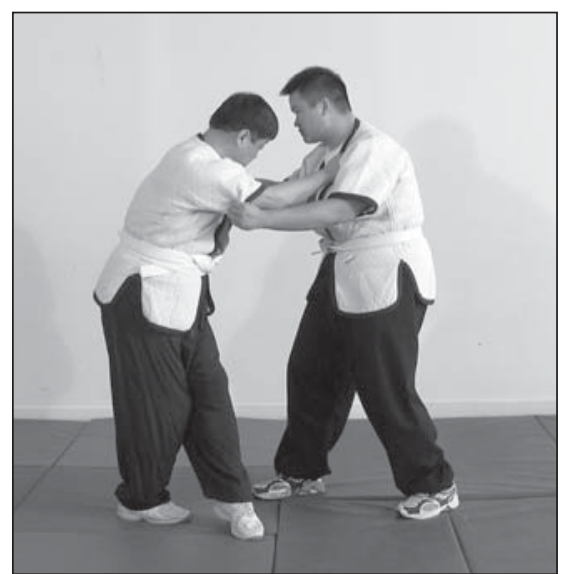

Paso cruzado

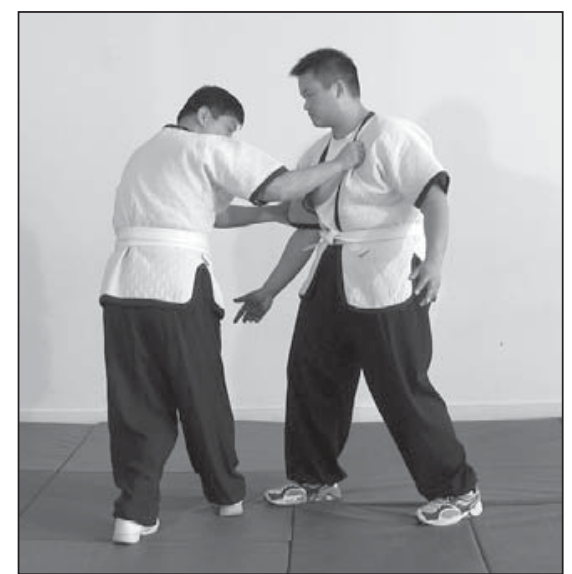

Paso cubierto

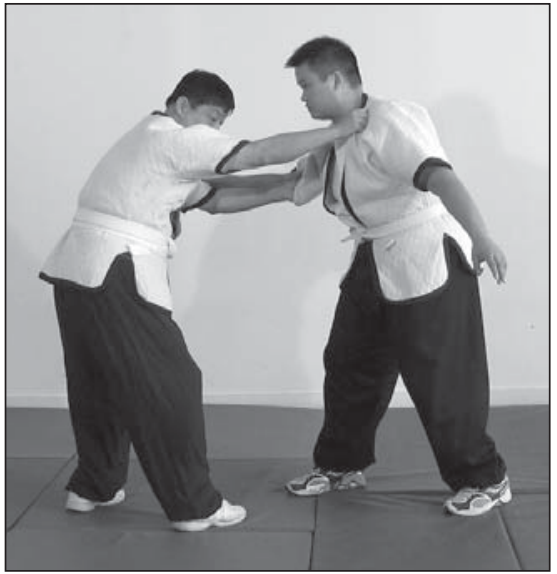

Paso en salto

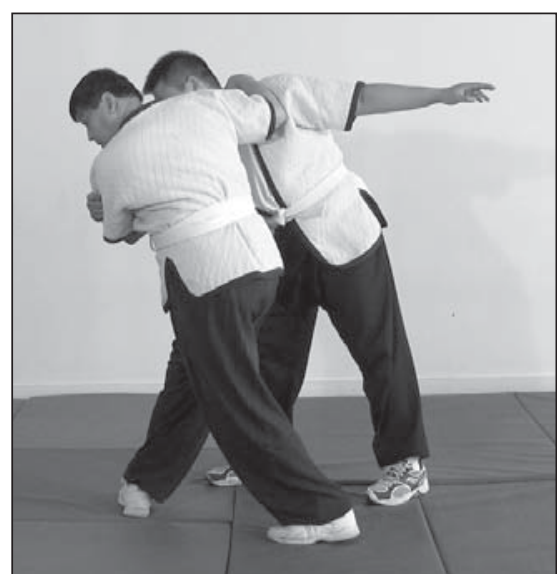

Paso hacia atrás

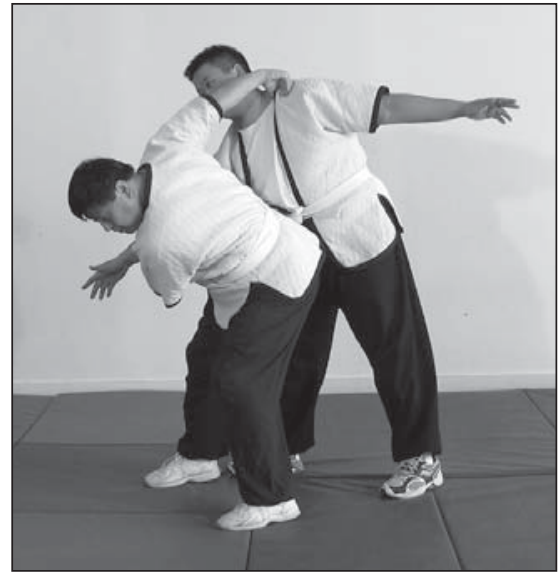

Figure 18

Posiciones iniciales

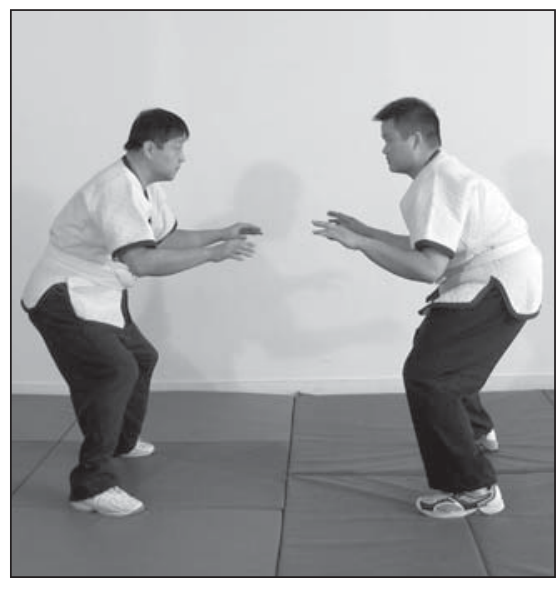

Posiciones de "empujar el carro"

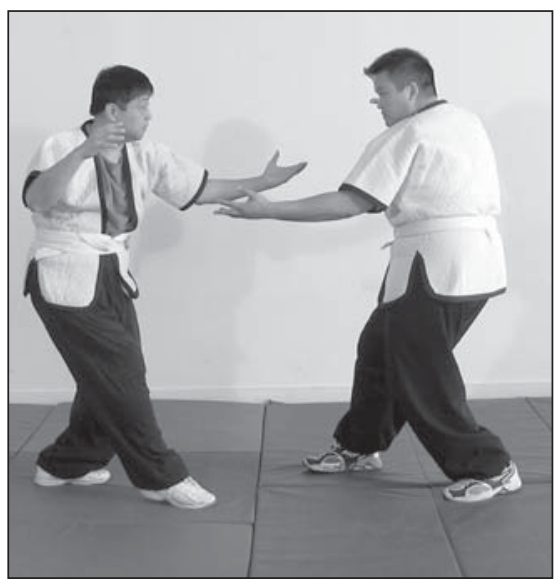

Posiciones opuestas

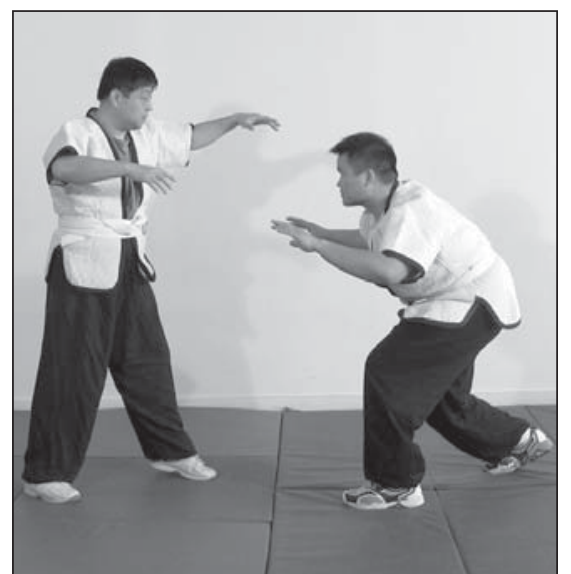

Postura alta (izquierda) y postura baja (derecha) 
pie sobre el otro por delante. Este paso se usa con frecuencia para moverse lateralmente. El paso cubierto ( gai bu) se usa para hacer girar el cuerpo, cruzando por delante un pie sobre otro. Este paso se usa habitualmente para cambiar la dirección. El paso hacia atrás (bei bu) para retroceder con un giro del cuerpo. Este paso se usa frecuentemente para girar el cuerpo hacia atrás y acercar la cadera al oponente. El paso en salto (tiao bu) es saltar con ambos pies al mismo tiempo para girar el cuerpo hacia atrás.

Cuando se da un paso, la posición del pie es siempre importante. Se necesita evaluar constantemente donde se encuentra la mejor y la peor posición del pie. La buena posición pone en problemas al oponente, mientras que una mala posición le dará la oportunidad de hacerse contigo. El momento más peligroso es cuando el pie comienza a tocar el suelo después de moverse, cuando se ha trasladado menos del cincuenta por ciento del peso sobre él, porque el pie todavía no está estable y es difícil moverse o cambiar.

\section{Movimiento del cuerpo}

El juego de piernas tiene que combinarse siempre con un adecuado movimiento del cuerpo. Conceptos importantes sobre el movimiento del cuerpo en el Shuai Jiao son:

Chou - evasión repentina: mover tu cuerpo repentinamente de una posición para que el oponente falle en su objetivo.

Che - distanciarse: escaparse del control del oponente.

Shan - eludir rápidamente: esquivar ajustadamente evitando la fuerza del oponente.

Nian - pegarse: mantener el contacto con tu oponente.

Kong - vaciar: provocar el ataque de tu oponente y hacer que su fuerza se dirija hacia un lugar vacío.

El movimiento del cuerpo es importante porque todas las técnicas de manos y piernas del Shuai Jiao necesitan coordinarse con el cuerpo. La mayor parte de las técnicas de proyección usan las técnicas de manos para controlar o mover al oponente, provocando su perdida del equilibrio, mientras que al mismo tiempo las técnicas de pie o piernas se usan para tirarle. Esto se basa en la estratagema de "inmovilizar arriba y poner la zancadilla abajo". La clave reside en el movimiento del cuerpo, o más precisamente, de la cintura. Se dice que la cintura es el punto central de control.

Para conseguir una buena posición de agarre desde el comienzo, se necesita mantener el cuerpo en buenas posiciones de partida (chu jia o chu shi), como en la Figura 18. Estas posiciones permiten realizar sencillamente tanto ataques como defensas.

Otro movimiento importante es el movimiento de la cabeza llamado "cambio de cara" (bian lian), como en la Figura 19. El cambio de cara se usa para dirigir el cuerpo al volverse hacia atrás o para realizar giros. La mayor parte del tiempo, para colocar una zancadilla bien, se necesita usar el "cambio de cara" para dirigir el giro del cuerpo cuando se finaliza la técnica. Normalmente este es el último punto en soltar tu fuerza y hace que cada parte del cuerpo trabaje de forma conjunta. Por ejemplo, si se usa la zancadilla con gancho hacia atrás, primero necesitarás acercarte y girar tu cuerpo hacia delante y hacia la izquierda de tu oponente, y luego levantar tu pierna derecha hacia atrás para elevar su pierna izquierda. En este momento, dependiendo de cómo este de alta tu pierna, podría ser todavía difícil tirar al oponente porque su cuerpo esta en tu lado derecho y su pierna derecha todavía puede aguantar bien su cuerpo. Por eso aquí el punto clave es cambiar la

\section{Figura 19}

Cambio de cara en la zancadilla con gancho hacia atrás

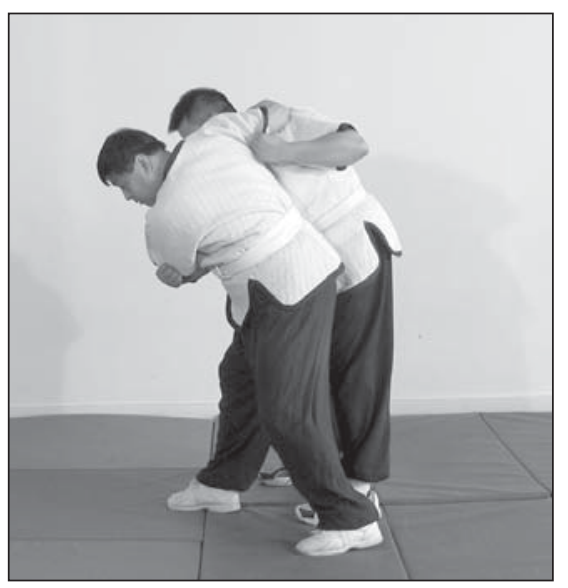

Aproximación y giro del cuerpo

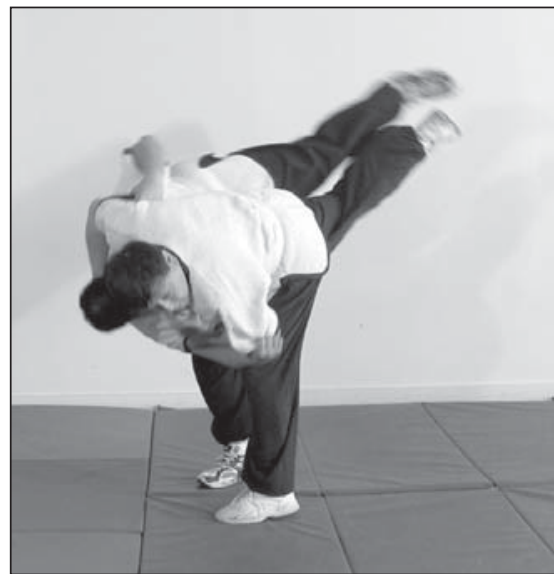

Elevación de la pierna derecha hacia atrás

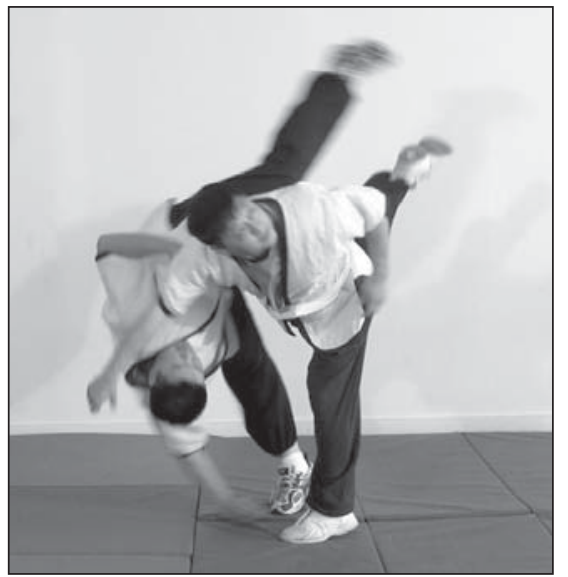

Cambio de cara hacia la izquierda 
cara después de levantar su pierna, girar la cara hacia la izquierda. Este cambio de cara provoca que el cuerpo gire hacia la izquierda y que ambos brazos envuelvan al oponente y le tiren. En este momento, tu cuerpo esta sobre el suyo y la posición de su pierna derecha no puede soportar bien su equilibrio.

\section{El principio de equilibrio y desequilibrio}

El Shuai Jiao tiene muchas técnicas de proyección. El principio básico para desequilibrar es mover el centro de gravedad del cuerpo fuera de alineación respecto a su base de sustentación. Cuando se mueve a una persona y comienza a perder el equilibrio, automáticamente se reajustará para recobrar su equilibrio, normalmente tirando o empujando de sus brazos y/o moviendo sus pies. La mayoría de las técnicas de Shuai Jiao requieren usar las manos para mover al oponente hacia un lado, lo que significa mover su centro de gravedad. Entonces, generalmente, se usa el pie para poner la zancadilla en el otro lado para bloquear su reajuste. Esto genera fuerzas opuestas entre las partes alta y baja del cuerpo, causando que el cuerpo se gire y caiga. Algunas técnicas pueden realizarse muy rápida y repentinamente, sin una zancadilla con el pie de modo que el oponente no tenga tiempo para reequilibrarse. La Figura 20 muestra estos principios básicos.

Aunque este principio es sencillo, las habilidades son complejas en detalle. Obviamente, en un combate real pueden suceder muchas variantes de situaciones. Así siempre se tiene que saber como adaptarte dinámicamente para solucionar el problema y desarrollar la técnica. La mayor parte del tiempo cuando tratas de proyectar al oponente, tu centro de gravedad también se está moviendo, incluso fuera de su punto de apoyo. Esta es la razón por la que es común ver a la gente cayéndose inmediatamente después de lanzar a su oponente. Por eso la situación ideal es aquella donde, con tu acción tiras a tu oponente, y luego usas las fuerzas de reacción generadas para restablecer tu propio equilibrio.

\section{Zancadillas}

En el Shuai Jiao, hay varios tipos diferentes de técnicas para zancadillear. A veces la gente las clasifica bajo las siguientes clasificaciones: zancadillas de pequeño movimiento (xiao ban zi), zancadillas de gran movimiento (da ban zi), zancadillas cara a cara (dui lian ban zi), zancadillas con giro de la cintura atrás (diao yao ban zi), etc. Pero la distinción no es del todo clara y algunas técnicas pueden pertenecer a diferentes categorías.

Las técnicas de pequeño movimiento son rápidas y repentinas. Normalmente necesitas obligar al oponente a cometer un fallo y entonces se aprovecha la oportunidad rápidamente. Los movimientos tienen que ser muy ágiles y precisos.

Las técnicas de gran movimiento son las técnicas de fuerza. Sólo cuando se está muy seguro de que se puede controlar al oponente es cuando se pueden utilizar este tipo de técnicas. Puesto que el movimiento es grande, si falta algo darás al oponente más de una oportunidad para defenderse contra él. Para lograr un buen control normalmente se necesita tener buenas técnicas de agarre y buen juego de piernas para dominar el movimiento del oponente.

Las técnicas cara a cara significan que tú y tu oponente estáis cara a cara cuando se le zancadillea. La mayoría de los movimientos pequeños son de este tipo.

Las técnicas de giro de la cintura atrás significan que necesitas girar tu espalda hacia tu oponente y colocar tu cadera o glúteos cerca de la cadera o estómago del oponente cuando se prepara un lanzamiento. Estas proyecciones son técnicas de gran movimiento.

Aunque la mayoría de las técnicas de poner la zancadilla se hacen con la pierna o pie, hay muchas zancadillas especializadas. Por ejemplo, algunas veces el oponente ejerce fuerza muy rígidamente, pudiendo entonces utilizar únicamente las técnicas de manos y un buen juego de piernas para lanzarle sin colocar una zancadilla de pierna. 


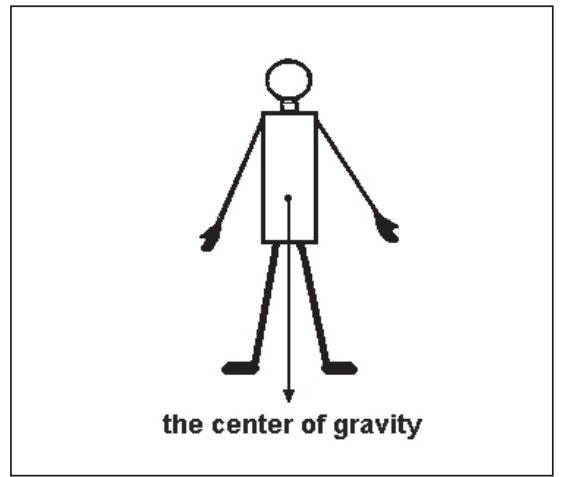

a. Equilibrio estable - el centro de gravedad esta entre los pies.

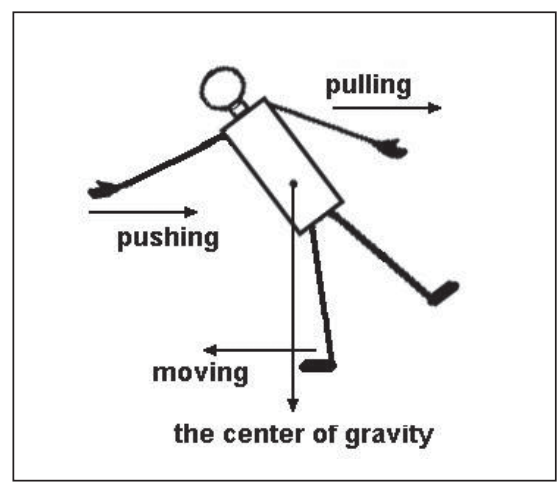

d. Ajuste del equilibrio acercando la mano izquierda, alejando la mano derecha, o moviendo el pie izquierdo hacia la izquierda.

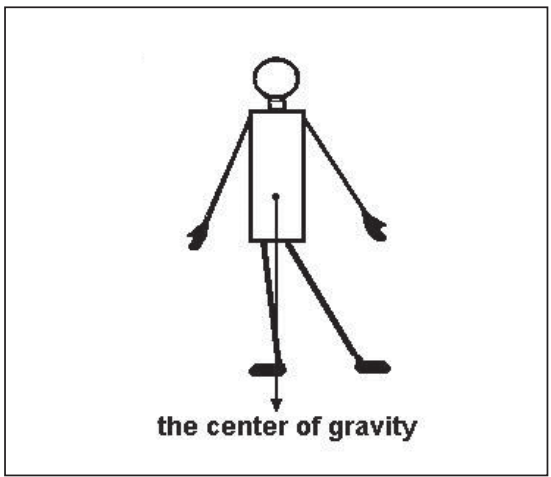

b. Equilibrio inestable - el centro de gravedad esta en un pie.

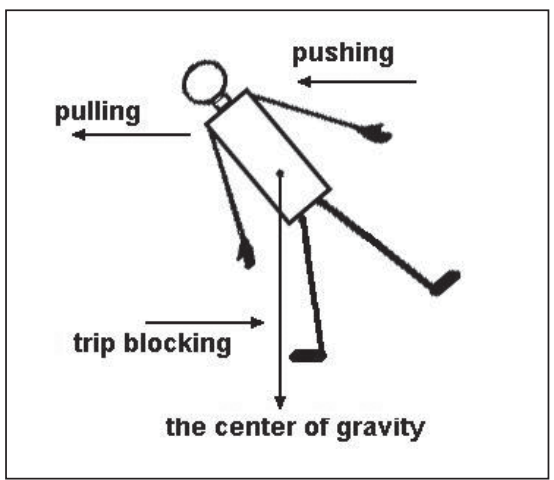

e. Primer principio de lanzamiento - empujando y/o tirando de la parte superior del cuerpo hacia la izquierda y colocando una zancadilla con la mano, pie, pierna o cadera para bloquear la reequilibración de la parte inferior del cuerpo hacia la izquierda.

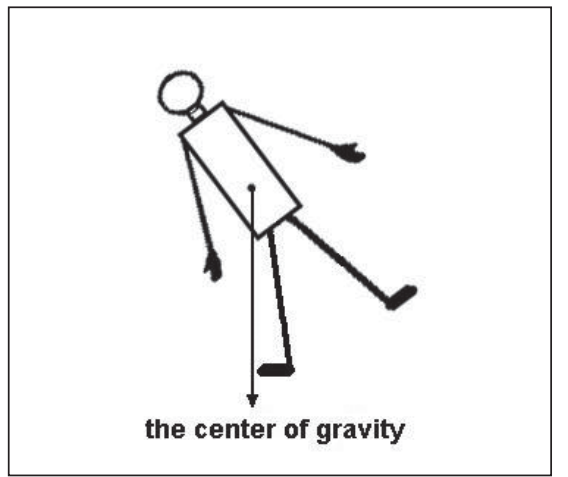

c. Desequilibrio - el centro de gravedad esta fuera de alineación con los pies.

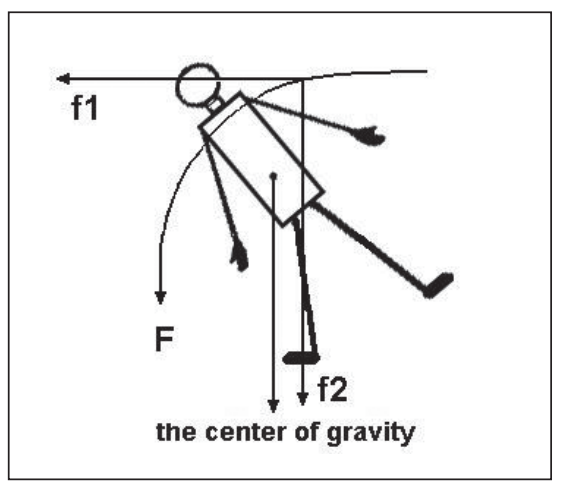

f. Segundo principio de lanzamiento una fuerza con una curva $F$ a través del cuerpo tiene dos partes. F1 es la fuerza horizontal hacia la izquierda que mueve la parte superior del cuerpo hacia la izquierda, y F2 es la fuerza vertical que presiona el cuerpo hacia abajo para dificultar el ajuste del pie.

\section{Algunos de los principios incluidos para preparar una buena proyección son:}

1. Confunde al oponente e induce una reacción "incorrecta".

2. Comprende el cambio entre yin y yang.

3. Usa direcciones de fuerza contrarias.

4. Haz que tu oponente se mueva alrededor tuyo.

5. Logra un buen agarre.

6. Consigue que tu oponente se mueva contigo.

7. Entiende cómo utilizar la fuerza de tu oponente.

Los ojos tienen que estar muy atentos para detectar cualquier error que cometa el oponente. Tu sensibilidad tiene que ser muy buena para que puedas sentir los cambios en la fuerza y en la dirección. Tus movimientos tienen que ser muy rápidos, ágiles, precisos y coordinados. 
Tu fuerza tiene que ser repentina, poderosa e integrada. Tu juego de piernas tiene que ser ligero y estable.

Algunas técnicas tienen más de cien variantes. Cuando prácticas las técnicas de zancadillear, primero deberías aprender la forma básica cuidadosamente, ya que es la experiencia resumida de todas las generaciones anteriores. En otras palabras, la forma básica ha sido probada por muchas personas en combates reales. Después se continúa aprendiendo las variaciones para lograr un aprendizaje más profundo.

No es cierto que cada técnica vaya a ajustarse a ti perfectamente. Puede que necesites combinar tu propia personalidad o condición física para desarrollar tus propias variantes. A lo largo de la historia maestros famosos desarrollaron sus propias variaciones. En la mayoría de las ocasiones cuando decimos que alguien puede realizar una zancadilla muy bien, queremos decir que puede usar la misma forma básica, empleando sus muchas variaciones en función de lo que exija la situación. No importan los cambios que introduzca el oponente, no puede escapar de esta técnica básica.

Por otra parte, para cada forma de zancadilla existe al menos una forma de defensa. Así cuando se aprende una técnica para zancadillear también se necesita aprender su defensa. También se han desarrollado muchas variaciones para las técnicas defensivas. Por lo tanto, no hay ninguna técnica que garantice la victoria, sólo importa lo bien que se ejecute.

\section{Algunas técnicas comunes}

Nadie sabe cuantas técnicas de zancadilla existen exactamente en el Shuai Jiao, ya que muchos grupos han desarrollado diferentes técnicas y variantes a lo largo del tiempo. Pero hay algunas técnicas que son practicadas comúnmente por todos los grupos. Entender esto puede ayudar a comprender los principios básicos del Shuai Jiao y sus técnicas específicas. En este punto se presentarán algunas de las técnicas típicas del Shuai Jiao:

\section{Patada salpicante (Po Jiao)}

Po significa "salpicar rápidamente todo el agua de un contenedor". Jiao significa "pie" o "patada". Toma nota por favor de que en el Shuai Jiao no puedes dar una patada a la pierna de tu oponente o a cualquier parte de su cuerpo de un modo fuerte o directo. Por lo que aquí una patada significa colocar el pie o pierna contra el oponente para evitar que su pierna o alguna parte de su cuerpo se muevan. De esta manera Po Jiao quiere decir combinar técnicas de mano a modo de salpicar agua con una patada por abajo.

Po Jiao es generalmente una técnica de cara a cara y de pequeño movimiento. Por ejemplo, ya has cogido la manga derecha de tu oponente con tu mano izquierda y su cuello con tu mano derecha. Entonces ejecutas los cuatro movimientos de Po Jiao:

1. Tira de tu mano izquierda mientras presionas con tu mano derecha hacia tu izquierda y hacia abajo, moviéndole hacia su derecha. Al mismo tiempo, dando un paso adelante y a la izquierda con tu pie izquierdo, coloca el pie delante de su pie derecho, como si dieses una patada a su pierna derecha (Figura 21-a).

2. De repente cambia tu fuerza hacia la dirección contraria: tirando de tu mano derecha hacia tu lado derecho y abajo para hacer que su cabeza se incline a su lado izquierdo, y con tu mano izquierda empuja hacia arriba para ayudar a que tu mano derecha mueva su cuerpo. Al mismo tiempo, gira tu cuerpo a la derecha, provocando que su cuerpo se mueva a la izquierda alrededor del tuyo (Figura 21-b). 


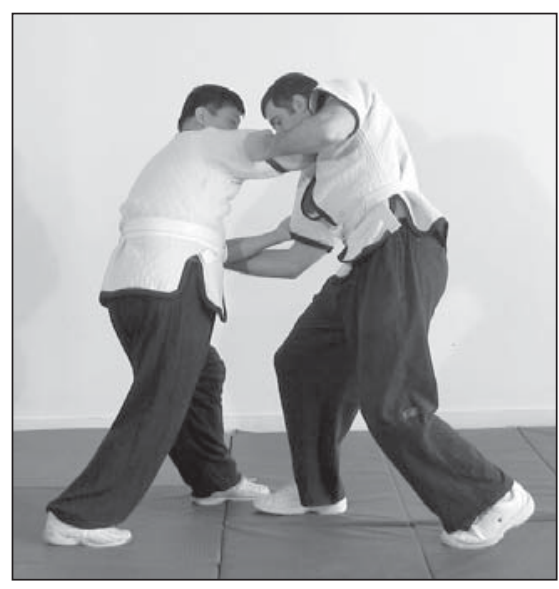

a.

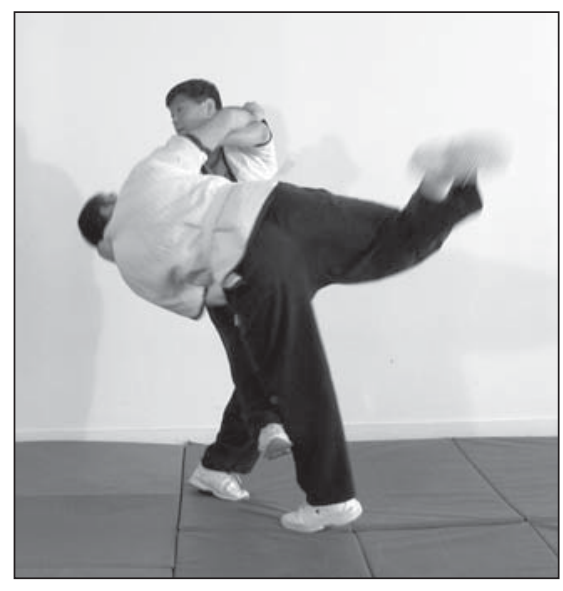

d.

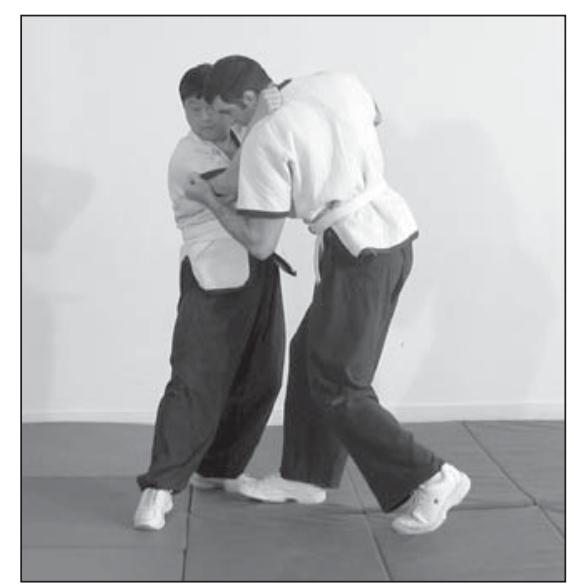

b.

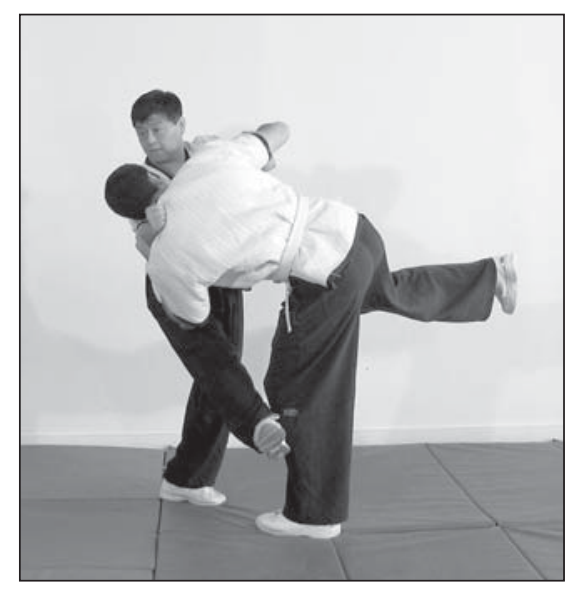

c.

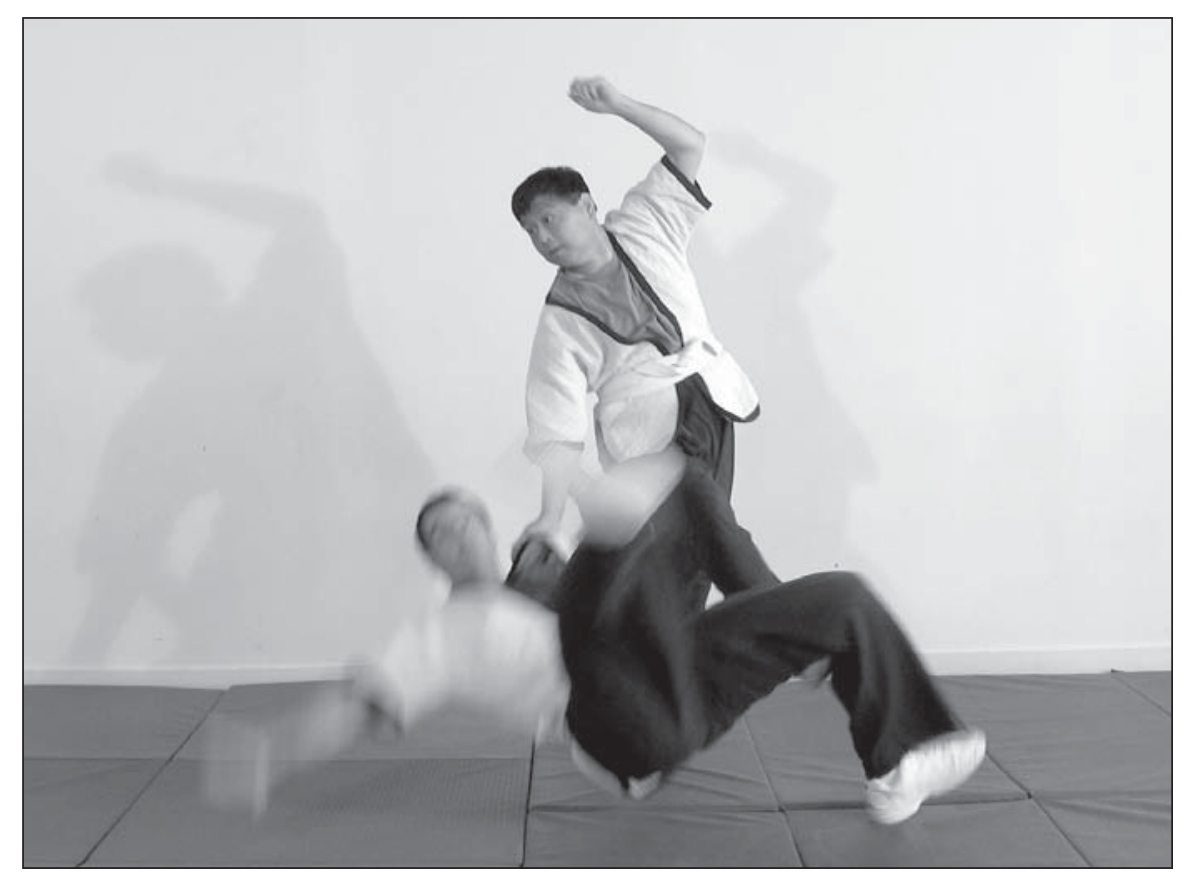

e.

3. De manera continuada tira de tus manos y gira tu cuerpo, luego cambia el peso hacia la pierna izquierda y lanza tu pierna derecha hacia fuera, poniéndola en el lado izquierdo de su espinilla izquierda (Figura 21-c).

4. De forma continuada tira de tus manos hacia tu derecha y bájalas ligeramente. Al mismo tiempo cambia la cara hacia la derecha y atrás. Esto provoca que tu cuerpo se gire hacia atrás y tire de tu oponente a tu alrededor. Ya que tu pie derecho esta bloqueando su pierna izquierda hacia la izquierda, y tus manos están tirando de él hacia su izquierda, este par de fuerzas hacen que su cuerpo se gire y pierda el equilibrio, provocando que caiga hacia su izquierda (Figura 21-d, e).

Si puedes hacer todos estos movimientos de forma rápida, continua y suave, puedes realizar una hermosa proyección. 


\section{Gran gancho exterior (Da Dehele)}

Figura 22

Gran gancho exterior

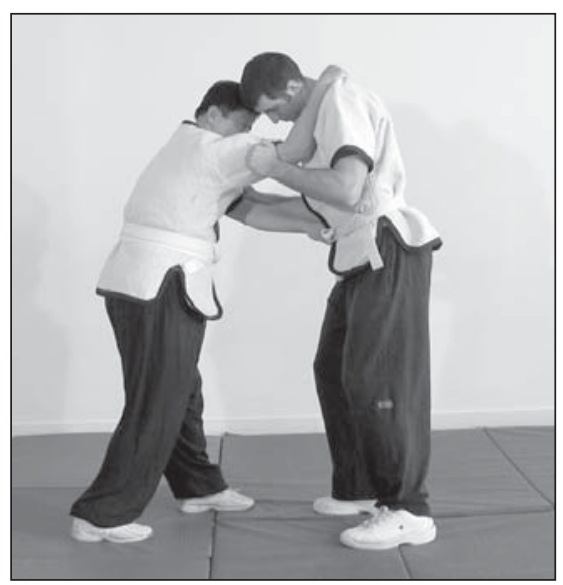

a.

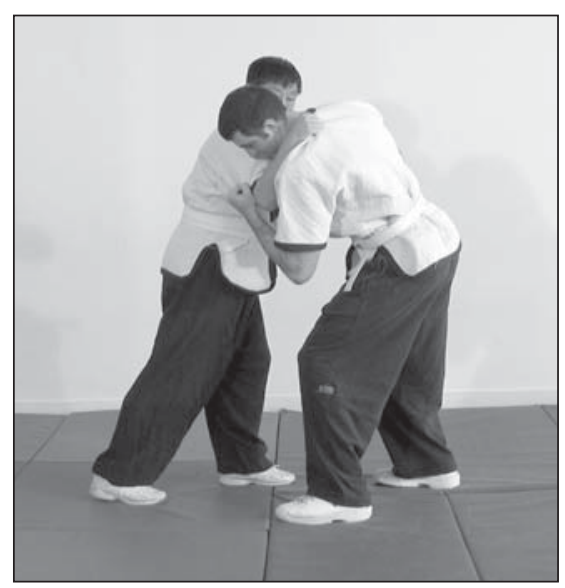

b.

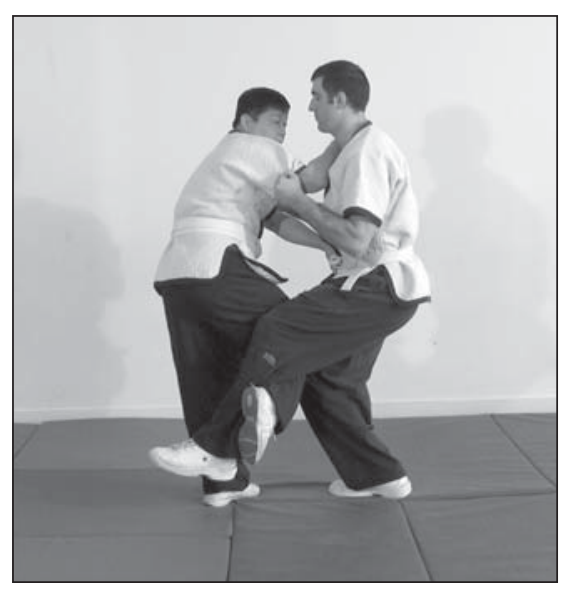

d.
Da significa grande, y Dehele es una palabra de origen mongol que significa "gancho exterior". Con esta técnica, doblas tu pierna y tu pie a modo de gancho hacia el exterior. Existe otra técnica llamada Xiao (pequeño) Dehele. Ambas técnicas tienen los mismos principios, pero los movimientos de Da Dehele son más grandes potentes. Da Dehele es una técnica de cara a cara típica y normalmente pertenece a la categoría de técnicas de gran movimiento. Por ejemplo, has agarrado el centro del cinturón de tu oponente con tu mano izquierda y el cuello de su traje con tu mano derecha. Entonces puedes realizar los tres movimientos de Da Dehele:

1. Con ambas manos, tira ligeramente de tu oponente hacia tu derecha y luego hacia ti. Debes acercarle mucho hasta que el centro de su cinturón este exactamente delante de tu ombligo (Figura 22-a, b).

2. Suelta tu mano derecha del cuello de su traje y colócala sobre la parte alta de su pecho o incluso en su cuello, al mismo tiempo estira tu pierna derecha entre sus piernas y tira hacia atrás inmediatamente. Esto permitirá a tu pierna derecha enganchar su pierna izquierda por detrás (Figura 22-c, d).

3. Tira fuerte de tu mano izquierda para mantener su cuerpo cerca del tuyo, entonces empuja con tu antebrazo derecho hacia delante para hacer que su cuerpo se incline hacia atrás, y mueve tu pierna derecha atrás para enganchar su pierna izquierda hacia arriba y adelante (Figura 22-e, f).

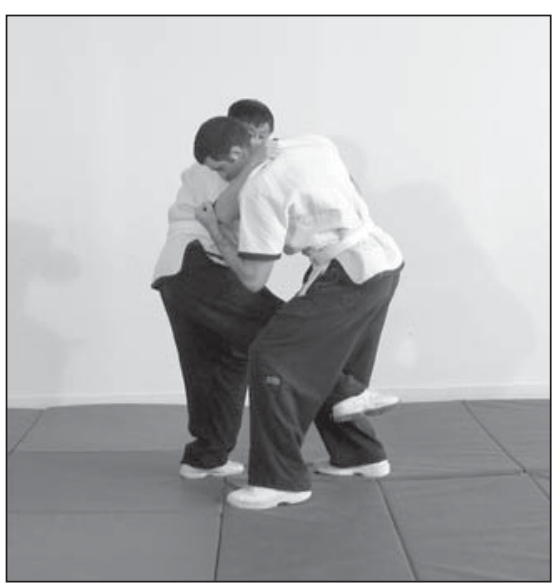

La combinación de estas tres fuerzas provocará que su cuerpo caiga hacia atrás. Puesto que tu mano izquierda puede soltar su agarre en el centro del cinturón de forma natural en el último momento, esto provocará que la parte posterior de su cabeza golpee el suelo en primer lugar cuando su cuerpo caiga hacia atrás, así que esta técnica es muy peligrosa. Si puedes realizarla fuerte y rápidamente, puede lesionar a la gente gravemente. Desde la década de los 60 ha sido ilegal usar esta técnica en las competiciones nacionales.

c.

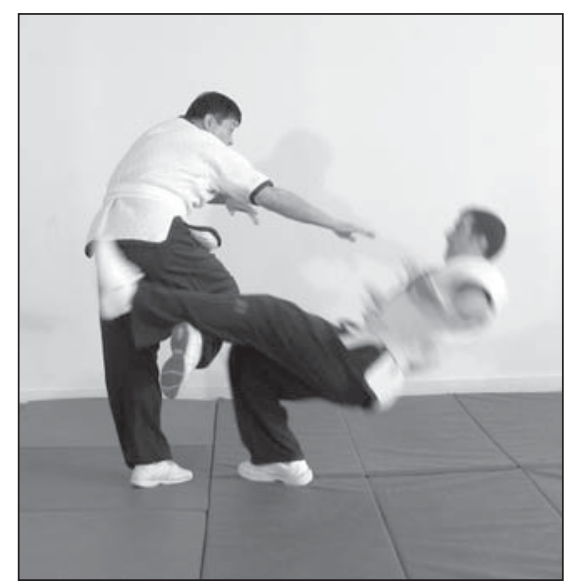

e.

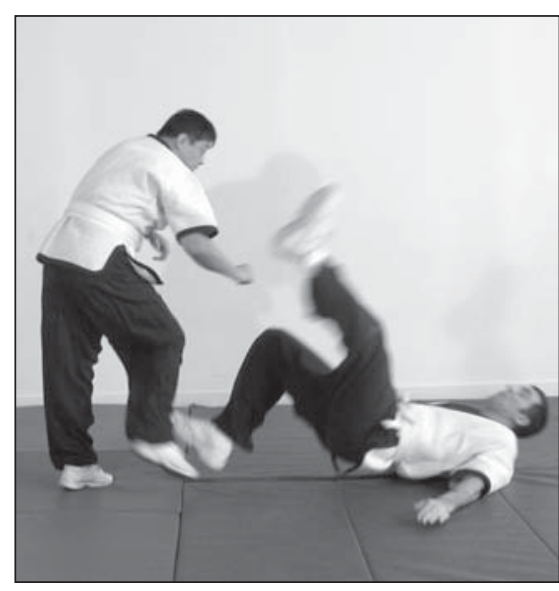

f. 
Así que si la practicas, por favor asegúrate de no soltar tu mano izquierda y así proteger a tu compañero.

\section{Gran giro del cuerpo (Da Bie Zi)}

"Bie" significa "usar algo para mantener o sujetar el otro lado". En el Shuai Jiao, Bie o Bie Zi significa girar el cuerpo atrás y usar la parte posterior de tu pierna para bloquear la pierna de tu oponente mientras tiras de él hacia el otro lado. Hay muchas técnicas de Bie. Aquí vamos a analizar la más famosa - Da Bie Zi, o Gran Giro del Cuerpo.

Da Bie Zi es una técnica de gran movimiento y también es una técnica típica de giro de la cintura. Requiere girar el cuerpo y usar un juego de piernas muy hábil. Por ejemplo, suponiendo que ya has cogido la manga derecha de tu oponente con tu mano izquierda y agarrado el cuello de su traje con tu mano derecha, entonces realizas los siguientes cuatro movimientos:

1. Tira de su cuerpo hacia tu lado derecho ligeramente y después empuja hacia tu izquierda aprovechando su reacción en ese sentido (Figura 23-a). Siguiendo este empujón, gira tu cuerpo hacia la izquierda y da un paso hacia adelante colocando tu pie derecho delante de su pie derecho (Figura 23-b).

2. Gira tu cuerpo de forma continuada, dando un paso atrás con tu pie izquierdo hasta que se coloque en frente de su pie izquierdo (Figura 23-c).

3. Levanta tu pierna derecha delante de su pierna derecha al nivel de la rodilla (Figura 23-d).

4. Haz un cambio de cara hacia la izquierda y arriba. Esto provocará que tu mano izquierda tire de su cuerpo hacia delante y a los lados y que tu mano derecha envuelva su brazo bajo tu brazo derecho. Al mismo tiempo tu pierna derecha se mueve a modo de látigo hacia atrás, buscando su pierna derecha (Figura 23-e).

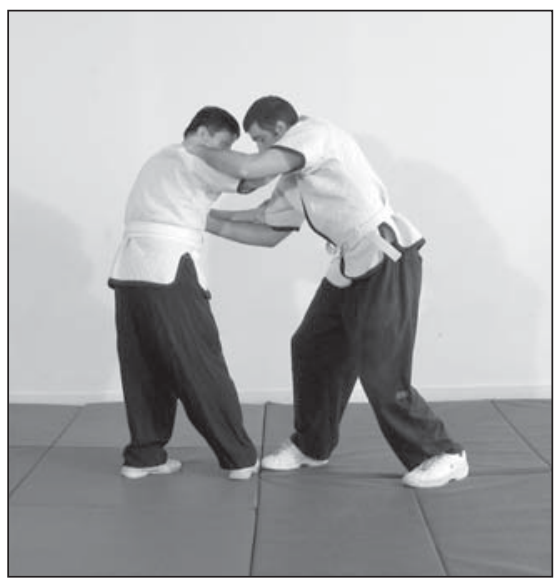

b.

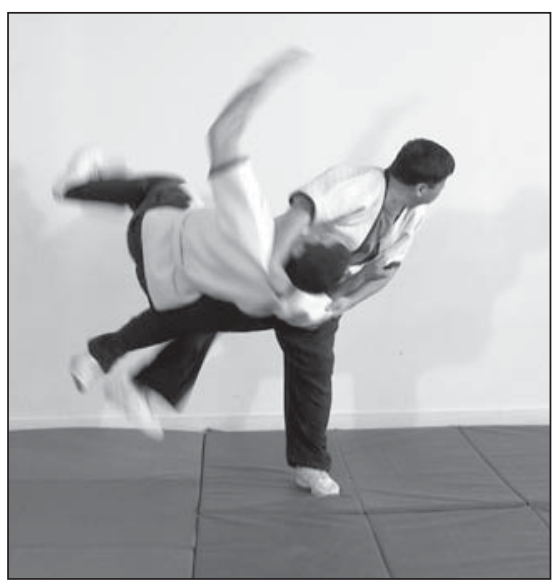

e.

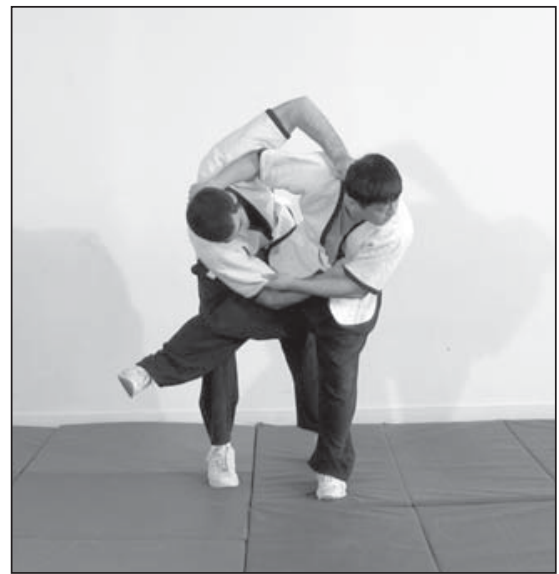

d.

\section{Figura 23 \\ Gran giro del cuerpo}

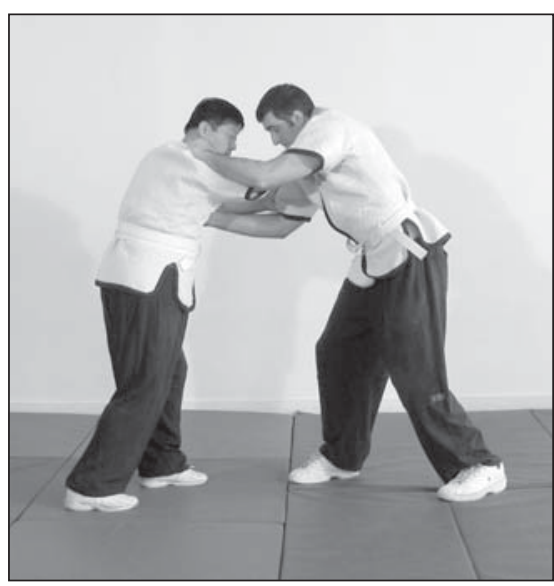

a.

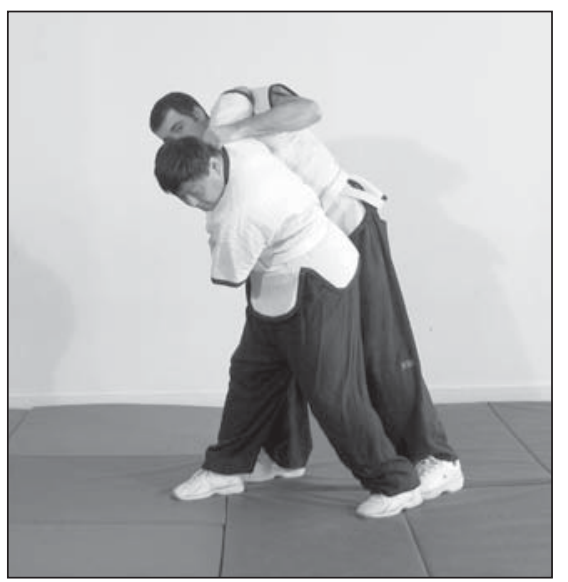

c. 


\section{Figura 24 \\ Introducir y esquivar}

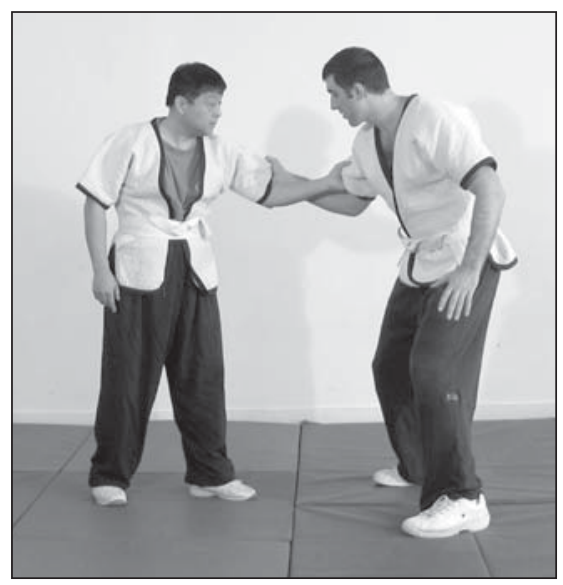

a.

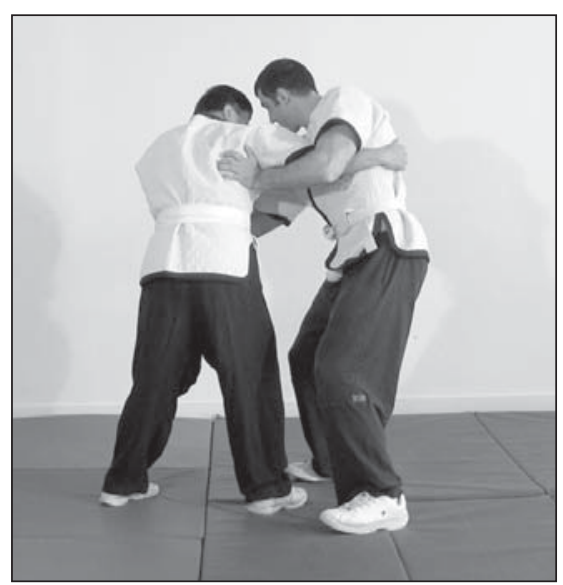

b.

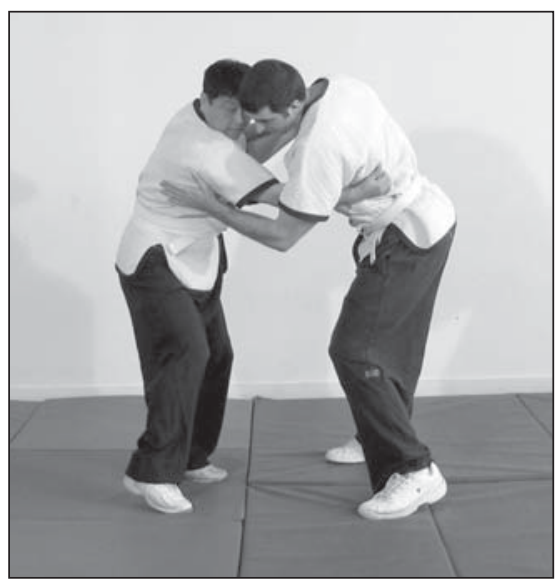

c.

Con tu pierna bloqueando la suya, esta combinación de fuerzas provocará que su cuerpo se retuerza alrededor de tu cuerpo, pierda el equilibrio y caiga hacia delante. Mediante esta técnica, realizada correctamente, puedes proyectar a tu oponente con limpieza. A veces si hay partes de tu técnica que no están lo suficientemente bien hechas o son un poco lentas, puedes caer a continuación de tu oponente, golpeando su cuerpo. Esto le provocará normalmente una lesión, así que se cuidadoso.

\section{Introducir y esquivar (Cha Shan)}

Cha significa "introducir" y Shan significa "esquivar". Cha Shan es una técnica de cara a cara, y también un tipo de zancadilla de mano típica. Esta técnica requiere del juego de piernas, pero sin una zancadilla de pierna. Cha Shan incluye dos movimientos, introducir y esquivar. Por ejemplo, asumiendo que ya has cogido la manga derecha de tu oponente con tu mano izquierda, con tu mano derecha sin agarre, entonces:

1. Tira de tu mano izquierda hacia tu lado derecho girando ligeramente tu cuerpo a la derecha (Figura 24-a).

2. De repente cambia ligeramente la fuerza de tu mano izquierda hacia la izquierda y abajo, dando un paso adelante con tu pie derecho, girando un poco tu cuerpo hacia la izquierda, e introduciendo tu mano y brazo derechos sobre la espalda de tu oponente bajo su brazo izquierdo. Puede parecer que quieres girar tu cuerpo alrededor para realizar alguna técnica de giro de cintura atrás (Figura 24-b). Por supuesto, si sientes que tu oponente no ofrece una resistencia adecuada, se puede utilizar alguna técnica de giro de cintura atrás, para proyectarle. Pero si notas que se resiste con fuerza a tu movimiento de entrada, con la intención de empujar con fuerza tu lado derecho para bloquear el giro y la entrada de tu cuerpo, entonces deberías:

3. Usar rápidamente tu mano derecha para coger la espalda de su traje (Figura 24-c), tirar hacia ti, al mismo tiempo que das un paso atrás con tu pie derecho y giras tu cuerpo hacia la derecha al menos más de 125 grados, como si fuese una esquiva rápida (Figura 24-d, e).

Tu rotación del cuerpo y tirón de mano deben ser rápidos, repentinos, potentes y coordinados. El paso hacia atrás debe ser rápido, como si esquivase hacia un lado para evitar ser golpeado por un coche que circula rápido. La clave de esta técnica esta en hacer que tu oponente se resista con fuerza cuando introduces tu

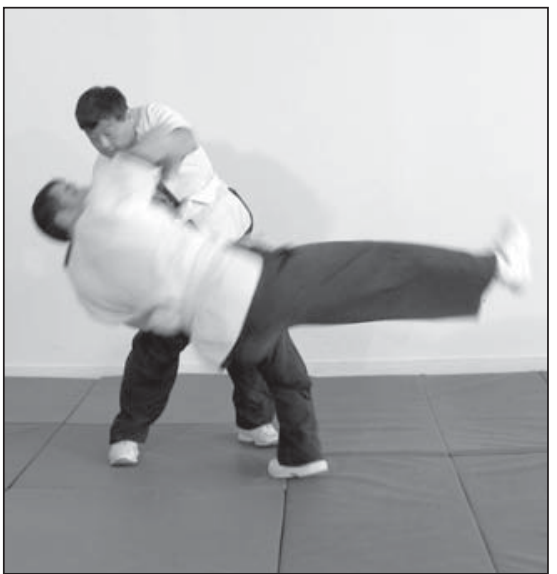

d.

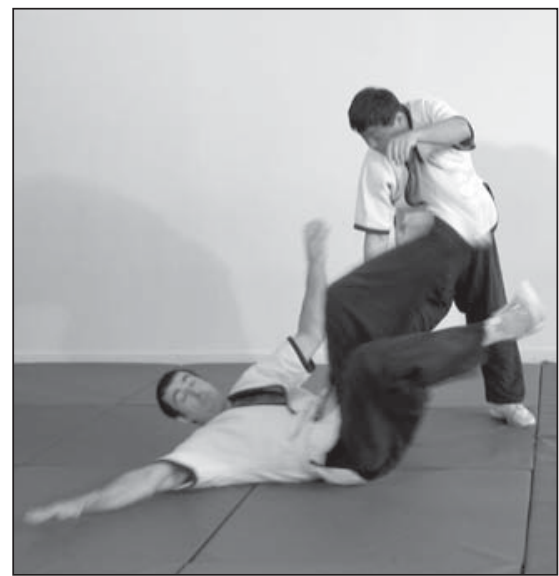

e. 
brazo, y luego apropiarse de su fuerza de reacción para tirarle hacia ti realizando la esquiva.

Aunque hay cientos de diferentes técnicas fundamentales y variantes en el Shuai Jiao, la mayoría de las personas sólo usan unas pocas técnicas muy bien. Debes practicar tantas como puedas. Esto no significa exactamente que puedas llegar a usarlas, pero sí sabrás como defenderte de ellas. Sólo cuando puedas entender una técnica, tendrás la oportunidad de defenderte contra ella.

En el Shuai Jiao las habilidades defensivas son sencillamente tan importantes como las habilidades ofensivas. Siempre que se desarrolló una habilidad ofensiva, se creó una habilidad defensiva como respuesta. Por eso se dice que no hay técnica que no pueda ser neutralizada. De esta manera el desarrollo de las habilidades defensivas promueve un ulterior desarrollo de habilidades ofensivas.

Normalmente la gente escoge las habilidades ofensivas que encajan con su tipología y luego las practican intensamente hasta que pueden usarlas muy bien. Para estas técnicas, también se investigan los posibles cambios y variantes.

La combinación de técnicas es también muy importante. Hay muchas técnicas de combinación en el Shuai Jiao. Algunas técnicas son estrictamente de ataque -usas una técnica ofensiva después de otra, continuamente, hasta que proyectas a tu oponente-. Otras contienen técnicas defensivas y ofensivas de manera que se transita sin solución de continuidad de la defensa al ataque.

\section{Métodos de entrenamiento}

El entrenamiento básico de gongfu es muy sustancioso en el Shuai Jiao. Hoy día muchas escuelas de artes marciales cogen prestados los métodos de entrenamiento del Shuai Jiao. Hay muchos métodos para desarrollar la fuerza, el equilibrio, la flexibilidad, la agilidad, la coordinación, y la integración. También, la naturaleza altamente antagónica del Shuai Jiao entrena las habilidades de combate de una manera muy realista y efectiva de un modo que las artes marciales que se practican en solitario no pueden realizar.

Existen dos partes en el entrenamiento básico de Shuai Jiao. La primera es el acondicionamiento general (jiben gong). El acondicionamiento general es la base del gongfu de acondicionamiento físico, desarrolla la fuerza y flexibilidad del practicante. La segunda parte es específica del deporte, llamada Banzi Gong -la base de las técnicas de zancadillear-. El Banzi Gong entrena la habilidad para realizar zancadillas de manera coordinada. En cada parte del entrenamiento, se utilizan prácticas con y sin implementos.

En el entrenamiento básico, la característica más importante es que el movimiento siempre enfatiza la integración de todo el cuerpo. Cada parte del cuerpo debe moverse conjuntamente de manera coordinada. Por ejemplo, levantar las piedras dobles parece un ejercicio de fuerza de brazos, y sin embargo en este ejercicio se ha de aprender a levantar la piedra con la fuerza de todo el cuerpo, de manera que pies, piernas, cintura, espalda y hombros trabajan conjuntamente con los brazos. Puesto que una parte del entrenamiento básico es el mismo o es similar al entrenamiento de todas las artes marciales chinas tradicionales, en este punto presentaremos sólo algunas habilidades que son únicas del Shuai Jiao. Las seis primeras habilidades son la base del acondicionamiento físico y las últimas tres son la base de las técnicas de zancadillear. Estas habilidades deberían ser practicadas por ambos lados. Aquí sólo describimos por un lado. 


\section{Métodos de práctica sin implementos}

Figura 25

Posición de rotación de pies

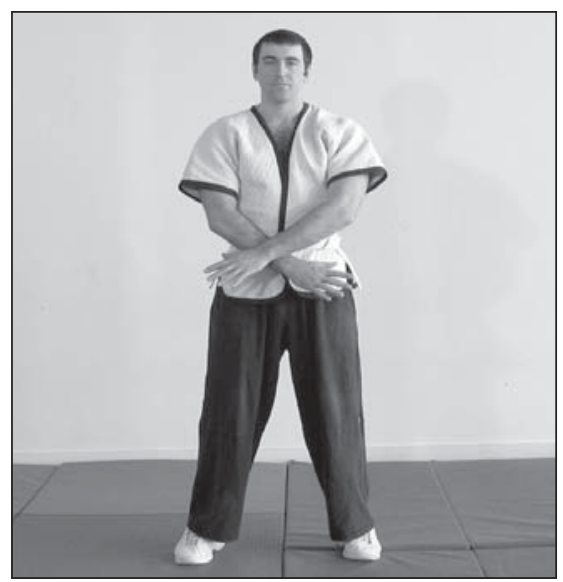

a.

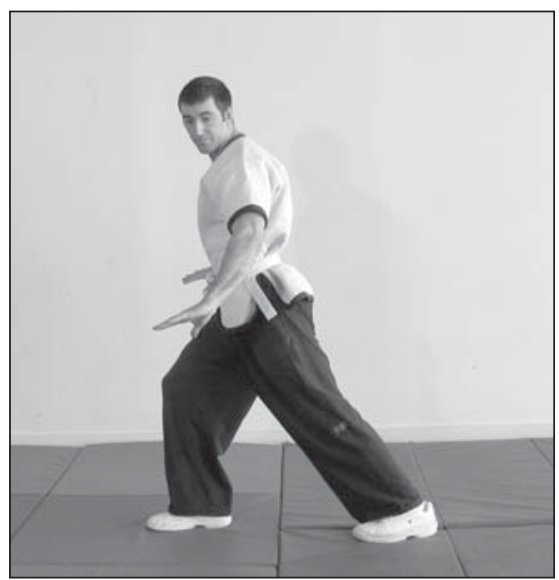

b.

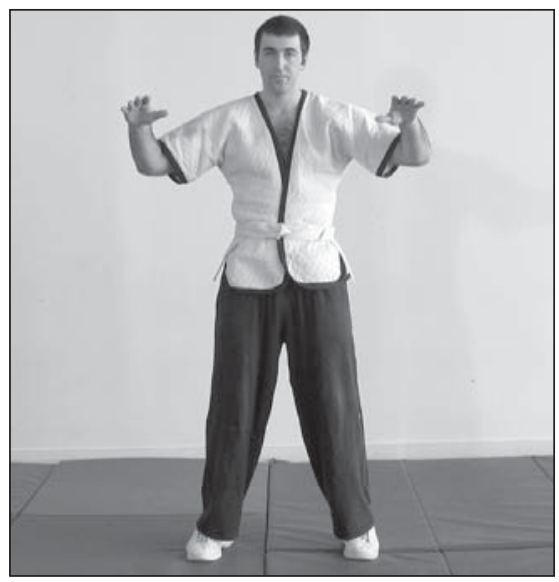

e.

Wai Zhuang - posición de rotación de pies: hay dos ejercicios: Da (Grande) Wai Zhuang y Xiao (Pequeño) Wai Zhuang. Da Wai Zhuang usa ambos pies. Toda la planta de los pies debe estar en contacto con el suelo y el cuerpo gira casi 90 grados. Este ejercicio es bueno para desarrollar la coordinación de la cintura y las piernas. En el Xiao Wai Zhuang, sólo la base de los dedos toca el suelo y el cuerpo gira sólo levemente. El Xiao Wai Zhuang es bueno para desarrollar la coordinación de las caderas y los tobillos. Véase la Figura 25.

Xiao Zhuanzi - pequeño taladro: giro del cuerpo hacia atrás agachándose: gira el cuerpo y agáchate como para taladrar el suelo. El Xiao Zhuanzi es bueno para desarrollar la fuerza y la flexibilidad en las piernas y las caderas. Véase la Figura 26.

Huo Yao - estirando la cadera: gira la cadera hacia la izquierda y hacia la derecha acompañando con el brazo derecho, estirando el pie y pierna derecho hacia la derecha. El Huo Yao es bueno para desarrollar la coordinación de la cintura con los brazos y las piernas, y también para estirar la cintura, brazos, y piernas. La Figura 27 muestra esta técnica.

Ti Tui - patada frontal alta: lanza la pierna derecha hasta aproximadamente un ángulo de 45 grados a la izquierda. La pierna de apoyo está ligeramente flexionada. Este ejercicio incrementará la flexibilidad y fuerza para dar patadas. La Figura 28 muestra esta técnica.

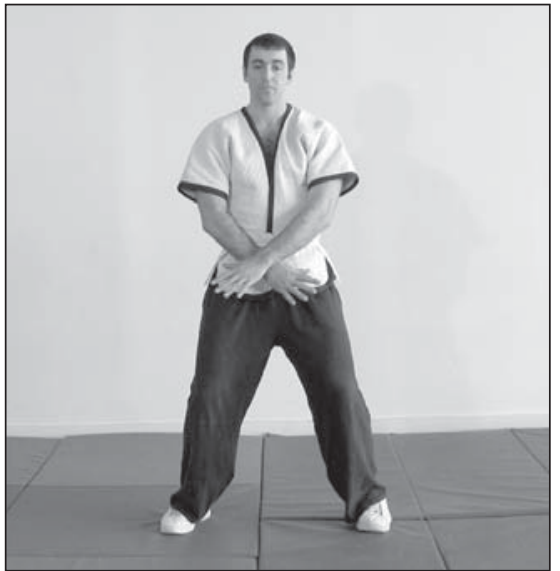

c.

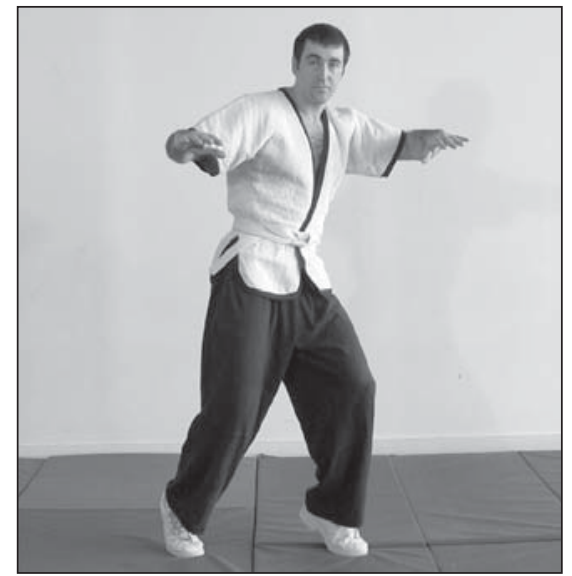

f.

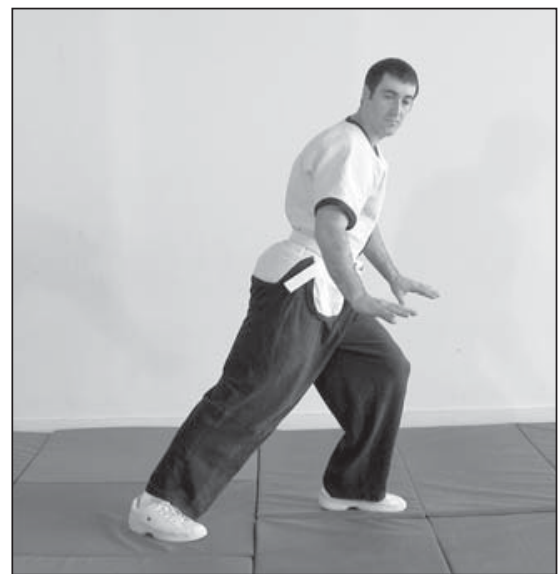

d.

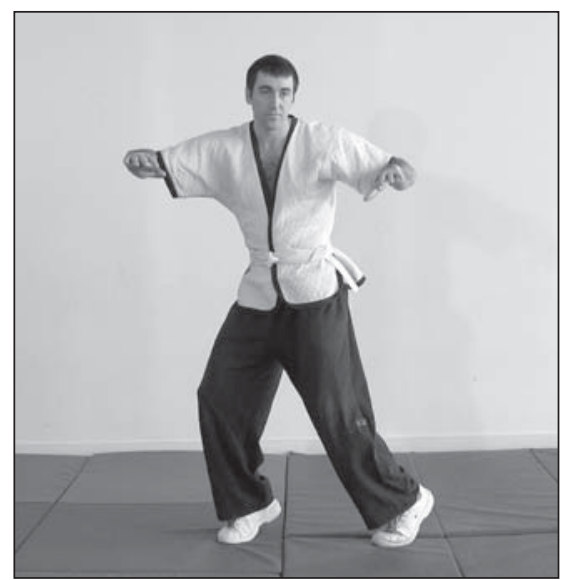

g. 
Figura 26

Taladro pequeño

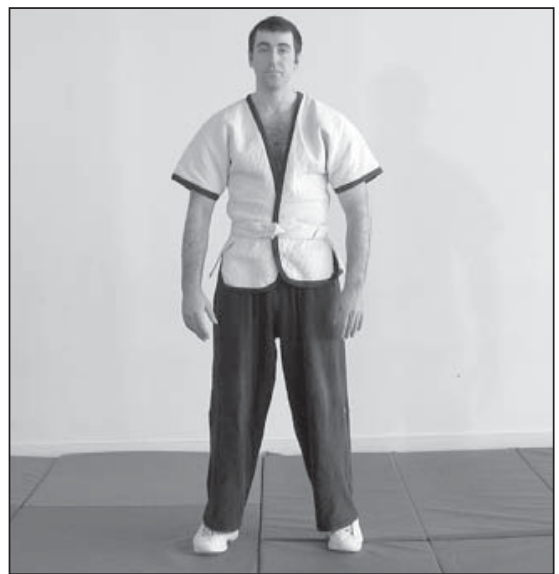

a.

Figura 27

Estirando la cintura

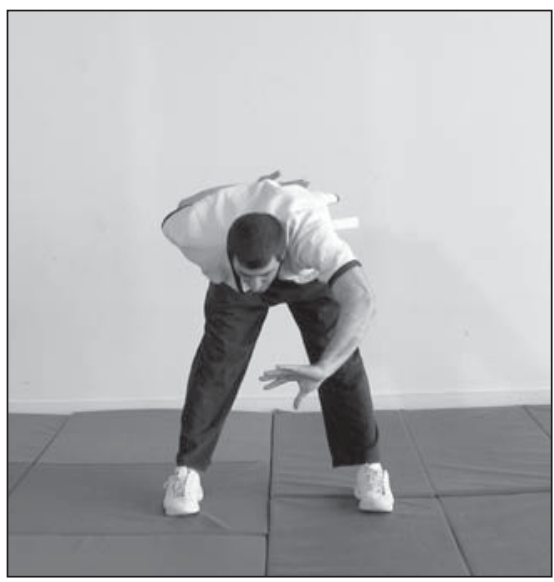

a.

Figura 28

Patada frontal alta

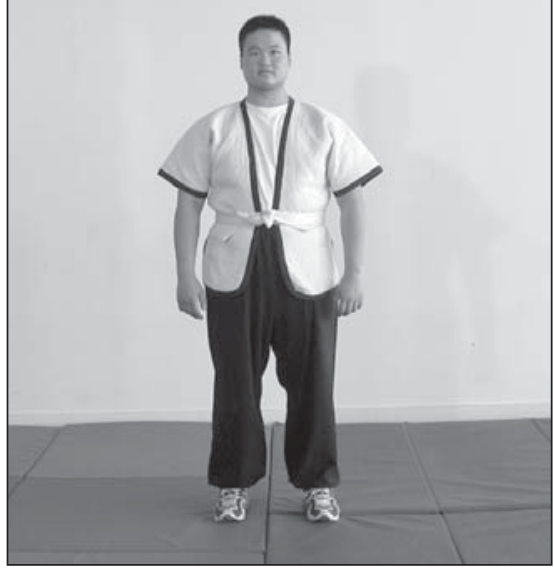

a.

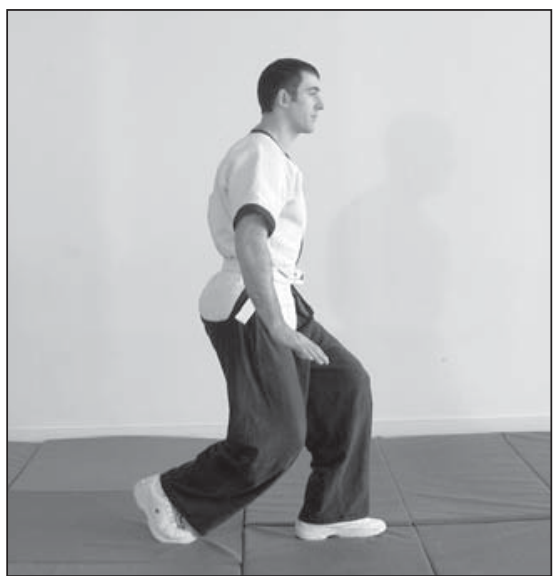

b.

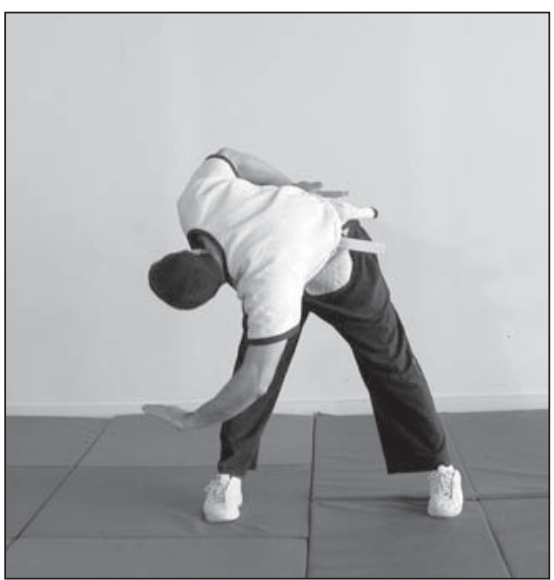

b.

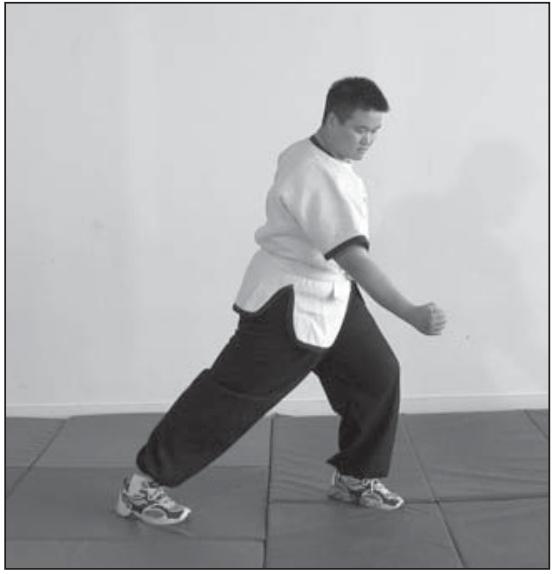

b.

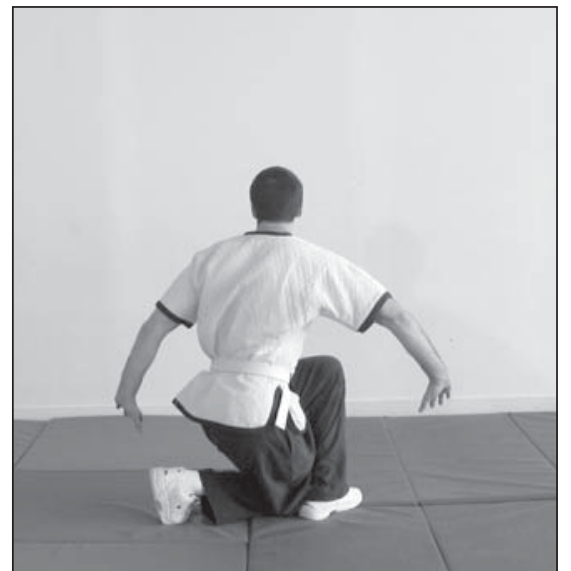

c.

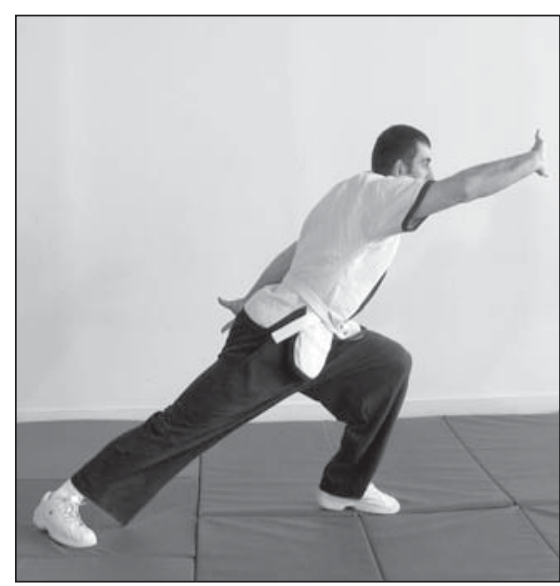

c.

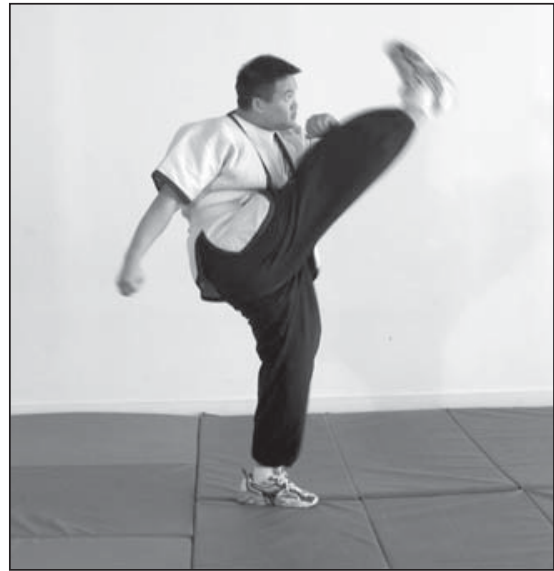

c. 
Figura 29

Sacando la pierna

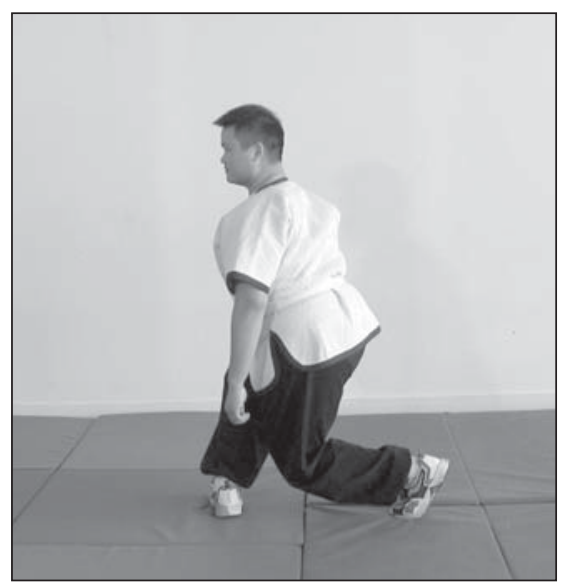

a.

\section{Figura 30}

Enroscando la pierna

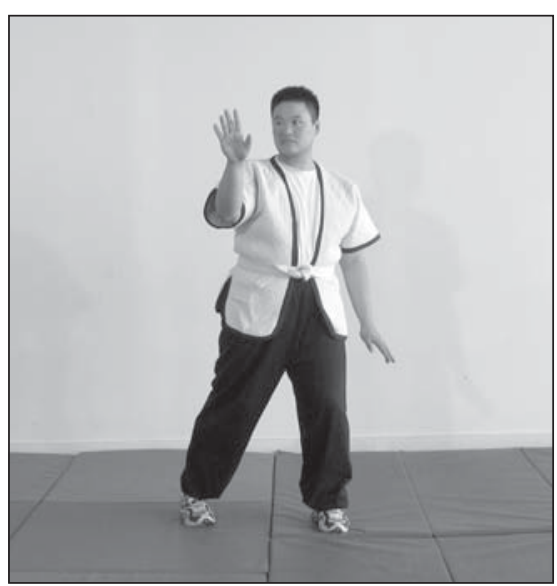

a.

Figura 31

Patada cruzada

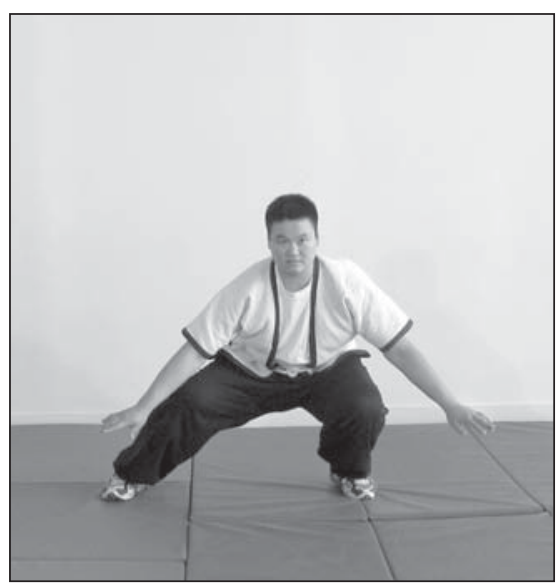

a.

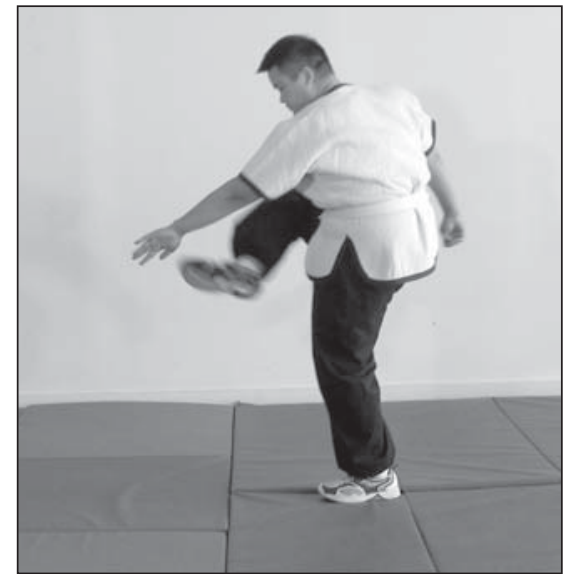

b.

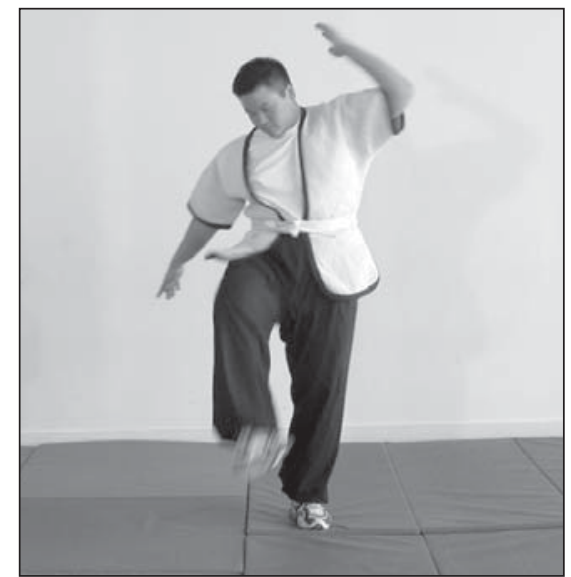

b.

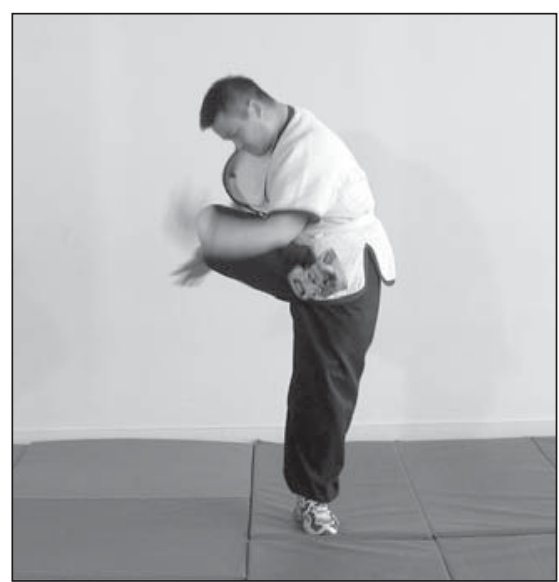

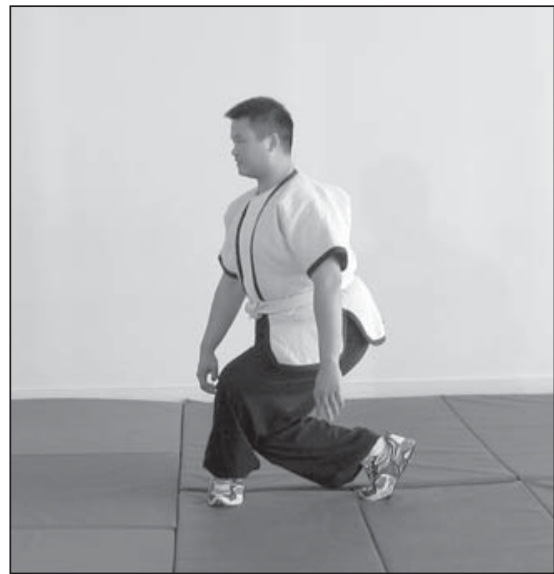

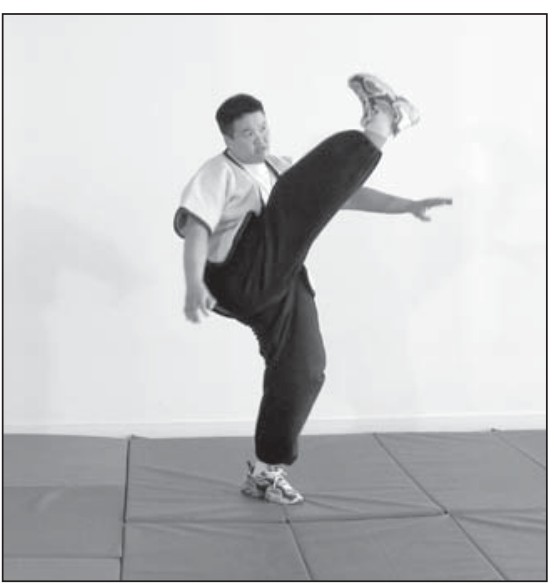

b.

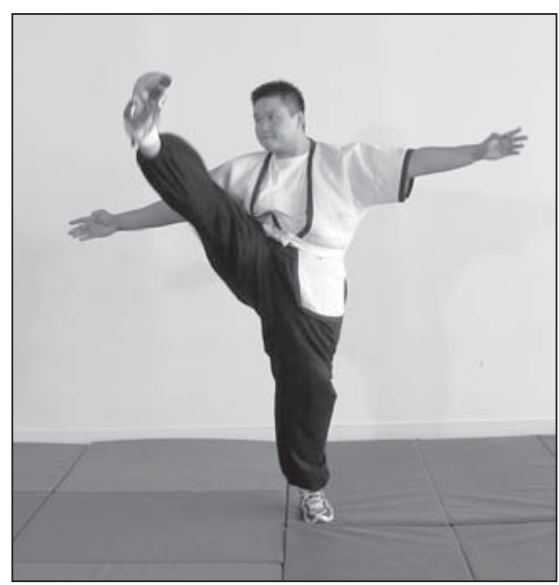

c. 
Chou Tui - sacando la pierna: gira el cuerpo hacia la derecha y agáchate en una postura de piernas cruzadas. Levanta el cuerpo y sube la pierna derecha hacia delante y colócala detrás de la pierna izquierda, luego vuelve a agacharte otra vez. Cuando la pierna derecha se eleve, usa la mano izquierda para golpear la punta de ese pie. El Chou Tui es bueno para desarrollar la flexibilidad y la fuerza en las caderas, la cintura, y las piernas. La Figura 29 muestra esta técnica.

Pan Tui - enroscando la pierna: gira ligeramente el cuerpo a la izquierda y de repente gira a la derecha. Al mismo tiempo da un golpe cortante con la mano izquierda hacia abajo y pega una patada con el pie derecho doblando la rodilla derecha. El Pan Tui es bueno para desarrollar la flexibilidad y la fuerza de las caderas, la cintura, y las piernas. La Figura 30 muestra esta habilidad.

Guo Tui - patada cruzada: agáchate y cambia el peso a la pierna izquierda. Eleva el cuerpo y da una patada al frente y a la izquierda con la pierna derecha. Sigue hacia el frente y a la derecha, pasando por encima de algo. El Guo Tui incrementará la habilidad para dar patadas y la flexibilidad en las caderas. La Figura 31 muestra esta técnica.

Tiao Beng $\mathrm{Zi}$ - saltando y estallando: da un paso adelante con el pie derecho y luego un paso atrás con el pie izquierdo y agáchate. Eleva el cuerpo y date la vuelta.

Ambas manos se convierten en puños, como si cogieran algo. Tira hacia delante y flexiona el cuerpo hacia abajo

Figura 32

\section{Saltando y estallando}

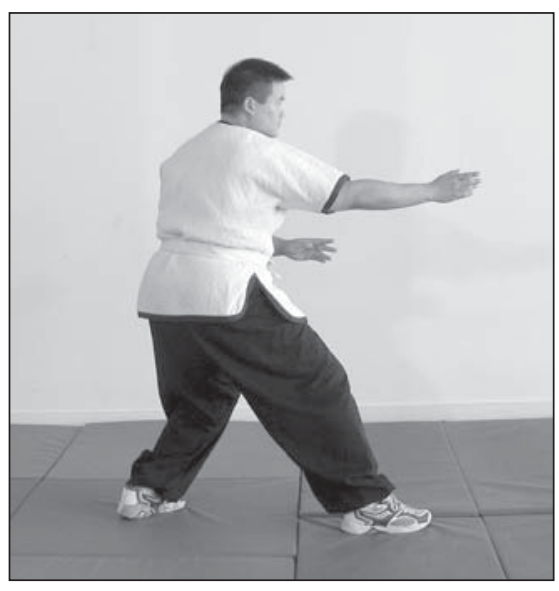

a.

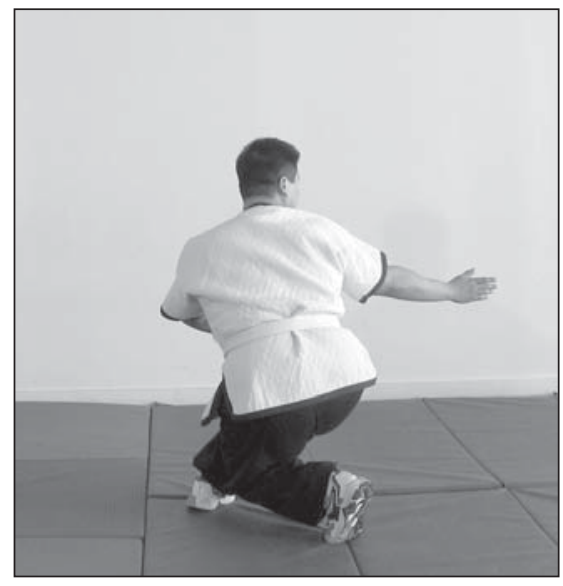

b.

liberando explosivamente la fuerza con la mano. Tira hacia delante y abajo golpeando hacia atrás con los glúteos. Para practicar esto, deberías moverte rápido, los pasos se realizan a modo de salto y la fuerza debería ser integrada y explosiva. El Tiao Beng Zi es bueno para desarrollar la coordinación de todo el cuerpo. La Figura 32 muestra esta técnica.

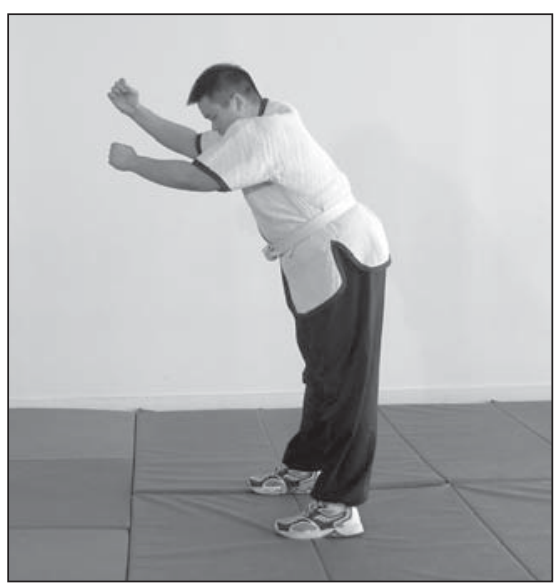

c.

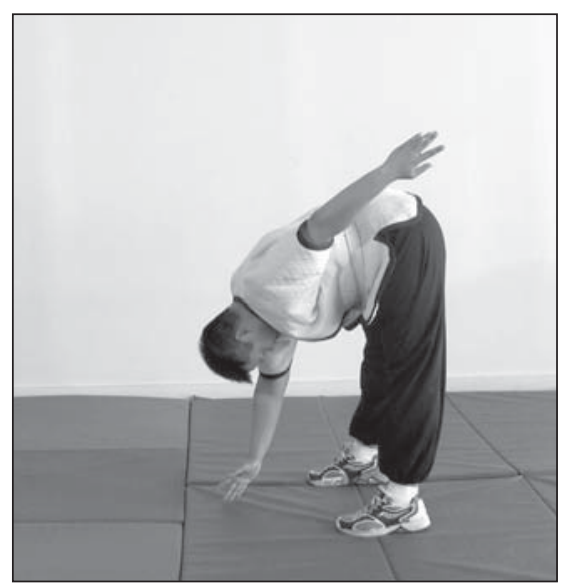

d. 
Figura 33

Rotando el cuerpo con la pierna como un muelle

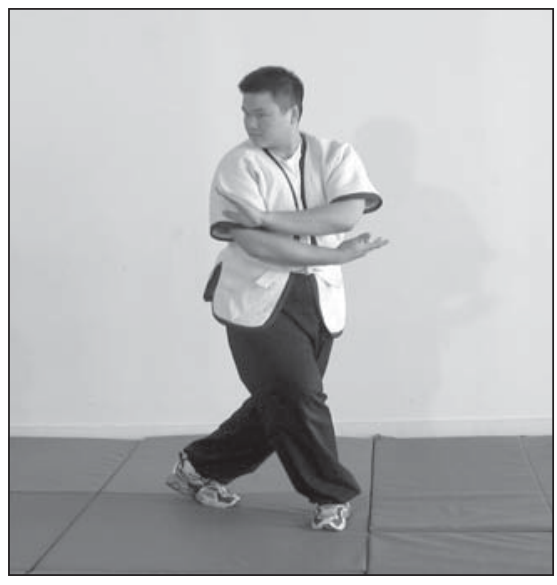

a.

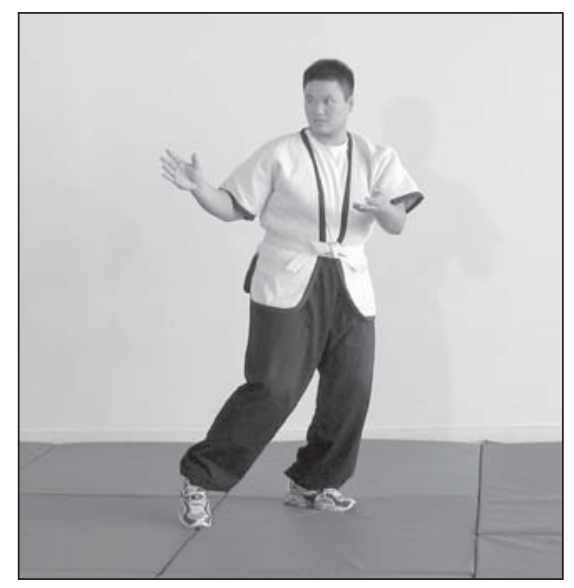

b.

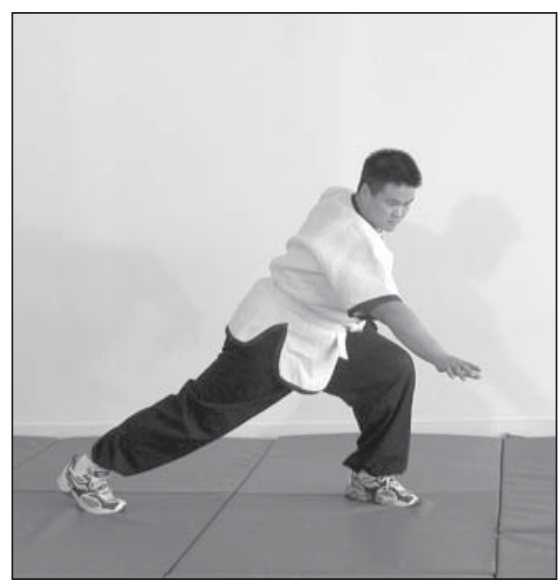

C.

\section{Figura 34}

\section{Levantarse y enganchar hacia atrás}

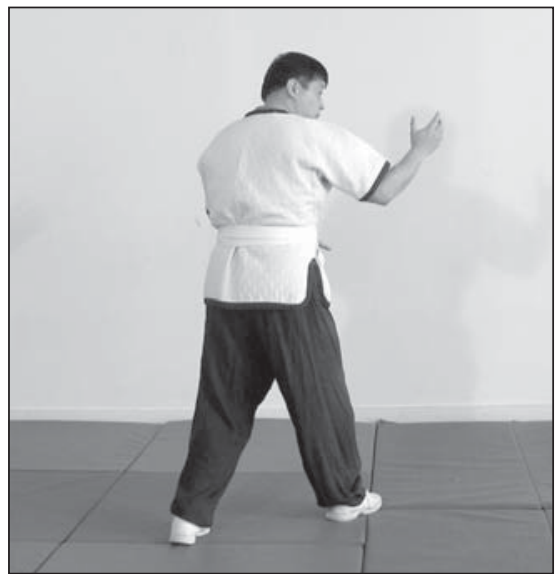

a.

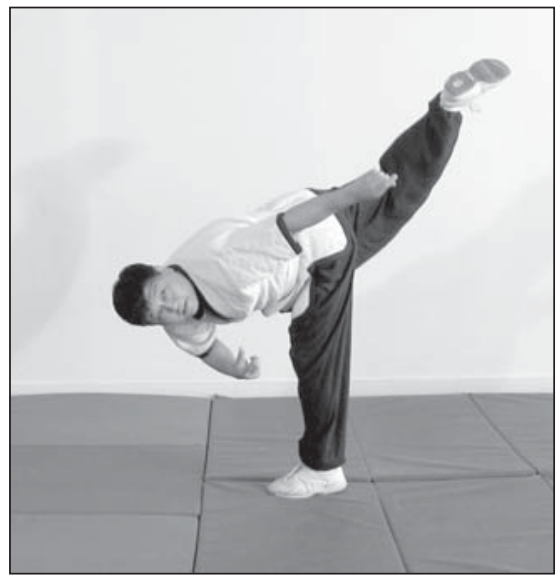

d.

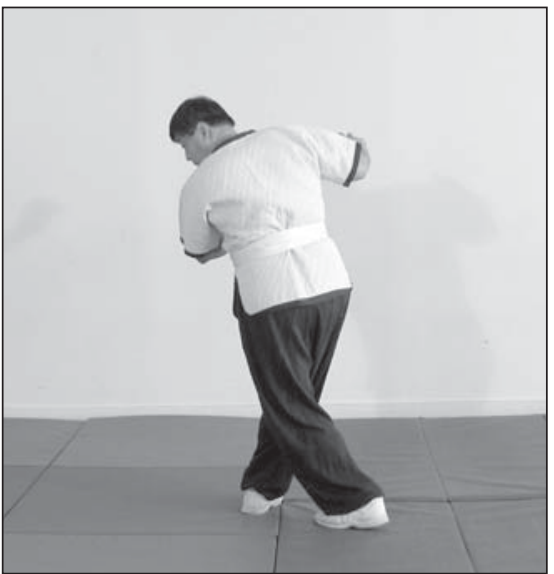

b.

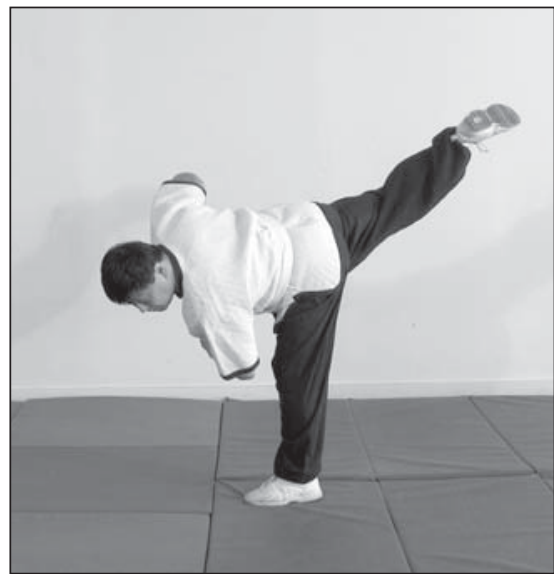

c.

Tan Ning Zi - rotando el cuerpo con la pierna como un muelle: gira el cuerpo ligeramente a la derecha y luego de repente date la vuelta a la izquierda. Al mismo tiempo húndete y da una palmada con la mano derecha hacia abajo y adelante, dando una patada hacia atrás con el pie derecho. La pierna derecha se debería estirar lejos hacia atrás y debería mantenerse estirada. El Tan Ning Zi es bueno para desarrollar la coordinación de la fuerza a través de los brazos, la cintura, y las piernas. La Figura 33 muestra esta técnica.

Liao Gou Zi - levantarse y enganchar hacia atrás: para crear un hueco da un paso adelante con el pie derecho y da un paso hacia atrás con el pie izquierdo para girar el cuerpo hacia atrás. Luego levanta la pierna derecha desde atrás. Cuando la pierna alcanza su punto más alto, gira la cabeza hacia la izquierda y arriba (bian lian). Esto también hará girar al cuerpo hacia la izquierda. El Liao Gou Zi es bueno para desarrollar el juego de piernas así como para aumentar la flexibilidad y la fuerza de las piernas. La Figura 34 muestra esta técnica. 


\section{Entrenando con implementos}

En el Shuai Jiao, hay muchos tipos de implementos desarrollados especialmente para entrenar diferentes tipos de habilidades. Algunos de estos pueden ser difíciles de obtener hoy en día. En este punto presentamos algunos de las más comunes.

Xiao Bangzi - palo corto: un palo de 10-12 pulgadas [25,4-30,5 cm.] de longitud envuelto en dos piezas de tela gruesa, usado para desarrollar la fuerza de torsión. Las manos retuercen en direcciones opuestas. Aunque las manos realizan el giro, la fuerza debería nacer en los pies, y luego pasar a través de las piernas, espalda, hombros, brazos, y finalmente llegar a las manos. Véase la Figura 35.

\section{Figura 35}

\section{Palo corto}

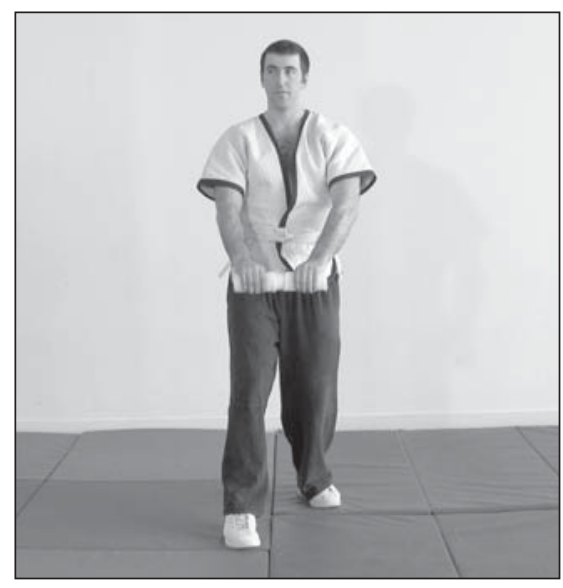

$1 \mathrm{a}$.

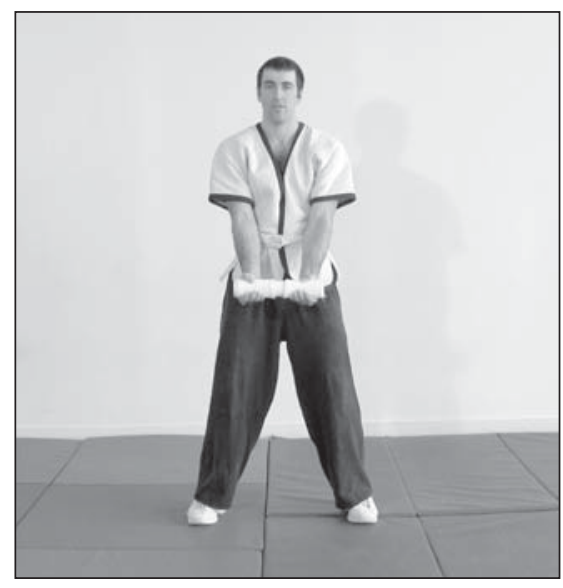

$2 \mathrm{a}$.

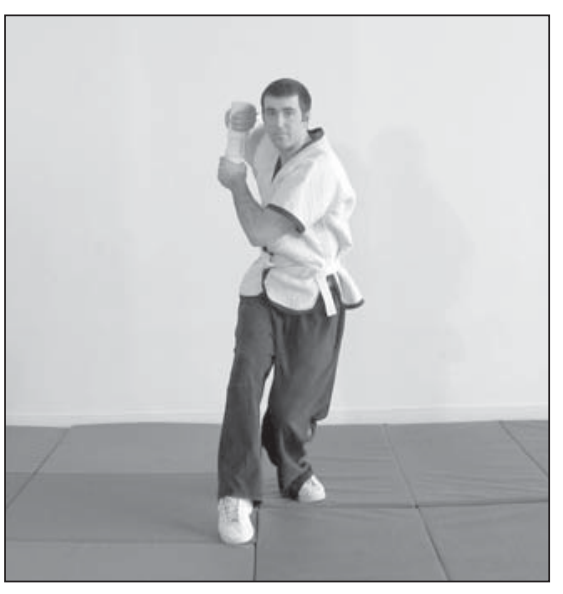

$1 b$.

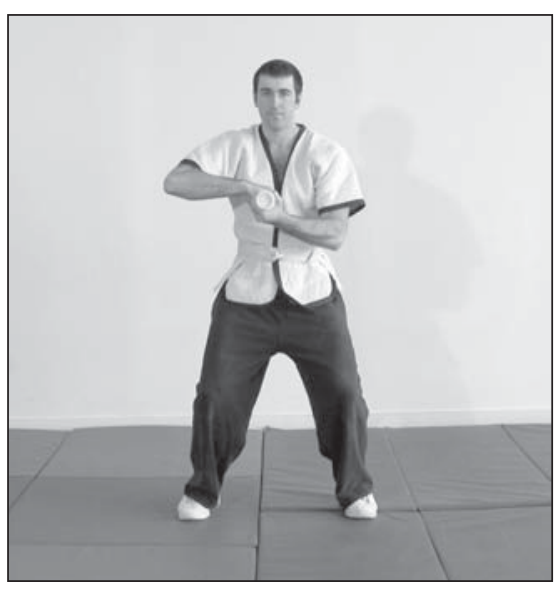

$2 b$.

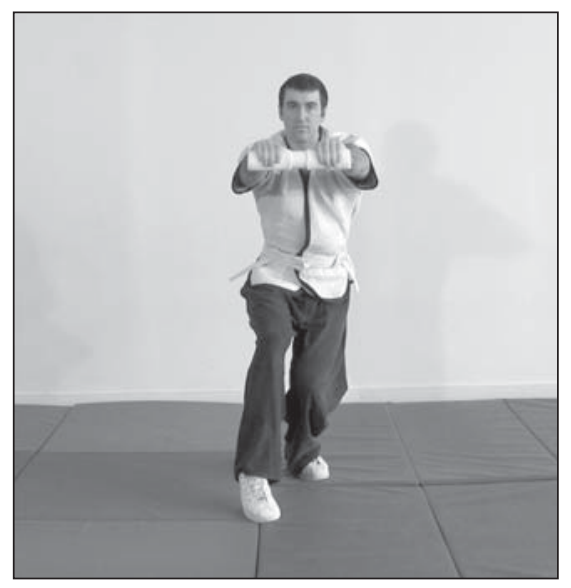

1c.

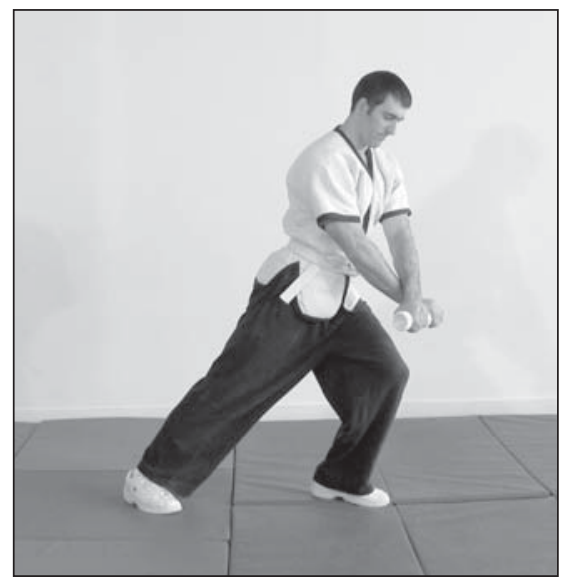

2c. 
Da Bangzi - palo largo: se trata de un palo de tres pies de largo [91,5 cm.] que se usa para desarrollar la fuerza en sentido lateral donde las manos tiran o empujan al mismo tiempo en direcciones opuestas o en la misma dirección usando la fuerza de todo el cuerpo. Ver la Figura 36.

Ma Bianzi - trenza de cáñamo: este instrumento se compone de dos o cuatro cuerdas de cáñamo o lino que se atan en una trenza. Hoy en día se puede usar un

\section{Figura 36}

\section{Palo largo}
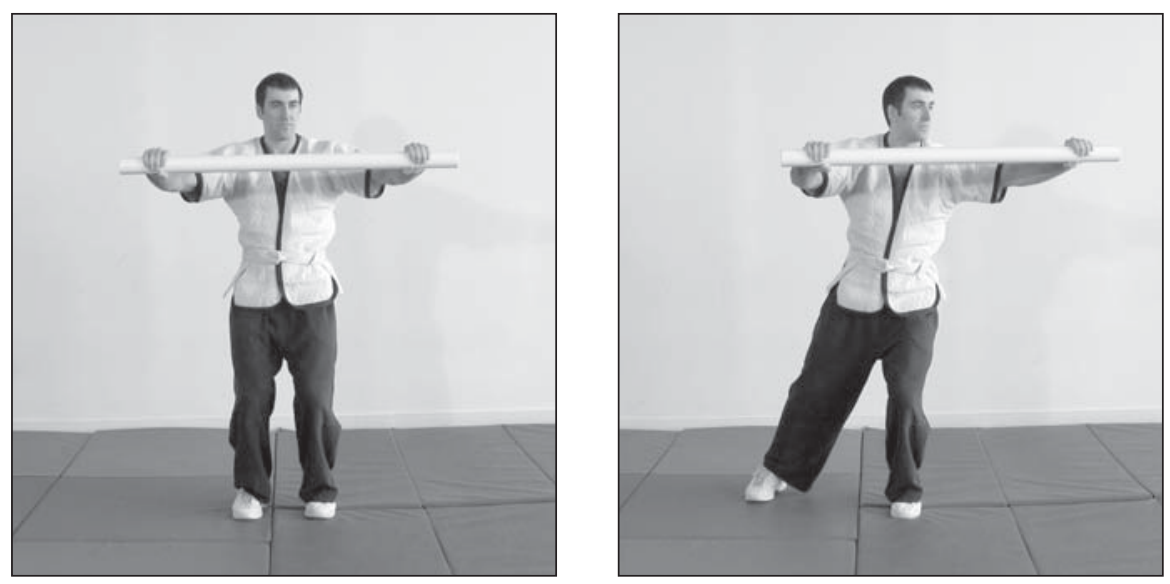

1a.

$1 b$.

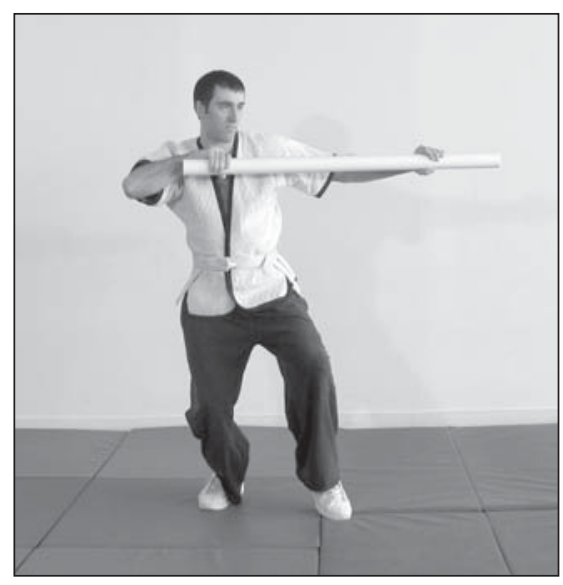

$1 c$.

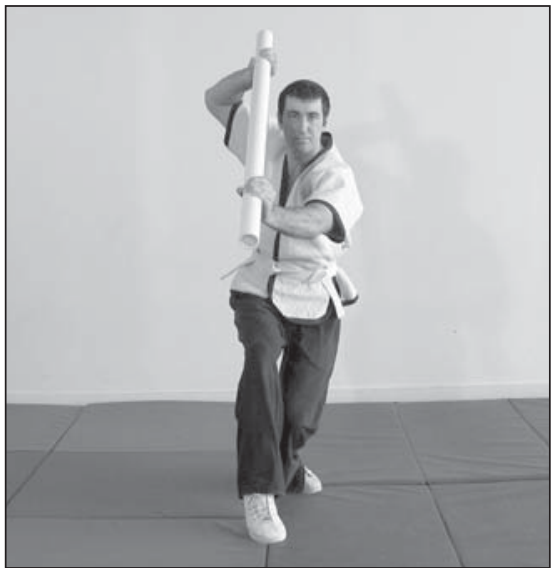

$2 b$.

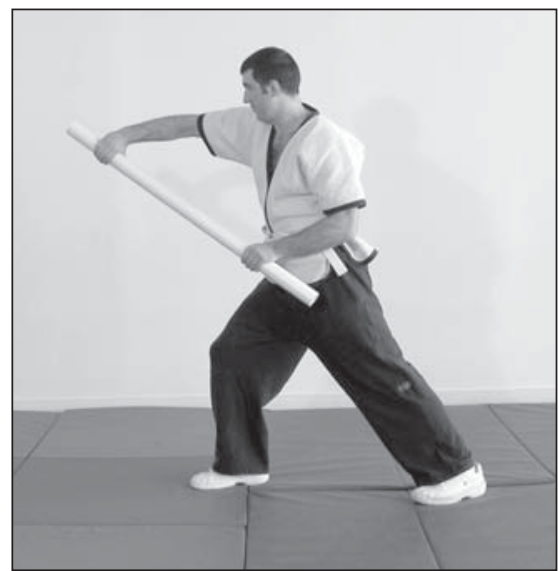

3a.

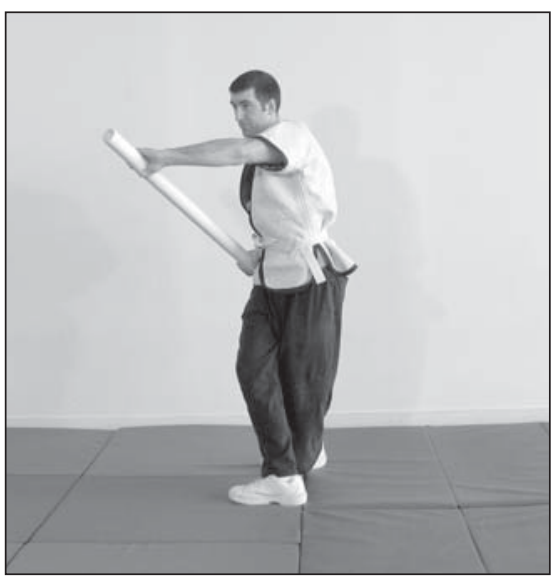

3c.

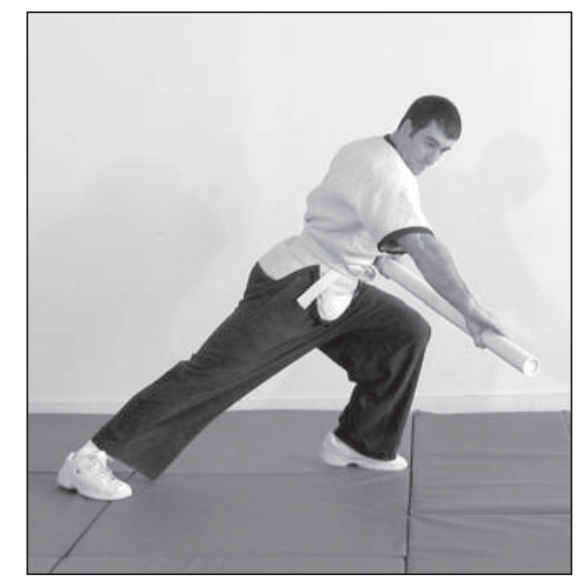

$3 \mathrm{~d}$. 


\section{Trenza de cáñamo}

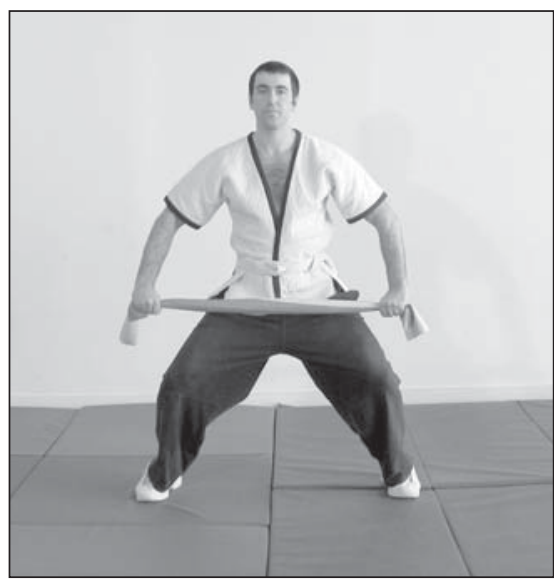

cinturón de vestir, una cuerda de nylon o de goma. La trenza de cáñamo se usa para desarrollar la fuerza de sacudida o de vibración. Ambas manos tiran fuerte y rápidamente de la cuerda en direcciones opuestas, al mismo tiempo que se giran cuerpo y piernas. Se debería sacudir todo el cuerpo haciendo que la cuerda suene o restalle. Véase la Figura 37.

Tui Zhuan - empujando el ladrillo: el Tui Zhuan es bueno para desarrollar la fuerza de empuje. Coge un ladrillo en cada mano y empújalo en distintas direcciones. En cada ocasión, la fuerza de empuje debería comenzar desde los pies, pasando a través de las piernas, espalda, hombros, brazos y luego a través de las manos. Véase la Figura 38.

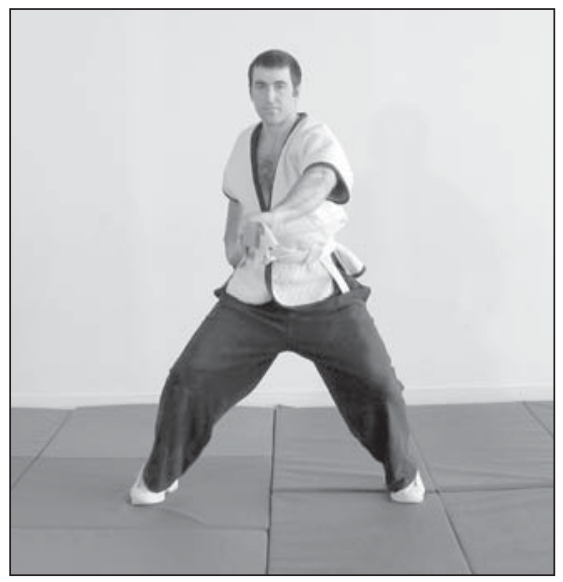

b.

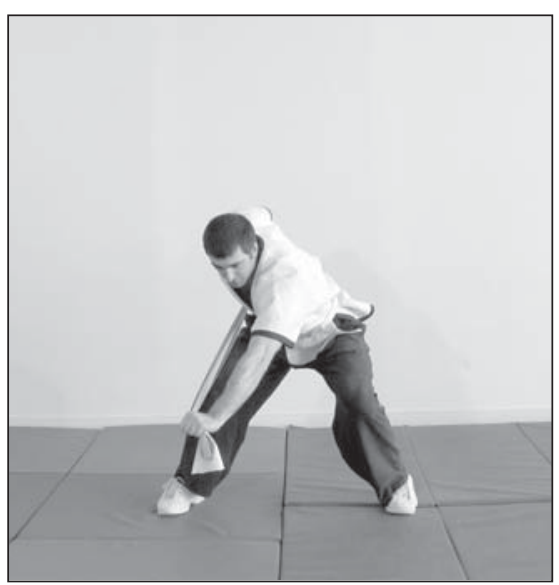

d.

b.
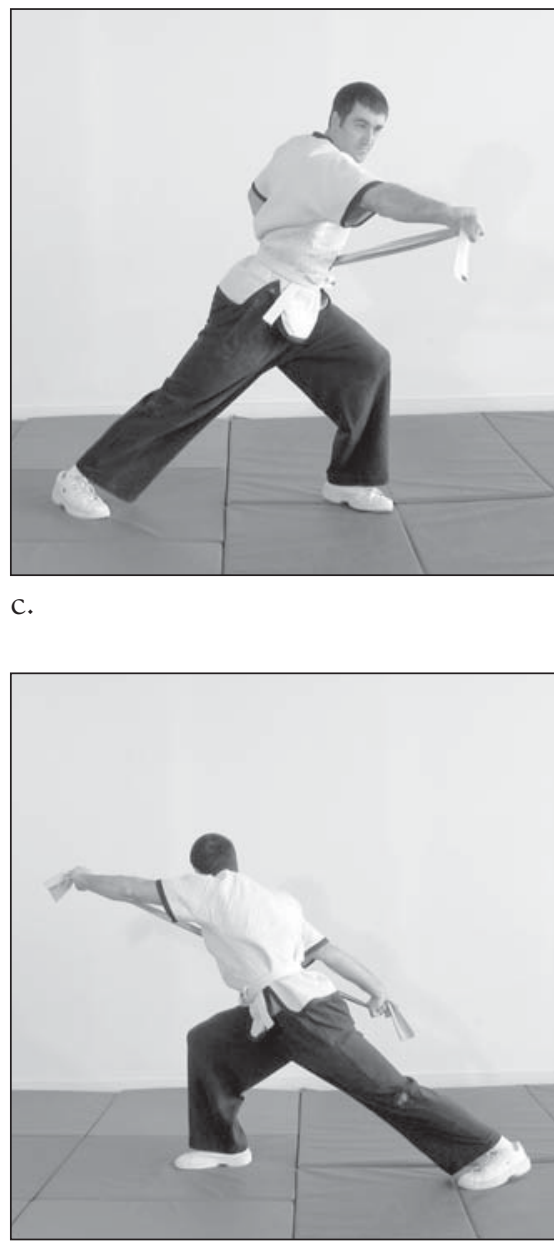

e.

Figura 38

\section{Empujando el ladrillo}

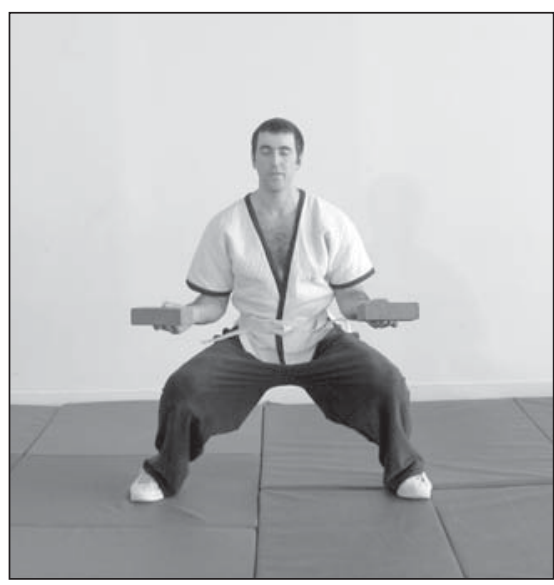

a.
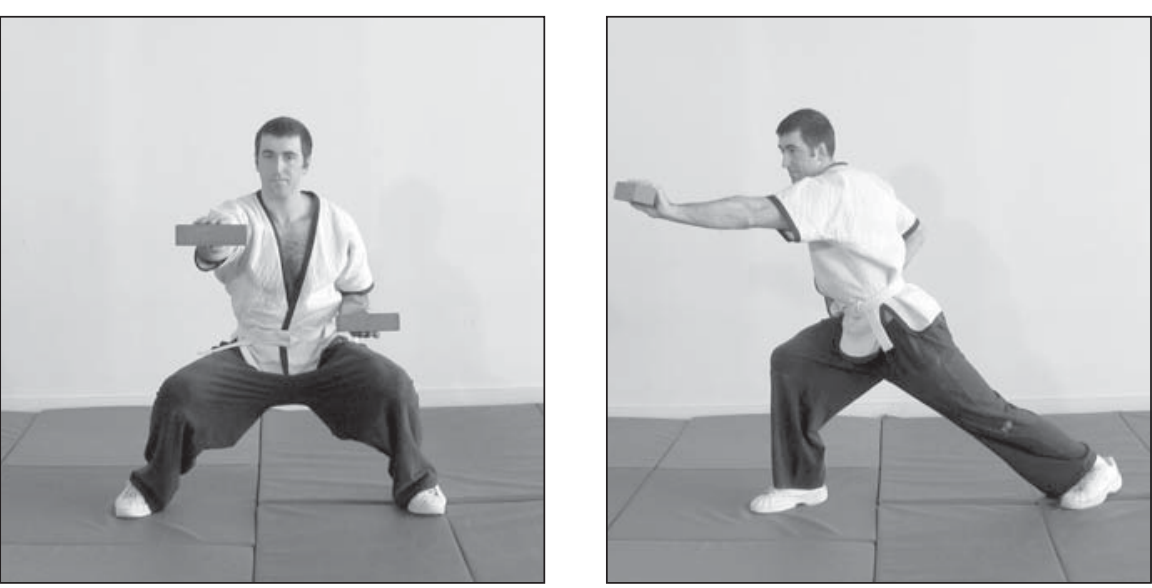

C. 
Figura 39

Girando una ladrillo grande

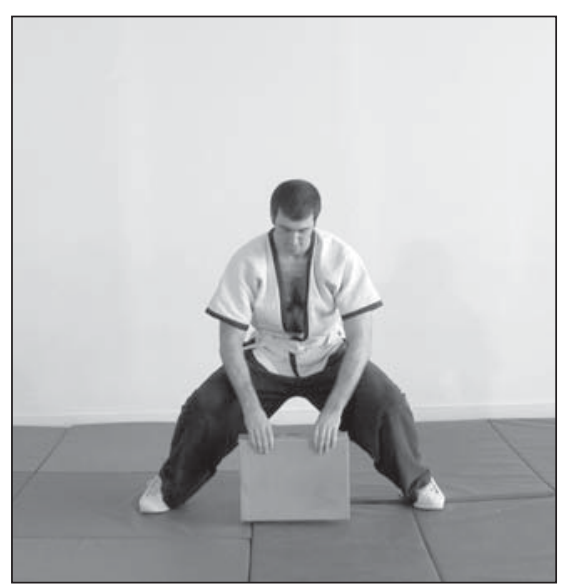

a.

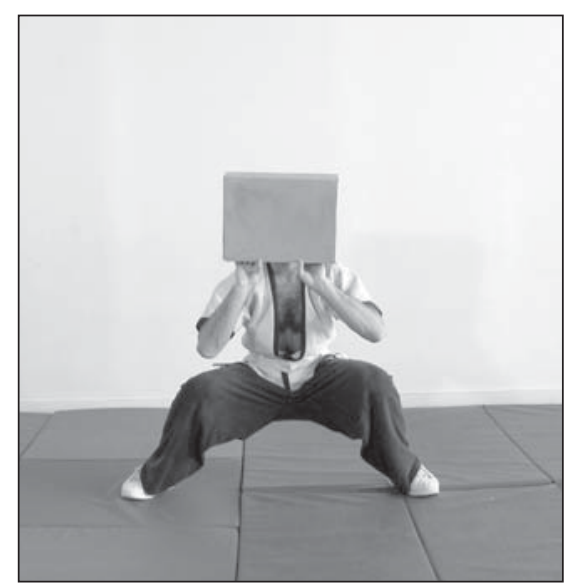

b.

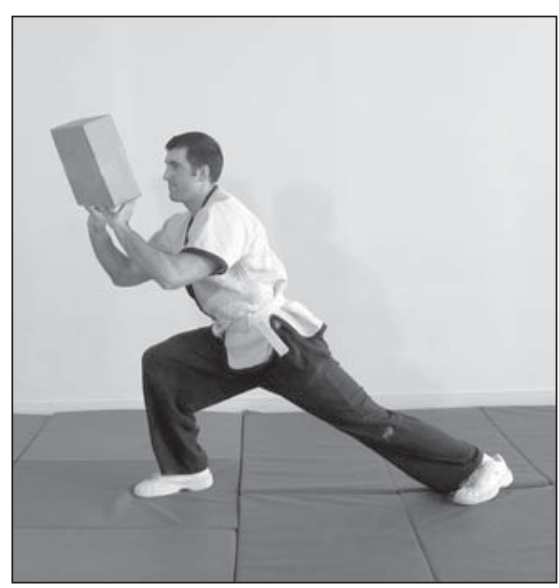

c.

\section{Figure 40}

Bastón largo

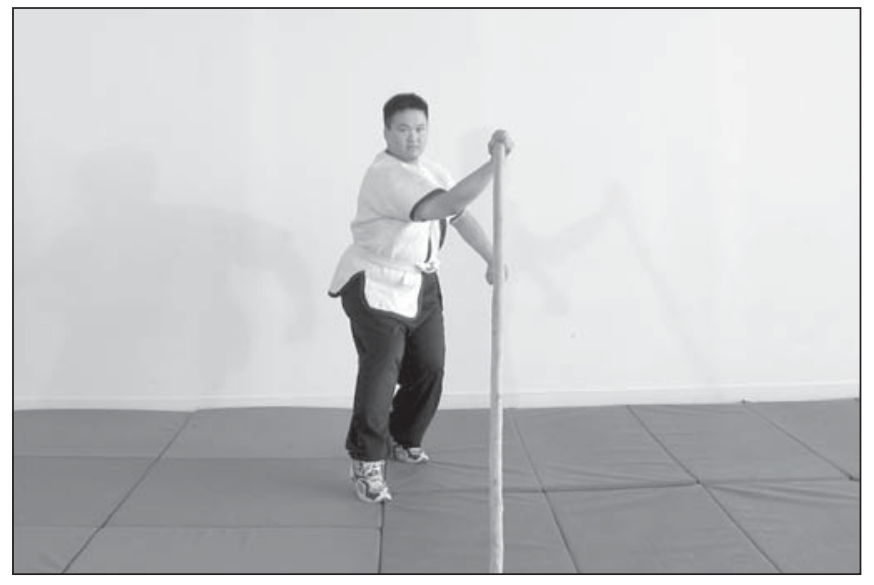

1a.

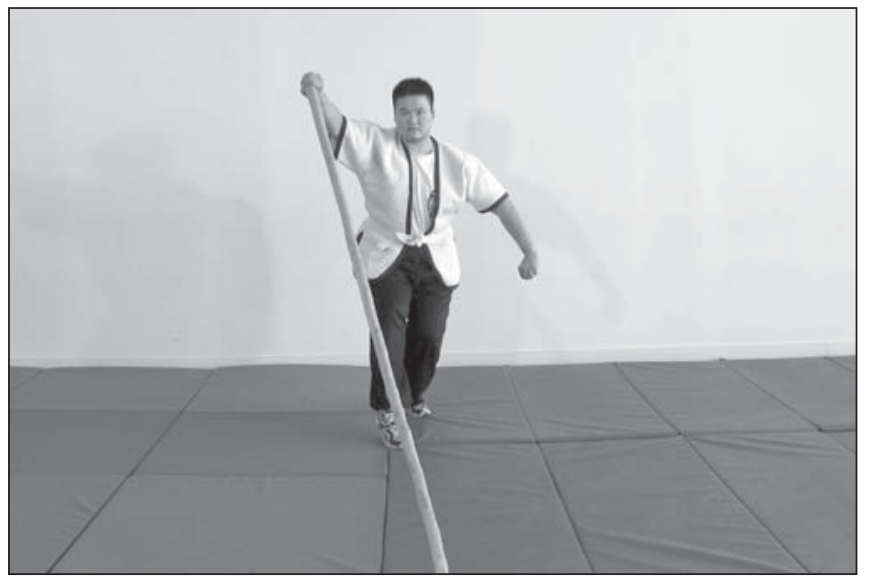

$1 b$.

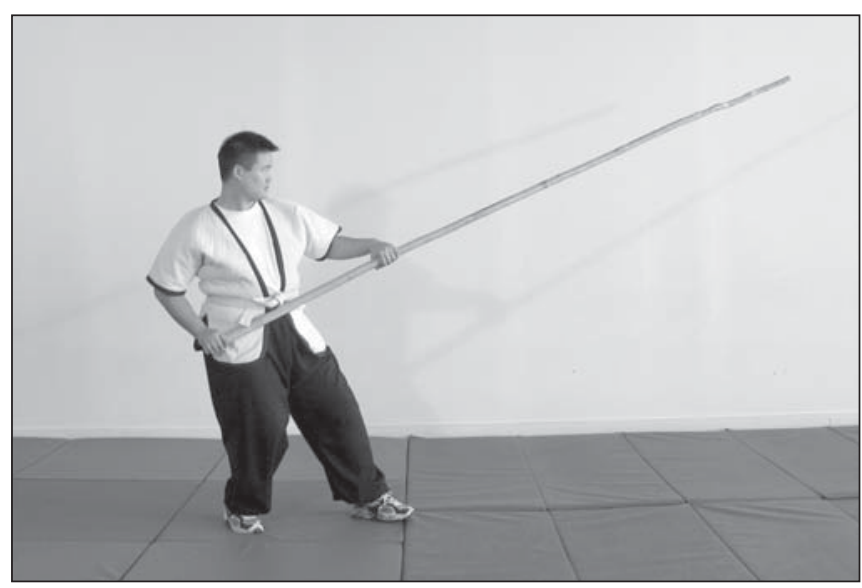

$2 b$. 
Fan Da Zhuan - girando un ladrillo grande: en esta ocasión el ladrillo, para la construcción de muros, es más grande de lo normal. El Fan Da Zhuan es bueno para desarrollar la fuerza de agarre y fortalece las muñecas. Coge un ladrillo grande con ambas manos y levántalo y gíralo en muchas direcciones distintas. Véase la Figura 39.

Da Ganzi - bastón largo: aquí el bastón debería ser de madera encerada blanca y de más de 12 pies [3,6 m.] de largo. Puede sostenerse en una o dos manos. La mayoría de los ejercicios de bastón largo son para desarrollar la fuerza de sacudida. El Da Ganzi es de gran ayuda para integrar y coordinar la fuerza de todo el cuerpo y también puede usarse como práctica por parejas. Véase la Figura 40.

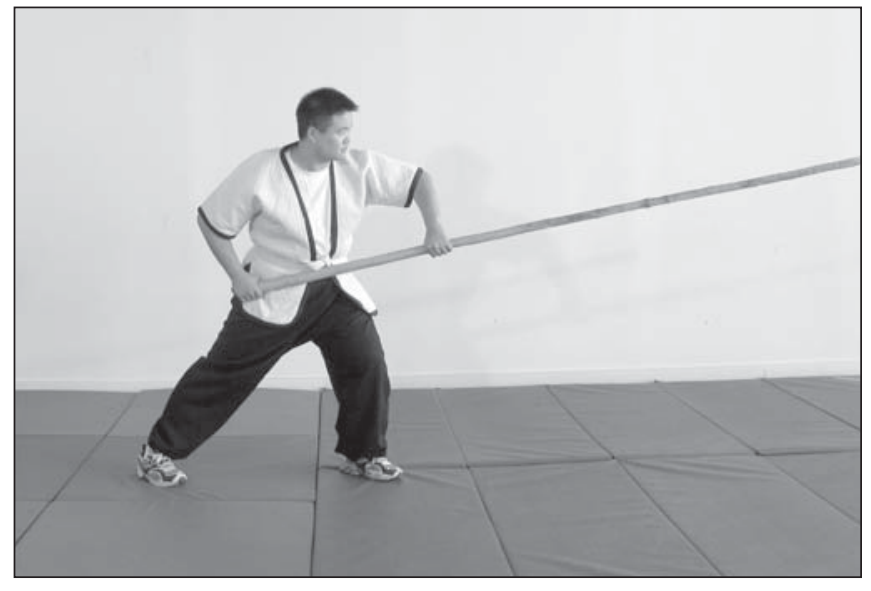

3a.

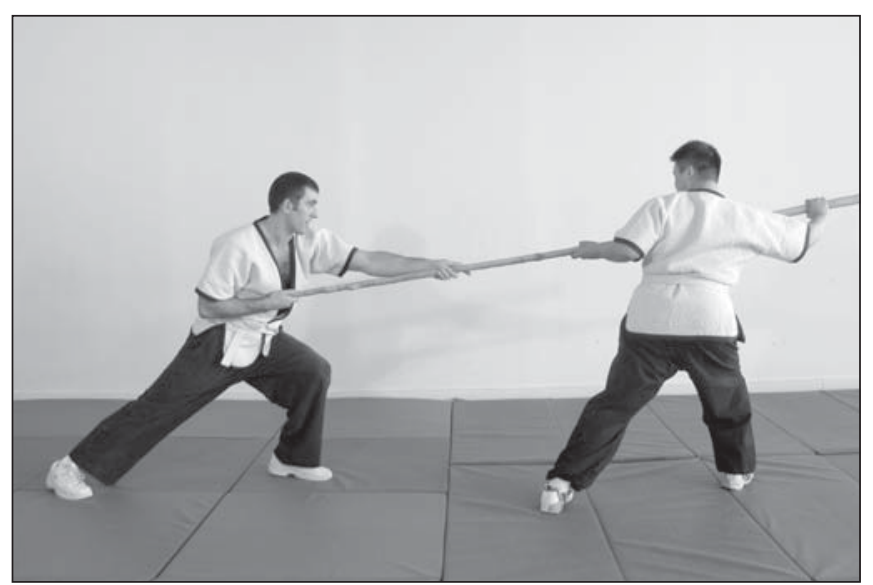

$4 a$.

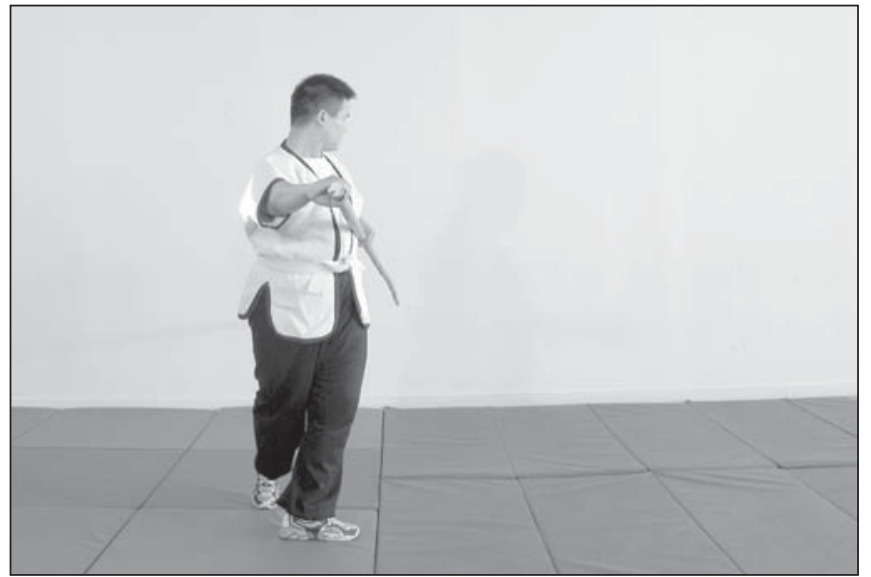

$3 b$.

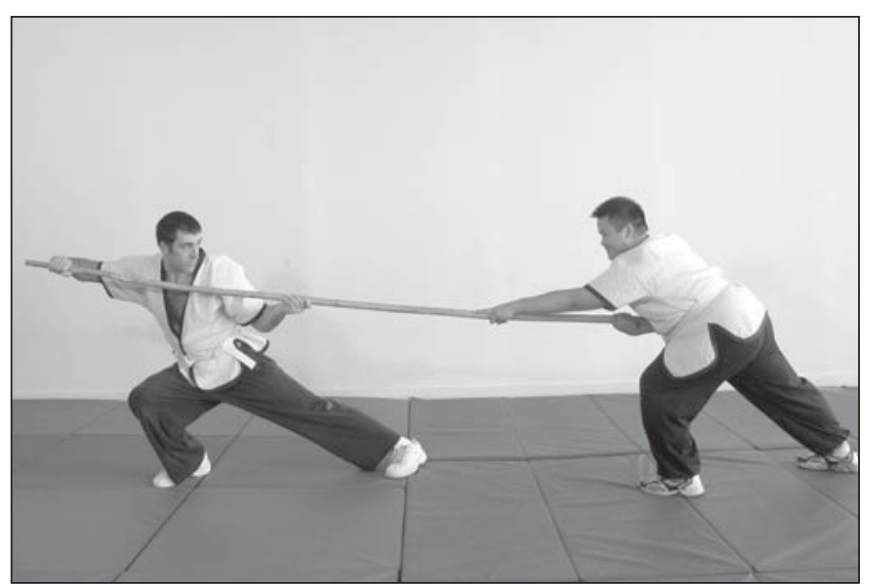

$4 b$. 
Sha Dai - bolsa de arena: la bolsa de arena pesa alrededor de 10 libras [4,5 kg.]. Se usa para desarrollar manos y dedos. Los ejercicios pueden ejecutarse en solitario o en pequeño grupo. La bolsa puede ser lanzada y cogida de muchas maneras diferentes. Véase la Figura 41.

Figure 41

Bolsa de arena

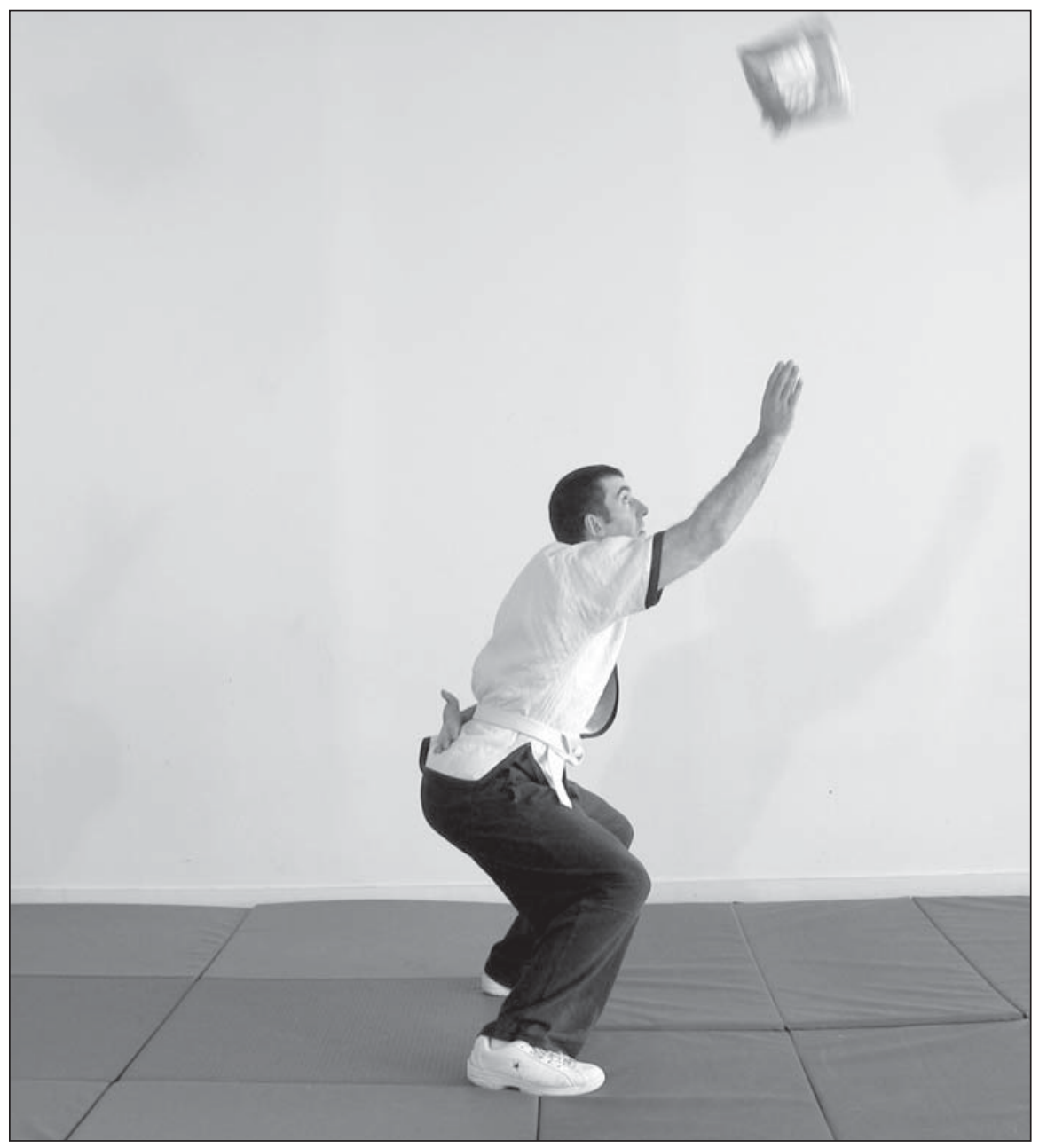

a.

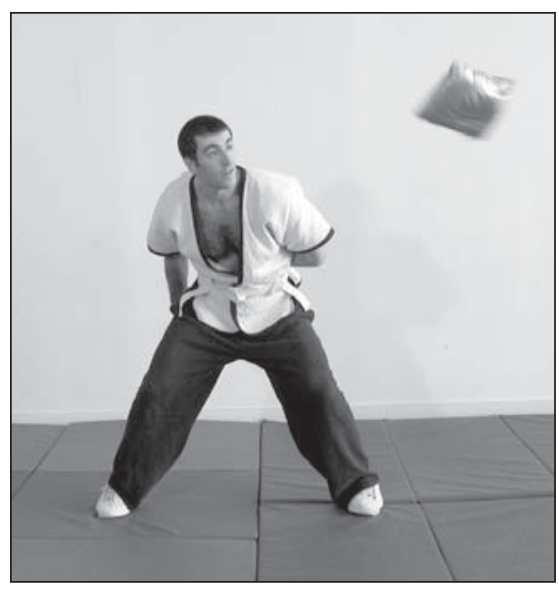

d.

e.

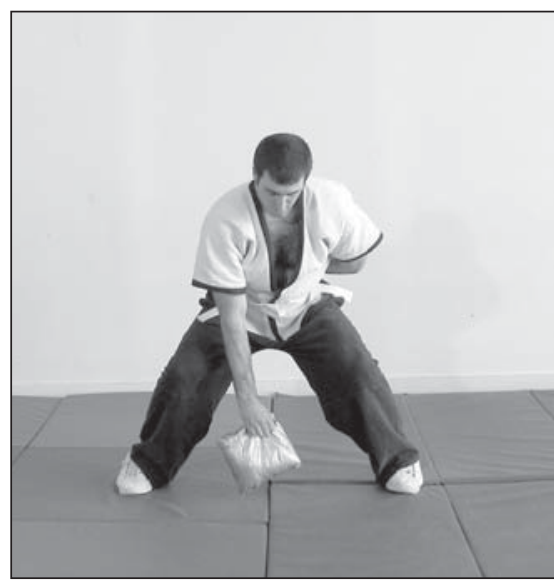

b.

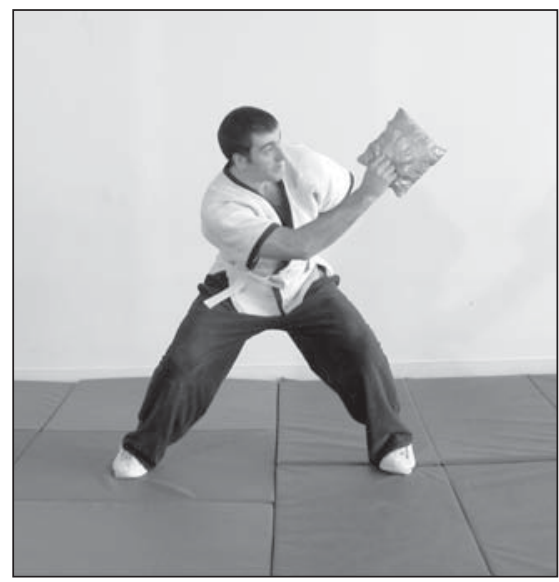

c.

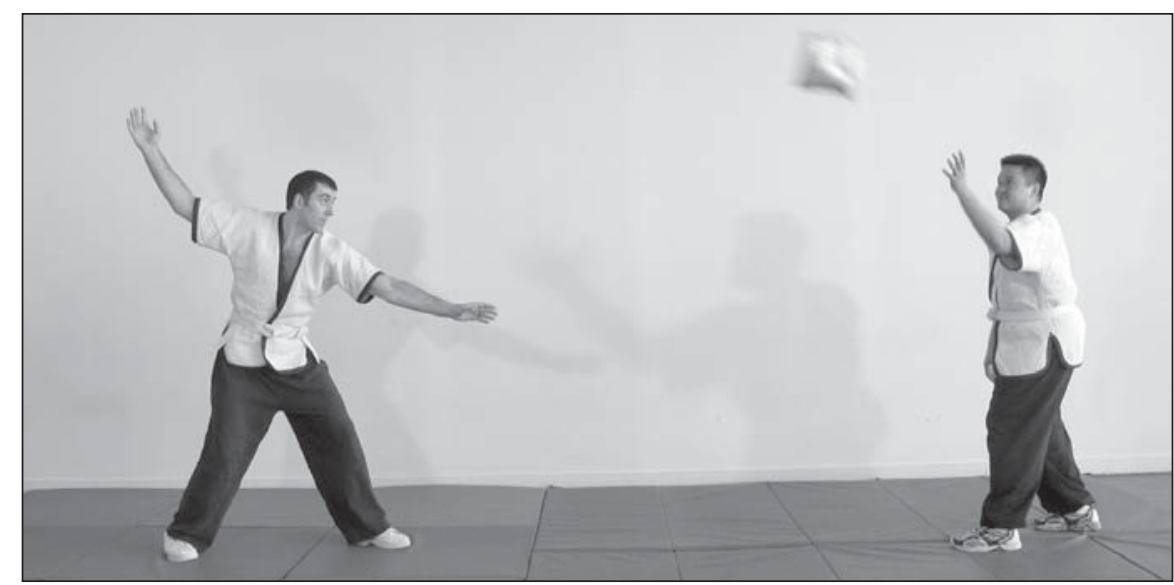


影

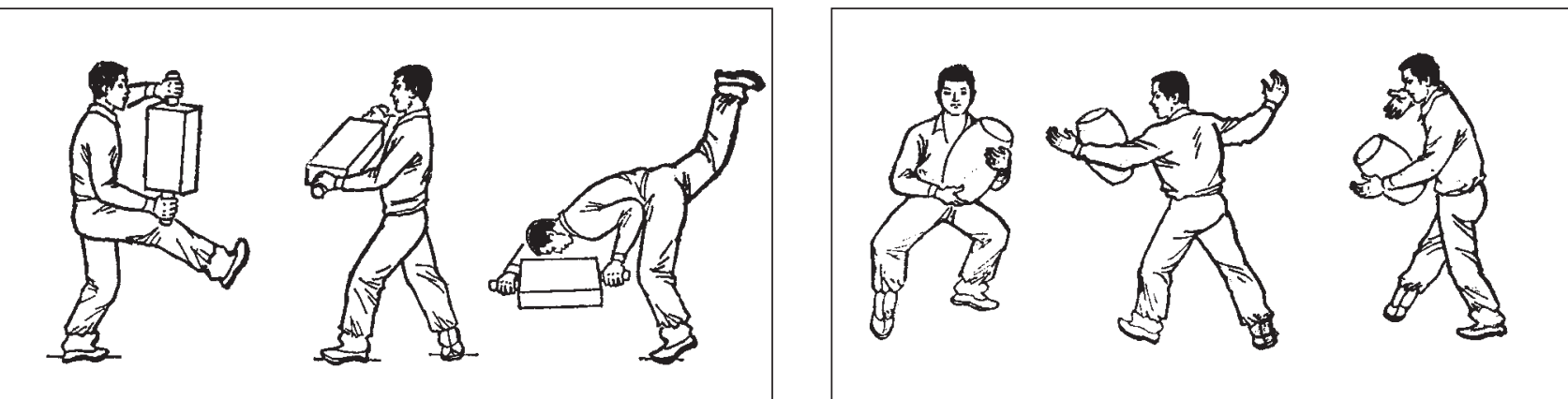

理

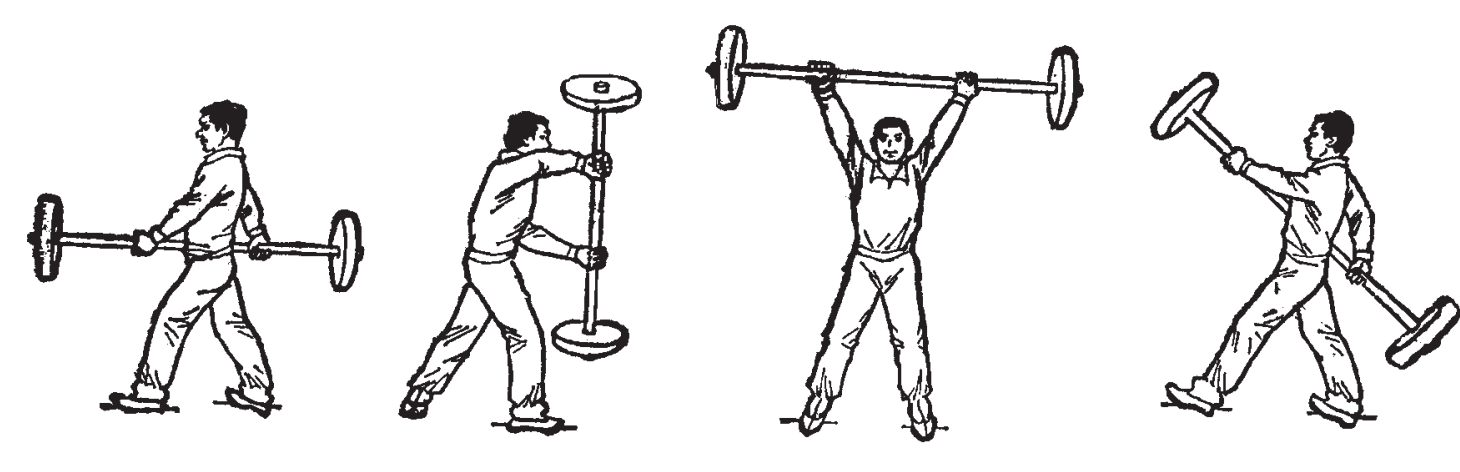




\section{La relación entre el Shuai Jiao y las artes marciales tradicionales chinas}

Una pregunta común que hace la gente es si el Shuai Jiao es un arte marcial y si las técnicas del Shuai Jiao se pueden utilizar en una pelea. Una vez que se obtiene un conocimiento profundo del Shuai Jiao, lo más probable es que se responda la primera pregunta de forma negativa y la segunda de forma positiva.

Observando estas preguntas desde una perspectiva histórica, tal y como hemos mencionado al principio, el Shuai Jiao ha sido separado de la práctica regular de las artes marciales y ha desarrollado muchos aspectos a su propia manera. Sin embargo, la relación entre el Shuai Jiao y las artes marciales es muy cercana. Las técnicas de cada una se han influenciado mutuamente. El estudio de las técnicas del Shuai Jiao proporciona retroalimentaciones a otras artes marciales, especialmente en los métodos de entrenamiento. También los conceptos de las nuevas artes marciales guían el desarrollo del Shuai Jiao. Por ejemplo, las ideas del Taiji de pegarse (zhan), meterse (nian), unirse (lian), continuar y seguir (sui), ofrecen muchas oportunidades, especialmente para los luchadores más pequeños. Estas ideas hicieron sus técnicas más refinadas y detalladas. La gente siempre dice que hay energía del Taiji en sus técnicas de Shuai Jiao. Debido a estas relaciones, a veces se afirma que el Shuai Jiao y las artes marciales son primas.

En las competiciones, el Shuai Jiao tiene sus reglas y limitaciones. Muchas técnicas de Shuai Jiao y sus variantes son muy peligrosas y pueden usarse directamente en una pelea. Sabemos por la historia que han muerto personas en competiciones de Shuai Jiao. En épocas tempranas, todos los luchadores del Shan Pu Ying también eran los guardaespaldas del emperador. Es imposible que las técnicas que practicaban cada día no tuviesen relación con su trabajo o que esas técnicas no pudieran usarse para proteger al emperador.

Desde un punto de vista técnico, la mayor parte de las técnicas rápidas de proyección (Kuai Jiao), por ejemplo, son muy fáciles de usar en una pelea. Además muchas de las técnicas de agarre pueden ser transformadas en técnicas de luxación. Muchos de los pequeños movimientos que usamos en el Shuai Jiao pueden tener un tremendo impacto en una pelea. Por ejemplo, en vez de sostener o tirar hacia arriba ligeramente al final de una proyección, si hundes y sueltas tu mano ligeramente puedes causar lesiones muy serias.

Recuerda que los aspectos de las técnicas que se desarrollan y los tipos de técnicas que están de moda en cada momento están en gran medida determinados por los objetivos e intereses de los practicantes. Si tu objetivo principal es la competición, tus habilidades se desarrollaran de acuerdo con las directrices que marca el reglamento de competición. En este punto no estarás practicando el sistema completo de Shuai Jiao, ya que estas ignorando los componentes de combate.

Por otro lado no se puede negar que el Shuai Jiao ha sido separado de las artes marciales tradicionales. Aunque hay muchas técnicas coincidentes, el Shuai Jiao es el Shuai Jiao y tiene sus propios caminos y métodos. El Shuai Jiao, definitivamente, no es un sistema de combate puro. Incluso el Wushu Jiao, o arte marcial del Shuai Jiao, el cual combina algunos elementos de las artes marciales, no es un sistema marcial puro. Esta distinción es muy similar a la manera en que generalmente excluimos el estilo de boxeo occidental de ser categorizado como un arte marcial, aunque muchas de sus técnicas son útiles para el combate.

La combinación del Shuai Jiao con cualquier arte marcial es muy popular y muy útil. Especialmente en el norte de China, casi todos los artistas marciales practican el Shuai Jiao. El Shuai Jiao no sólo aporta técnicas útiles sino también muchos otros beneficios. La naturaleza altamente antagónica, cercana, y físicamente intensa del Shuai Jiao proporciona tanto un gran acondicionamiento físico como mental, de ahí la expresión: "Artes marciales más Shuai Jiao, cuanto más practiques, más éxito tendrás". 


\section{Bibliografía}

Chen, K.Q. (1984). The beginning note of Long Qian Ji Wen. Beijing: Chinese Book Press.

Chen, Q.S. and Wang Y.M. (2002). Practical manual of Chinese shuai jiao.

Beijing: People Sport Press.

Cheng, S.Q. (1990). History of tianqiao. Beijing: Three Unions Bookstore Press.

Fu, Y.J. and Man, B.Z. (1983). Chinese shuai jiao. Beijing: People Sport Press.

Gu, S.Q. (1997). Chinese sports history. Beijing: Beijing Physical Education University Press.

Hatsuda, R.; trans. by Lu, Y. and Yan, H. (1984). Brief history of Chinese martial arts. Chengdu: Sichuan Science and Technology Press.

Ji, F.L. (1994). Chinese shuai jiao: Quick and skillful combat techniques. Beijing: Beijing Sport University Press.

Liu, B.G., Yang, S. and Shi, Y.Q. (Ed.) (1984). China's sports in ancient times. Beijing: The Press Commission of the Chinese Olympic Committee.

Su, X.L. and Li B.R. (2004). The history of shuai jiao in Beijing. Beijing: Xinhua Press.

Wang, L.X. (Ed). (1993). The old tianqiao of Beijing. Beijing: Wenjing Press.

Xi, Y.T. (1985). Chinese martial arts history. Beijing: People Sport Press.

Yao, Y.Z. (1982). The note of bamboo leaves pavilion. Beijing: Chinese Book Press.

Zhang, Y. (2001, April). Zhan, nian, lian and sui: Four important skills for push hands and fighting. Tai Chi Magazine 25 (2).

Zhao, E.X. (1998). Qing dynasty history manuscript. Beijing: Chinese Book Press.

\section{Agradecimientos}

Un especial agradecimiento para Strider Clark y Clayton Shiu quienes me ayudaron con las fotografías técnicas. Fotografías cortesía de Zhang Yun, Clayton Shiu, Tito Bayne, y Josh Heht. 